\title{
Training toward Advanced 3D Seismic Methods for CO2 Monitoring, Verification, and Accounting
}

Type of Report:

Date of Report:

Reporting Period:

DOE Award Number:

Submitting Organizations:

Preparers:
Final

August 20, 2012

December 1, 2009 - June 30, 2012

DE-FE002186 (UH budget G091836)

Department of Earth and Atmospheric Sciences

Allied Geophysical Lab

University of Houston

Houston, Texas 77004-5505

Prof. Christopher Liner - P.I.

Phone: (713) 743-9119

Fax: (713) 748-7906

Dr. Jianjun Zeng (research scientist) 


\section{DISCLAIMER}

"This report was prepared as an account of work sponsored by an agency of the United States Government. Neither the United States Government nor any agency thereof, nor any of their employees, makes any warranty, express or implied, or assumes any legal liability or responsibility for the accuracy, completeness, or usefulness of any information, apparatus, product, or process disclosed, or represents that its use would not infringe privately owned rights. Reference herein to any specific commercial product, process, or service by trade name, trademark, manufacturer, or otherwise does not necessarily constitute or imply its endorsement, recommendation, or favoring by the United States Government or any agency thereof. The views and opinions of authors expressed herein do not necessarily state or reflect those of the United States Government or any agency thereof." 


\begin{abstract}
The objective of our work is graduate and undergraduate student training related to improved 3D seismic technology that addresses key challenges related to monitoring movement and containment of $\mathrm{CO} 2$, specifically better quantification and sensitivity for mapping of caprock integrity, fractures, and other potential leakage pathways. We utilize data and results developed through previous DOE-funded $\mathrm{CO} 2$ characterization project (DE-FG26-06NT42734) at the Dickman Field of Ness County, KS.
\end{abstract}

Dickman is a type locality for the geology that will be encountered for $\mathrm{CO}_{2}$ sequestration projects from northern Oklahoma across the U.S. midcontinent to Indiana and Illinois. Since its discovery in 1962, the Dickman Field has produced about 1.7 million barrels of oil from porous Mississippian carbonates with a small structural closure at about $4400 \mathrm{ft}$ drilling depth. Project data includes 3.3 square miles of 3D seismic data, 142 wells, with $\log$, some core, and oil/water production data available. Only two wells penetrate the deep saline aquifer. In a previous DOE-funded project, geological and seismic data were integrated to create a geological property model and a flow simulation grid.

We believe that sequestration of $\mathrm{CO} 2$ will largely occur in areas of relatively flat geology and simple near surface, similar to Dickman. The challenge is not complex geology, but development of improved, lower-cost methods for detecting natural fractures and subtle faults. Our project used numerical simulation to test methods of gathering multicomponent, full azimuth data ideal for this purpose. Our specific objectives were to apply advanced seismic methods to aide in quantifying reservoir properties and lateral continuity of $\mathrm{CO} 2$ sequestration targets.

The purpose of the current project is graduate and undergraduate student training related to improved 3D seismic technology that addresses key challenges related to monitoring movement and containment of $\mathrm{CO} 2$, specifically better quantification and sensitivity for mapping of caprock integrity, fractures, and other potential leakage pathways.

Specifically, our focus is fundamental research on (1) innovative narrow-band seismic data decomposition and interpretation, and (2) numerical simulation of advanced seismic data (multi-component, high density, full azimuth data) ideal for mapping of cap rock integrity and potential leakage pathways. 


\section{CONTENTS}

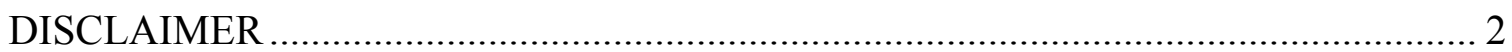

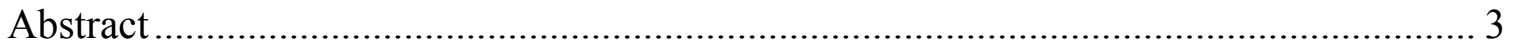

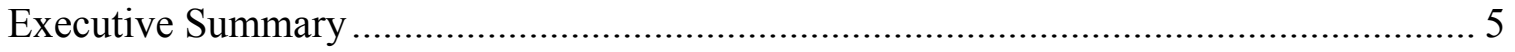

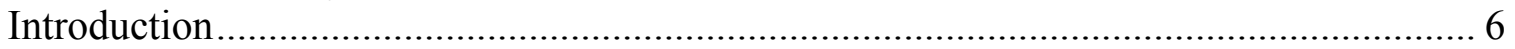



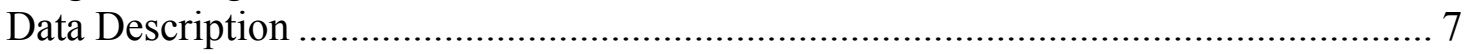

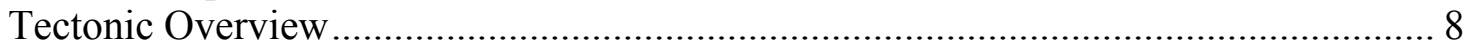

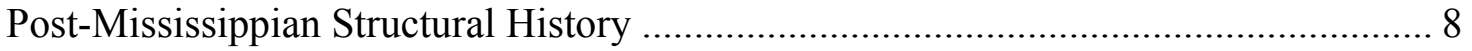

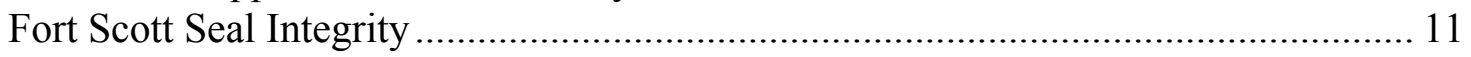

3D Seismic horizon mapping and depth conversion................................................. 12

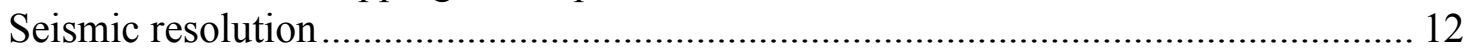

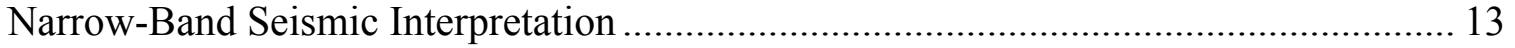

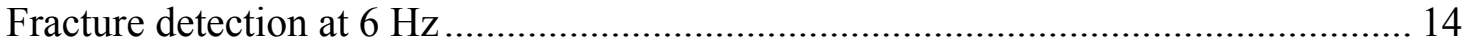

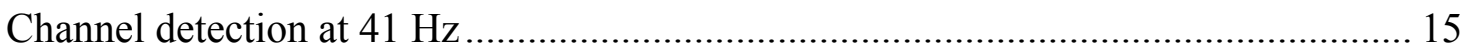

Elastic modeling and component rotation.............................................................. 16

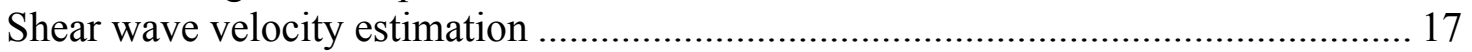

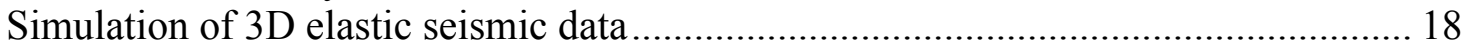



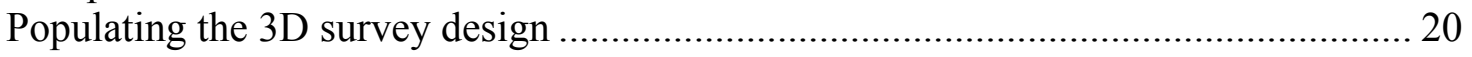

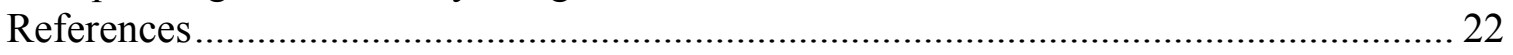

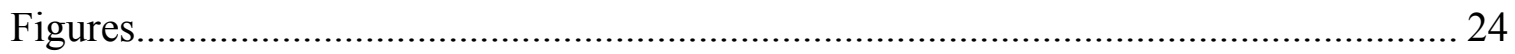

Appendix A: 3D Seismic acquisition and processing parameters ................................ 77

Appendix B: Seismic Unix narrow band decomposition shell script ........................... 79

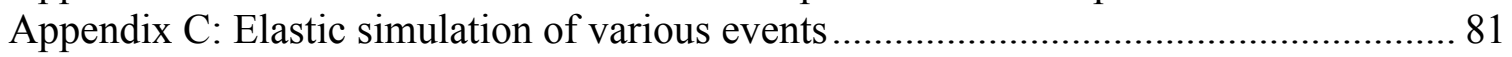




\section{Executive Summary}

The goals of this project were to develop innovative 3D seismic attribute technologies and workflows to assess the structural integrity and heterogeneity of subsurface reservoirs with potential for $\mathrm{CO}_{2}$ sequestration. Our specific objectives were to research narrow band seismic decomposition and elastic numerical simulation as an aide in quantifying reservoir properties of $\mathrm{CO} 2$ sequestration targets.

Our study area is the Dickman field in Ness County, Kansas, a type locality for the geology that will be encountered for $\mathrm{CO}_{2}$ sequestration projects from northern Oklahoma across the U.S. midcontinent to Indiana and beyond. Since its discovery in 1962, the Dickman Field has produced about 1.7 million barrels of oil from porous Mississippian carbonates with a small structural closure. Measured depth to the Mississippian is about $4400 \mathrm{ft}$ (1960 subsea), with an oil water contact at 1981 feet subsea and oil column of 35 feet. The top Mississippian is a karst surface, and the oil reservoir also includes sandstones of the Lower Cherokee group deposited on this irregular topography. These two oil reservoirs are the secondary targets of this study. The primary sequestration target is a porous Mississippian saline aquifer underlying the oil field.

There are 142 wells in the project area, with well $\log$ and some core data available, as well as production data from 23 wells. Only two of these wells penetrate the deep saline aquifer. A 3.3 square mile 3D seismic dataset was reprocessed through prestack time migration at the University of Houston. Geological and seismic data were integrated to create a geological property model and a flow simulation grid. Integrated depth maps were made for the Stone Corral, Ft. Scott, Mississippian, and Viola formation tops. The deep saline aquifer is in Middle Mississippian

We estimate a deep saline aquifer sequestration potential of $1 \mathrm{MtCO}_{2}$ in 1100 acres, or about $0.582 \mathrm{MtCO}_{2} / \mathrm{sq}$-mile. Our deep saline aquifer is part of the Western Interior Plains and Ozark Plateau aquifers that cover several hundred thousand square miles. The aquifer system is stable with water flow velocity of only about 40 feet per million years, which excludes the possibility that injected $\mathrm{CO}_{2}$ will be migrated to the surface through the aquifer water flow. The aquifer system studied at Dickman is an ideal carbon dioxide storage target. 


\section{Introduction}

This project is aimed at training for $\mathrm{CO} 2$ sequestration monitoring, verification, and accounting. We believe that in the U.S. mid-continent Carbon Capture and Sequestration (CCS) projects will likely have an initial phase where seismic and other technologies are used once in a setting with dense existing well control where they can be calibrated (such as the Dickman Field). The seismic effort will then be moved to the geologically similar permanent CCS site to characterize the site and establish a baseline survey. Almost by definition, the permanent site will only be sparsely drilled to minimize potential borehole leakage. The proposed training and research project does not involve fieldwork or subsurface injection of $\mathrm{CO} 2$.

The current project follows up a 2005-2009 DOE-funded research effort at the Dickman oilfield in Ness Co., Kansas (DE-FG26-06NT42734). In that study, conventional 3D seismic data was exhaustively interpreted with modern volume attribute technology to detect fractures that could form potential leakage pathways for future $\mathrm{CO} 2$ sequestration in similar geologic settings in the U.S. mid-continent. The current project assesses the added benefit of novel and rapidly evolving 3D seismic land acquisition technology. The seismic methods researched here could impact future commercial $\mathrm{CO} 2$ sequestration projects by supplying surveys ideally suited to fracture analysis, subtle fault detection, and monitoring of $\mathrm{CO} 2$ containment and leakage.

In brief, the method we studied for improved 3D seismic is the holistic use of recent developments, including three-component (3C) digital sensors, acquisition design that delivers high density full azimuth data, and interpretation of narrow-band (spectral) data volumes. Across the U.S. mid-continent the geology is very similar to our field location in Kansas. The Dickman site is less than 70 miles from a large coal-fired power plant. Unlike petroleum exploration which is inevitably pushed toward more remote and structurally complex geological settings, sequestration of $\mathrm{CO} 2$ will largely occur in areas of relatively flat geology and simple near surface similar to the Dickman Field. The challenge is not complex geology, but development of improved, methods for detecting natural fractures and subtle faults. Our project uses numerical simulation to train students and test rapid methods of gathering multi-component, full azimuth data ideal for this purpose. This better kind of 3D seismic data will be quantitatively analyzed and compared to the existing conventional seismic data.

In addition to the scientific goals, this project had a primary focus on education and training. Should carbon capture and sequestration ramp up to a large-scale effort, there will be a significant demand for an educated workforce with skills targeted to CCS. The organization chart and completed student list below indicates our success at both research and education. 

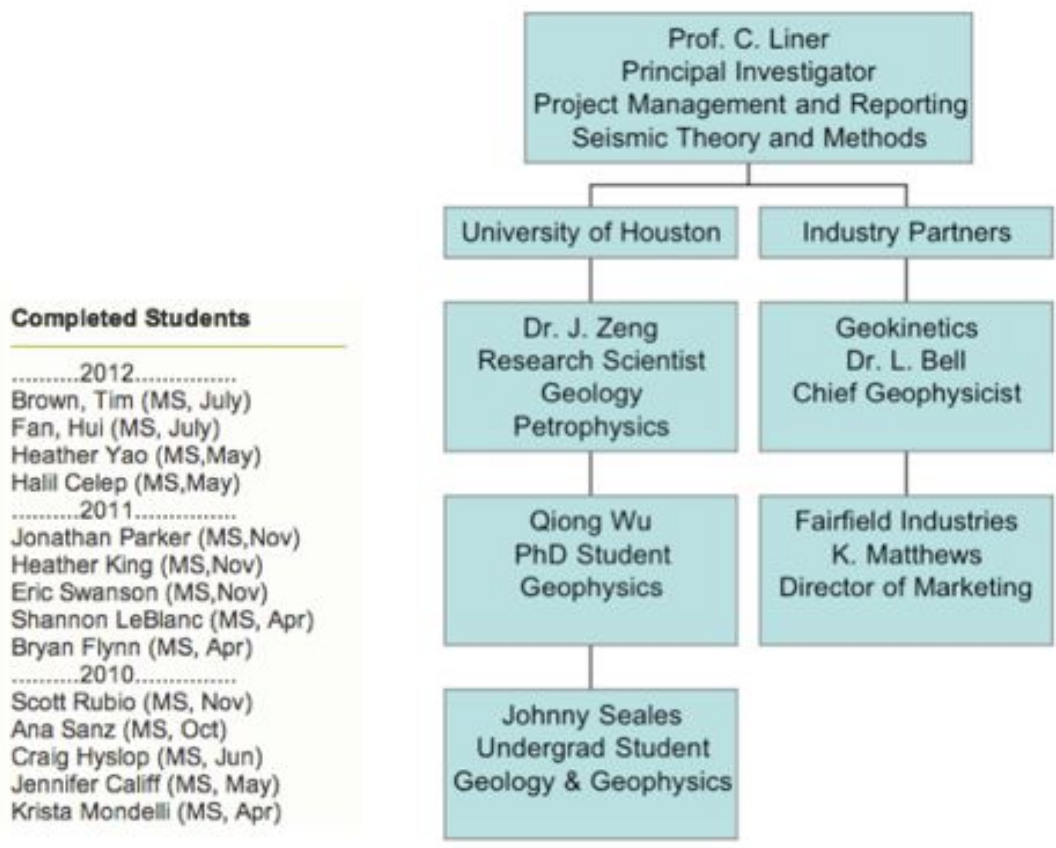

Project personnel and industry partners

\section{Geologic Setting}

The Dickman Field (Figure 1) is located in Ness County, Kansas, and has produced about 1.7 million barrels of oil since its discovery in 1962. Figure 2 shows a type log from the Stiawalt 3 well including the Pennsylvanian section through the CambroOrdovician Arbuckle formation. Fractured Mississippian porous and solution-enhanced shelf carbonates (dolomites) are oil-productive from a small structural closure, which has an OWC at about 1981 feet subsea and an oil column of about 35 feet. The contact between the porous Mississippian and the overlying seal (Pennsylvanian shale and conglomerates of the Cherokee Group) is a karst surface, and a slight angular unconformity dipping to the West. The Dickman Field oil reservoir also includes sandstones of the Lower Cherokee group locally deposited on the sub aerial karst of the Mississippian-Pennsylvanian regional unconformity. These two oil reservoirs are the secondary targets of this study. A secondary sequestration target is a porous Mississippian (Osage) saline aquifer underlying the oil field.

\section{Data Description}

There are 142 wells within the Dickman Field (Figure 3). Various core and log data are available as itemized in Figure 4, as well as monthly production data from 23 wells. A 3D seismic dataset was acquired in 2001 and reprocessed through prestack time migration at the University of Houston in 2007. The survey is 3.325 square miles and has 158 inlines and 169 crosslines with a square 82.5 bin (midpoint spacing). All acquisition and processing parameters are listed in Appendix A. 


\section{Tectonic Overview}

Major geological events include deposition of Middle-Upper Mississippian shelf carbonates, exposure of Mississippian strata and associated karst-development, and deposition of Pennsylvanian coal-bearing formations over the unconformity. These were affected by the continental collision to the south of the studied area, starting around $335 \mathrm{Ma}$ and ending around $310 \mathrm{Ma}$ (Figure 5).

At a smaller time scale, the geological events of the studied area, from oldest to youngest, are summarized as follows:

1. Short term post Gilmore City exposure, associated with the early stage of karst development, typical of a vertical erosion-dominated landscape concentrating on intersections of major NW and NE fractures as sinkholes at the Gilmore City (GMC) unconformity.

2. Deposition of Osage strata on GMC as a carbonate shelf, formation of litho facies that affect the distribution of primary porosity, and varying resistance to diagenesis, fracturing and erosion.

3. Short term exposure of Osage strata, resulting in bedding-perpendicular and/or bedding-parallel fracture and/or pressure solution zones in the present deep saline aquifer.

4. Shelf deposition of Warsaw-Salem (maybe even younger) carbonate strata, formation of carbonate facies that affect the distribution of primary porosity of the reservoir and the varying resistance to diagenesis, fracturing, and erosion.

5. Longer term post Mississippian exposure of Salem/Warsaw, associated with mature stage karst development along planes of weakness (fractures), typical of horizontal erosion-dominated landscape, such as underground caves/tunnels and collapsed tunnels connecting relic sinkholes, resulting in fractured zones, pressure solution zones and karst breccia zones that favor hydraulic conductivity of the carbonate reservoir.

6. Deposition of Lower Cherokee cherty conglomerate and sandstone within the relic channels on the Mississippian Unconformity, resulting in sandstone reservoirs.

7. Interwoven cyclic carbonate shelf and coastal coal swamp facies, ending with the Fort Scott Limestone, as a group acting as sealing layers.

8. Post-Pennsylvanian folding and fracturing to form a shallow NE35-oriented fold perpendicular to the axis of Central Kansas Uplift (CKU), formation of several 20-40 ft closures oriented in NE direction.

9. Post-Pennsylvanian faulting on the NW flank of the fold, both Mississippian and Pennsylvanian Fort Scott strata at the foot wall were lifted and tilted to SE, resulting in a sealing NE Boundary Fault for the Dickman project area.

\section{Post-Mississippian Structural History}


Geometry and properties of Penn sandstones and Miss carbonates in the Dickman area are defined by: 1) sedimentary facies in various deposition environments controlled by paleo-geography and syn-depositional structural activities, and 2) post-depositional faulting/fracturing or deformation. The following discussion focuses on the post-Miss structure activities that affected the deformation and fracturing of the Miss and basal Penn strata. The analysis provides basic information related to geometry and style and of the 3D fracture system in the Dickman area.

The Kansas Geological Survey has recently updated the regional stratigraphic chart for Kansas (Sawin et al., 2009). We have synchronized the local stratigraphy at the Dickman field to the new regional chart (Figure 6), including the project target interval of Ft. Scott to top Viola ('This Study' blue box in Figure 6). The purpose of this synchronization is to reconstruct a regional structural deformation history that may have controlled the faulting and fracturing events in the target strata.

The major post-Miss uplift event marked by the Miss unconformity was a result of continental collision. Basement faulting to the south west of the Central Kansan Uplift provides secondary structural control. The basement faulting has been active from Cambrian to the present day, as revealed by basement structures and the present day drainage system.

Significant differences in local structure patterns exist between the younger Penn and older Miss strata. The Ft. Scott structure is oriented primarily NE-SW, while the Miss exhibits both NE and NW trending features. The top of the Ft. Scott Limestone shows a NE-plunging fold-like structure. The south end of this structure, overlying paleo-lows of the Miss unconformity, formed a hydrocarbon closure $(35 \mathrm{ft})$ producing from the Lower Cherokee Sandstone. The north end of this structure is a drag fold on the footwall side of a fault. The NE boundary fault offsets the Ft. Scott significantly, suggesting that its latest faulting activity was post-Penn. Whether or not this fault is syn-depositional (during Penn time), cannot be determined due to lack of well data on the hanging wall (NW) side.

Unlike the Ft. Scott, the older Miss unconformity shows structural complexity, including isolated lows and highs, very likely controlled by both NE and NW oriented structures. The thickness and lithology of the Penn strata is controlled by Miss paleo-topography. There is no significant lateral thickness variation between the Ft. Scott Limestone and Base Penn Limestone. The thickness variation occurs mainly in the lower Penn section, between the basal Penn Limestone and the Miss unconformity. This indicates a stronger topographic-control on the deposition mainly during the early Penn, including the Cherokee Sandstone and the basal Penn limestone. This topographic control is regional with the basal Penn Limestone and the Cherokee Sandstone laterally interwoven on top of the Miss unconformity.

Ft. Scott to Miss unconformity isopach mapping indicates that deposition of the Penn strata mold-casted the Miss paleotopography. The Penn section thins coincident with Miss highs, and thickens at Miss lows. As shown in Figure 7, the sediment infill was mostly coarse Lower Cherokee Sandstone on the channel bend cut into the Miss 
unconformity. With better horizontal continuity than sparse formation tops, the seismic clearly reveals the Lower Cherokee channel bend.

The development of this paleotopography was related to a pre-Penn structural framework that had a stronger contribution from NW-oriented structures. Most of the NW-oriented discontinuities cut through only the Gilmore City and Miss unconformities. The thickness of Miss strata shows no significant variation, suggesting that structural movements are probably post-Miss.

The thickness of the Penn strata, however, varies significantly across some faults. For instance, the Penn thickness in the down thrown side of one fault is over 152 feet (Tilley 4), but only $96 \mathrm{ft}$ on the up-thrown side (Tilley1b and 2). Faulting was likely predepositional rather than syn-depositional. This further indicates that Miss paleotopography was the major control on lower Penn thickness and lithology variation.

The Miss paleotopographic highs were separated by NW structures. The topography seen on the Miss unconformity at Dickman is similar to some present day carbonate plateaus, where the dissolution of exposed carbonate strata is much stronger along fault and fractured zones forming karst sinkholes or caves. When caves collapse, residual hills are formed. Well data in the Dickman Field support karsting as the origin of the observed Miss unconformity topography. Salem Limestone, the youngest Miss carbonate below the unconformity, shows significant thickness variation, it is generally much thicker on the topographic highs (about 33-41 ft at Dickman 1 and 3a), and thinner at topographic lows (10-14 ft at Dickman A2 and Tilley 1). This is especially true within the Lower Cherokee Sandstone channel (Phelps 1a and Staiwalt 1). These topographic highs with thicker Salem Limestone were the erosional residual hills on the Miss karst topography. Miss lows are due to preferred dissolution along NW and NE fractured zones.

In summary, interpretation of several major post-Miss events were supported by Dickman well and seismic data.

1) Tectonic movement after the deposition of Miss carbonate strata resulted in the regional uplift associated with NE and NW faults and fracturing. Structurally controlled karst topography developed on the exposed Miss surface.

2) This karst topography controlled deposition of early Penn strata, evidenced by interwoven basal Penn limestone and sandstone units with varying thickness.

3) The paleo-geography control on the Penn deposition became less important during the late Penn, as shown by near constant thickness of the Cherokee (coal/sand/shale) and Ft. Scott limestone complexes.

4) Faulting along the NW direction became less active during Penn time, and did not affect deposition of upper Penn strata.

5) The latest faulting episode along the NE-direction was post-Penn, resulting in a NE-oriented shallow fold structure. This developed a hydrocarbon closure in the Penn Cherokee Group to the southwest, and a NE boundary fault as a major hydrocarbon seal in the Dickman, Sargent and Humphrey field areas. 


\section{Fort Scott Seal Integrity}

The coal-bearing shale beds within the Fort Scott and Cherokee Group are considered to be seals for the oil producing zones in Dickman field, including the simulation targets of this study. Therefore some comments on the Fort Scott Limestone are provided below.

The Fort Scott Limestone is the lowest formation in the Marmaton Group, stratigraphically overlaying the Cherokee Group (Figure 6). A black shale bed below the Fort Scott Limestone marks the uppermost part of the Cherokee Group, which is uniformly identified from GR logs in the Dickman survey area. The top of the Fort Scott Limestone is taken as the hanging datum of the stratigraphic model for flow simulation of our study (Figure 6, blue box). The thickness of the upper Fort Scott limestone ranges from 25 to $30 \mathrm{ft}$ in the survey area.

The Marmaton group containing the Fort Scott Limestone has been described from a large belt of outcrops (10 to 25 miles in width) along the Kansas-Missouri border. Moore (1949) defines the Fort Scott Limestone formation as being composed of two limestone members separated by a shale member. The total formation thickness ranges from 13-145 feet with an average of about 30 feet throughout Kansas (Merriam,1963). The upper member is the Higginsville Limestone that is light to dark gray with a medium-grained crystalline texture and a brecciated appearance. Irregular wavy beds and stems of fusulinids and large crinoids are found throughout the member with the upper portion mostly made up of a coral called Chaetetes. The middle member is the Little Osage Shale that is a grey to black fissile shale with an interbedded layer of coal in the lower section and a very thin limestone in the middle. Both are less than 1 foot in thickness in Kansas. Fossils are scarce throughout the middle member. The lower member is more variable depending on location, but can generally be described by an upper portion that is light gray with a coarse crystalline texture and irregular bedding and a lower portion that is tan, brownish, or dark gray fossiliferous limestone with thicker and more regular bedding. The upper portion contains Chaetets and fusulines while the lower portion commonly contains mollusks and conchoidal fractures.

The Marmaton group, as well as the Cherokee group (stratigraphically below it), is dominantly composed of marine and non-marine deposits indicative of numerous advances and retreats of a shallow sea. Throughout both groups, the sequences approximately follow the following order Merriam (1963): "(1) non-marine sandstone, commonly uneven at the base, occupying channels cut in subjacent rocks, (2) sandy, silty, and clayey shale, unfossiliferous or containing land plant remains, (3) underclay, (4) coal, (5) black platy shale containing conodonts, and commonly bearing small spheroidal phosphatic concretions, (6) gray to brownish clayey or calcareous shale, or limestone containing a varied assemblage of marine invertebrates." The fossiliferous limestone portions of the Fort Scott Limestone (6) are indicative of the latest stage of an advance of a shallow sea while the intervening shale portion would indicate slight retreats of the sea before further advance allowing deposition of the overlying upper units of the Fort Scott. While sequences often lack certain lithologies from the above description, the order of 
appearance is generally followed throughout the Marmaton group (including formations extending above the Fort Scott Limestone) and Cherokee group below.

The process of integrating geological data (well logs, formation tops, core) with seismic (amplitude, attributes) to create a geological property model and, ultimately, a flow simulation grid is summarized in Figure 8. A key initial step is mapping of key geologic horizons in the seismic data and then making integrated depth maps.

Figure 9 shows wells with key geophysical logs (sonic, density, time-depth curves). And Figures 10a-d are maps showing well penetrations, formation top (subsea), and seismic reflection time for the Ft. Scott, Lower Cherokee, Mississippian unconformity, and oilwater contact.

\section{D Seismic horizon mapping and depth conversion}

The Dickman 3D seismic project covers an area of 4121 acres, of which less than half contain live data (Figure 1). There are 142 wells in the project, and 60 are within the live seismic area. Well logs were obtained for 58 wells, most of which are within the area of seismic data. This allows for independent verification of formation picks in those wells. Using well log data, Stone Corral, Mississippian, and Viola picks were added for wells which did not have picks in the seismic project and verified for those wells which already had picks. Only two wells for which logs were available (Stiawalt 3 and Sidebottom 6) penetrated the Viola.

After verifying picks, horizon time structure was interpreted in the seismic project. First, the tops of the Stone Corral and Mississippian horizons were picked along every fifth line and traced in the project, creating 2D horizons (Figure 11). Because the Stone Corral is a seismic thin bed, only 30-50 feet thick, it appears in the seismic data to have a 90degree phase shift and was picked at the negative-positive zero crossing. The top of the Mississippian was picked along a seismic trough (maximum negative amplitude). The $2 \mathrm{D}$ horizons were computer interpolated into 3D horizons. The edges of the seismic data have significant distortion due to edge effects, therefore we only considered the interior lines away from those edges.

Detailed mapping was done for Stone Corral, Ft. Scott, Mississippian, and Viola. To avoid a lengthy digression, the procedure will only be described here for the Miss. Figure 12 shows the time structure of the top Mississippian.

Final depth maps are shown in Figures 13a-d for Stone Corral, Ft. Scott, Mississippian, and Viola.

\section{Seismic resolution}

Seismic resolution is related to wavelength $(\lambda)$. Vertical resolution is approximately $1 / 4$ of the wavelength, while lateral resolution is the larger of and $\lambda / 2$ and bin size $(82.5 \mathrm{ft}$ in our 
survey). Wavelength is obtained from the relationship $\lambda=\mathrm{v} / \mathrm{f}$, where $\mathrm{v}$ is velocity and $\mathrm{f}$ is frequency. In the context of our study, the velocity is P-wave speed in the vicinity of the target level, which we take as the Ft. Scott through Miss interval. Following standard practice, we use dominant frequency as revealed by Fourier analysis.

To estimate frequency, seven wells representative of the entire survey area were chosen to confirm that dominant frequency does not have significant lateral variation. Traces within a $500 \mathrm{ft}$ radius around each tested location were extracted in the time internal 0.65$0.95 \mathrm{sec}$, and the Fourier amplitude spectrum was computed. The shape of the spectrum was somewhat variable, but the dominant frequency was consistently about $45 \mathrm{~Hz}$. We take this as a good representation of the dominant frequency of the entire area. The average velocity (estimated from sonic log) of the Ft. Scott through Miss section at Dickman is about $15000 \mathrm{ft} / \mathrm{s}$, giving a dominant wavelength of $330 \mathrm{ft}$. Thus vertical resolution is $82.5 \mathrm{ft}$, and lateral resolution is $165 \mathrm{ft}$.

\section{Narrow-Band Seismic Interpretation}

In our ongoing effort to relate seismic attributes to geologic features at Dickman, we have generated a series of narrow-band attribute volumes from migrated data. Unlike traditional time-frequency methods (Chakraborty and Okaya, 1994) that seek a trade-off of time and frequency resolution, we have chosen to use a pure frequency isolation algorithm. In fact, the method we use is traditional Fourier band pass filtering with a very narrow response centered on the frequency of interest.

The initial narrow band (NB) data was created using SeismicUnix (Cohen and Stockwell, 2010) hereafter termed SU. Specifically, the sufilter program was driven by a shell script (Appendix B) that implemented the following steps:

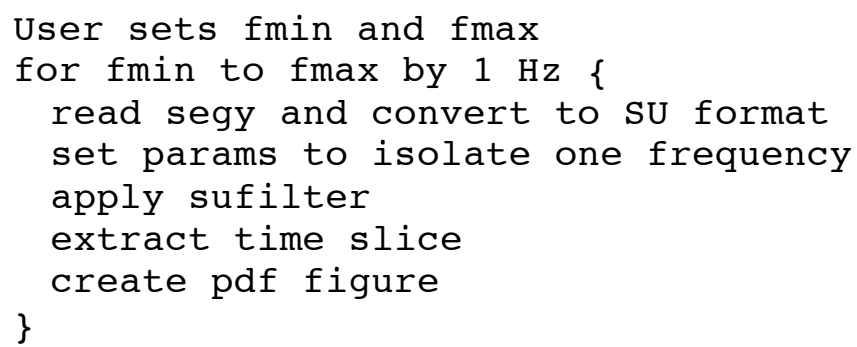

This allowed quick narrow band data scanning for features of interest in time slice or vertical view. Once a particular narrow band was selected for further analysis, sufilter was applied to the original data and the entire NB attribute volume was output to segy format and imported to SMT for further analysis.

In the vertical view, the narrow band results are not very enlightening. It is tempting to conclude the new data has no time information content, but in fact, there is time localization in the amplitude modulation of each trace although it seems to have little 
value in the vertical view. Analyzing the spectrally decomposed volumes in time-slice view reveals structural and stratigraphic features not seen in the broadband data.

\section{Fracture detection at $6 \mathrm{~Hz}$}

The term "fracture" in this work describes any surface along which a rock has lost cohesion. Features such as faults, joints, micro-cracks, and disconnected bedding surfaces are categorized as fractures. Joints are a type of fracture with relatively little or no displacement along its surface, while faults have significant shear-type displacement within a zone or along a planar surface (Twiss and Moores, 2006). Fractures form in response to body forces (force due to gravity) or surface forces (tectonic forces), and depending on the observational scale, fracture geometry can vary locally or extend regionally. Tectonic fractures form in response to surface forces, which correspond to a tectonic event. They often have complex geometries, dynamically change over a relatively small scale, and form in relation to major structures such as faults and folds (Nelson, 2001). Regional fractures form in response to body forces in a systematic way, usually as orthogonal pairs perpendicular to bedding. They usually reflect basin geometry, show minimal displacement, and have relatively consistent geometries over a regional scale (Nelson, 2001). Mississippian rocks in Central Kansas are believed to exhibit both these fracture types (Merriam, 1963).

Fracturing has been either interpreted or identified at various scales in Central Kansas. A map of the Central United States (Figure 15) shows that the majority of structural features north of the Ouachita Orogeny have either a NE-SW or NW-SE orientation (Jorgensen et al., 1993; Carr et al., 2005). Smaller scale features local to these major structures are likely to share the orientations. In addition, Nissen et al. (2009) interprets sub-vertical fracture sets in the Mississippian reservoir from geophysical data acquired at the Dickman Field (Figure 16) in general agreement with non-seismic geophysical data (Kruger, 1997). The results show a consistent bi-directional trend: NESW and NW-SE. Furthermore, clastic-filled vertical fractures crosscut horizontal wells adjacent to the Dickman Field (Carr et al., 2000). These fractures have large widths (up to $5 \mathrm{ft}$ ) and are filled with debris from eroded Upper Mississippian rock and encroaching Pennsylvanian deposits, demonstrating evidence of enhanced dissolution of Upper Mississippian strata during the CKU (Carr et al., 2000). Moreover, Figure 17 shows core photos taken from surrounding Dickman wellbores. The photos clearly show evidence of sub-vertical fracturing in the Upper Mississippian section.

The general consensus from past studies is that there are two dominant reservoir fracture trends in the greater Dickman area: an open northwest striking set and a healed, or sediment filled northeast striking set that crosscuts the former and impedes fluid movement throughout the reservoir. While past studies provide fracturing evidence from surrounding well control, geophysical methods have yet to provide a clear representation of fracture geometry within the Mississippian reservoir at the Dickman Field.

The Mississippian-Pennsylvanian unconformity is represented in the Dickman 3D seismic data at roughly $848 \mathrm{~ms}$. Producing a time slice through the full bandwidth volume at $848 \mathrm{~ms}$ exposes prominent features (Figure 18). The most notable is an incised channel, which represents Lower-Cherokee deposits. Moreover, other features include a 
northeast trending fault at the northern edge of the survey as well as evidence of karsting southwest of the channel. However, with exception to the fault, the broadband volume does not provide evidence of linear fracture trends at or near the unconformity boundary.

A $6 \mathrm{~Hz}$ narrowband image (Figure 19) provides visual evidence of natural fracturing in the Mississippian reservoir (Seales et al., 2011). The $6 \mathrm{~Hz}$ anomalies agree with the interpretation offered by Nissen et al. (2009), who hypothesized that curvature lineaments with similar orientations are indicators of natural fracturing.

\section{Channel detection at $41 \mathrm{~Hz}$}

Structural and stratigraphic characterization through narrow-band decomposition has been investigated. The initial plan was to build a frequency filter with a $2 \mathrm{~Hz}$ span across the top in order to isolate specified frequencies. The filter designed in Seismic Unix (SU) has proved to be quite beneficial for producing isolated frequency volumes for interpretation to test our hypotheses.

The filter was originally built in SU and Kingdom SMT, with the SU filter appearing to have better frequency isolation. We attribute this to the sine-squared smoothness of the SU filter versus the trapezoidal (sharp-edged) filter in SMT, since sharp filter edges are well known to generate artifacts. Figure 20 shows Dickman 3D seismic spectra from the the broadband, $6 \mathrm{~Hz}$, and $41 \mathrm{~Hz}$ filters as plotted in SU to a common scale. These two frequencies $(6 \mathrm{~Hz}$, and $41 \mathrm{~Hz})$ were chosen based on intriguing features observed in 848 ms time slice scans for various frequency filters separated by $1 \mathrm{~Hz}$. At $6 \mathrm{~Hz}$, there are linear features perhaps related to fractures (discussed earlier), and at $41 \mathrm{~Hz}$ additional channel detail is observed that not seen on the broadband data.

The broadband data sliced at $848 \mathrm{~ms}$ (Figure 18) clearly shows the main channel feature on the eastern side of the image and meandering south to north. There are no definite linear features depicted within the figure, nor any indication of a tributary type channel feed in to the main channel feature. Figure 20 shows the $848 \mathrm{~ms}$ time slice at $6 \mathrm{~Hz}$. There are multiple sets of features within this data that suggest possible fracture orientations (yellow lines).

Linear features in seismic time slice data automatically draw suspicion of being acquisition footprint, meaning amplitude stripes parallel to shot or receiver line orientation. The Dickman 3D shooting geometry is shown in Figure 21. The source lines are aligned N-S, and the receiver lines E-W. Comparing this to the $6 \mathrm{~Hz}$ data, we find the $6 \mathrm{~Hz}$ linear features do not align with acquisition geometry and are therefore more likely geological in nature.

Figures 22abc show the sequence of $40 \mathrm{~Hz}, 41 \mathrm{~Hz}$, and $42 \mathrm{~Hz}$ time slices at $848 \mathrm{~ms}$. The purpose of viewing these is to show persistence of a possible channel feature in the decomposed data. This channel feature is not seen in the broadband data of Figure 19, and is highlighted in the decomposed data by the yellow arrow highlighting the secondary, or feeder, channel location. We hypothesize this feature is a tributary feeding into the main channel. Figure 23 shows a modern analog in coastal Georgia. The area 
highlighted with the yellow circle shows a smaller tributary channel feeding in to a main channel with the channel bar being visible as is the case in our data.

To validate the channel feature seen in the decomposed data, log information for four wells lying in the main and tributary channel features were investigated. A cross section through these wells (Figure 24) was extracted from the $41 \mathrm{~Hz}$ data. Wells 1 and 2 lie either in or in close proximity to the tributary channel feature, and wells 3 and 4 lie within the main channel feature. The suspected channel feature is highlighted in this figure by the same yellow arrow as depicted in earlier figures showing the relation of this channel and the composed cross section.

A cross section through the wells is hung structurally and based on the interpretation of the gamma ray (GR) and resistivity (RES) logs for these four wells (Figure 25). The logs are shown equally spaced. Basic lithology can be determined from the GR log. From lowest to highest GR values, we have limestone (LS), sandstone (SS), and shale (SH) rock types. This is very important to our interpretation because the sequences in which these rock types occur can be correlated to the depositional environment. The black arrows placed on the GR logs in Figure 26 for each well indicate fining upwards sequences. These sequences are defined as moving from an area of lower gamma, or sandstone, to an area of higher values of gamma, or a muddier rock. This sequence is then capped at the top by a flooding event indicated by a sharp drop from high to lower gamma. With upward fining sequences identified for each well, an interpretation of the lithology and environment may be made.

The interpretation in Figure 27 supports the hypothesis of hidden channel features being decipherable through narrow-band decomposition. The base of the interpretation focuses on the blue area of the cross section representing Mississippian LS and dolomite. Above this, there are fining upwards sequences represented from base to flooding surface by yellow (SS) to gray (SH). Although hard contacts appear to be present within this interpretation, with respect to the fining upwards sequences, it should be noted that all contacts are assumed to be gradational with the exception of the flooding surfaces between the SH and overlying SS. Comparing features of sequences exhibited by the known channel feature and the suspected channel feature, it can be seen they are very similar. According to classification systems, these fining upwards sequences are characteristic of channel systems and therefore, it follows that these well logs were taken from channel environments. We conclude the $41 \mathrm{~Hz}$ data are, indeed, indicating tributary type channel features feeding into the main channel system seen in the broadband data.

Simple frequency filters can provide valuable data decomposition to the interpreter. This data can identify possibly fractured areas that need further investigation, and secondary channels features that may be unidentifiable in full bandwidth data. This capability can aid reservoir characterization, including our $\mathrm{CO} 2$ sequestration efforts.

\section{Elastic modeling and component rotation}




\section{Shear wave velocity estimation}

Elastic wave simulation requires compressional wave velocity (Vp), shear wave velocity (Vs) and density to compute elastic response for a layered earth model. Conventional sonic $\log$ provides Vp and we have five of these in the Dickman Field area (Figure 9), specifically Humphrey 4-18, Dickman 1, Dickman 6, Elmore 3 Noll C-3 and Sidebottom 6. Shear velocities can be obtained using a full wave sonic log, but no well in our study area has such a log. Therefore, we must estimate Vs before elastic modeling can be started. The Humphrey 4-18 well was chosen for Vs estimation and elastic forward modeling since it has a full log suite (including sonic) for lithology determination and a complete penetration of the deep saline reservoir which is a primary $\mathrm{CO}_{2}$ storage candidate (Figure 2). Although $\mathrm{H} 418$ is the best log suite we have available, it is far from perfect (Figure 28). The density $\log$ flips between reasonable values and $1.5 \mathrm{~g} / \mathrm{cc}$, a value far too low for Paleozoic clastic rocks. There are also several unrealistic spikes in the resistivity $\log$.

Many researchers hve investigated Vs estimation from Vp and other log information. Greenburg and Castagna (1992) have predicted Vs of Gulf of Mexico sandstones with different fluid saturation based on an empirical relationship between Vp and Vs in brine sands, with the calculation of fluid saturation effects by the Gassmann equation. Xu and White (1996) applied the theory of Kuster and Toksöz (1974) to porous model to build dry rock with different pore geometry (or pore aspect ratio), with constrains of measured porosity and $\mathrm{Vp}$, and fluid saturation effect on velocities estimated by Gassmann equation, while shear modulus and velocity were estimated based on the dry rock model. Liu and Han (2009) proposed a new scheme to estimate shear velocity based on laboratory measurements.

However, the above methods were derived mainly for clastic rocks (sandstone and perhaps shale), and therefore are likely to give inaccurate Vs at Dickman where a significant portion of the subsurface consists of carbonate rocks (limestone and dolomite). Therefore we developed a new Vs estimation technique that can be applied to all sedimentary rock types. Specifically, we calculate Vs from local Vp by assigning an empirical $\mathrm{Vp} / \mathrm{Vs}$ ratio based on litho-zones interpreted from well logs. This novel technique is referred as geological Vs estimation and is well-suited to potential CCS sites like the Dickman Field where conventional petroleum well logs are likely to be available. Figure 3 demonstrates the workflow of this technique, and the detailed implementation is described below.

Lithology and pore fluid density will affect the S-wave velocity and consequently the $\mathrm{Vp} / \mathrm{Vs}$ ratio. In the Dickman stratigraphic section there are many mixed layers along with a few pure shale, sandstone, limestone and dolomite. Therefore we need to use localized lithology discriminators based on two or more logs to determine lithology before S-wave velocity can be estimated for the elastic earth model. Four logs in the Humphrey 4-18 were taken into account; gamma ray (GR), density (RHOB), resistivity (RILD) and P-wave sonic (DT) of Humphrey 4-18 (Figure 28). The general workflow of our Vs estimation method is shown in Figure 29. 
We used gamma ray GR, PE and porosity logs as filters to break the geological section into discrete lithologies by the following steps (Figure 29a):

1. Gamma Ray (GR) was used to identify shale, sandstone, and carbonate based on cut-off values.

2. Carbonates were further filtered by PE log to distinguish limestone or dolomite. The PE log reads the size (area) of the reflecting surfaces of minerals. Pure calcite is the largest, reading around 5, pure dolomite is smaller around 3.14, and pure sandstone is 1.9. Given a limestone-dolomite mixture the PE value were mostly between 3.3 and 4.4 .

3. Porosity was estimated as NPOR $+\mathrm{DPOR} / 2$, where NPOR is neutron porosity, DPOR is density porosity. The resulting four lithologies are filtered by the porosity logs using $5 \%$ and $20 \%$ as threshold values to distinguish tight, intermediate and porous rocks for each litho-zone. There are $4 * 3=12$ types of different litho-zones, and the thickness of index varies with thickness of each litho-zone.

Each zone interval is thus assigned a lithology and associated $\mathrm{Vp} / \mathrm{Vs}$ ratio based on values in Figure 29b.

\section{Simulation of 3D elastic seismic data}

With Vp, Vs, and density models available, elastic modeling can be performed to generate multi-component seismic data. Elastic forward modeling for a 3D survey can be very expensive, so we exploit the fact that our earth model from the H418 well is horizontally layered. That means there is no variation in the $(\mathrm{X}, \mathrm{Y})$ directions and we can use specialized seismic modeling methods that exploit this symmetry. The best seismic modeling method for a horizontally layered earth is reflectivity modeling (Mallick and Frasier, 1987). We gratefully acknowledge Prof. Subhashis Mallick of the University of Wyoming for access to his elastic reflectivity modeling code (anivec).

The workflow for elastic simulation (Figure 30) consists of the following steps:

1. Generate 3D shot record. With anivec we can design a 2D geometry, input (Vp,Vs,density) well logs, assign forward modeling parameters, and calculate synthetic multicomponent shot records with radial, transverse, and vertical components. Each trace in the common shot gather is the simulated seismic response at a certain offset. Since the earth model is assumed to consist of 
isotropic horizontal layers, the resulting 2D shot record has radial symmetry in 3D.

2. Populate 3C data. Geokinetics has designed a hypothetical 3D 3C seismic survey for the Dickman Field area (Figure 31). Using the modeled 2D multi-component common shot gather, we can populate any trace in a 3D seismic survey design with the corresponding offset trace from the 2D synthetic gather. In a $3 \mathrm{D}$ seismic survey, every trace has an associated unique source and receiver location (Figure 32) that determine the offset and azimuth. For multicomponent data, field seismic sensor orientation is set to record $(\mathrm{H} 1, \mathrm{H} 2)$ components along standard compass directions (Figure 32).

3. Horizontal 3C rotation. Each synthetic trace has radial and transverse data components relative to the shot-receiver line (Figure 33), and these components must be rotated to acquisition components $(\mathrm{H} 1, \mathrm{H} 2)$ as shown in Figure 34. This projection process is called horizontal rotation and utilizes the SeismicUnix program suhrot.

In summary, forward modeling of 3D elastic seismic data here involves two steps: simulate 2D elastic shot gather data using a 1D elastic earth model; and generate 3D 3 component shot gathers by populating equal offset 2D elastic traces according to survey geometry and rotating the horizontal components to field orientation.

The motivation for considering multicomponent seismology lies in the nature of $\mathrm{P}$ - and $\mathrm{S}$-waves. Using single-component data (which is industry standard), the data is dominated by P-wave reflection events (Figure 35). Multicomponent data allows additional measurement of shear and mode-converted reflection events, a much richer wave field for estimating subsurface properties (Figure 36). Additionally, seismic waves in fractured media develop anisotropic behavior (Tsvankin et. al, 2010). For P-waves and S-waves this means that wave velocity depends on angle of propagation, a property that does not exist in isotropic media. Angle-dependence introduces measurable travel time and amplitude effects that can be used to estimate anisotropy and thus geological properties such as fracture orientation and density. These wave field characteristics are subtle but can be exploited using single-component seismic recording (which is industry standard). A strong and more direct fracture indicator is shear wave splitting, a process in which shear waves have different speeds parallel and perpendicular to the fracture direction. This effect can only be detected using multicomponent receivers.

Figure 37 shows the vertical and radial components of the synthetic shot record, with yellow dash lines indicating the Mississippian interval.

An important property of reflectivity elastic modeling used in our study is the ability to suppress certain kinds of waves and events. This is illustrated in Appendix C where a shot record based on the Humphrey 4-18 well is simulated in various ways, showing that shear and mode-converted waves carry much information not contained in a P-wave field. 


\section{Comparison to field data}

An important check on our seismic simulation work is comparison to field data, but there are many reasons that we should expect significant differences between synthetic and field data. These include near surface complications and irregular offset distribution in field data not in the synthetic.

For comparison purposes, we formed a super gather from the field data consisting of CMP gathers $4500-4505$ with a total of 303 traces with offsets from 587-8928 ft. The gather is displayed in Figure $\mathbf{3 8}$ where the field data irregular offset distribution is clearly seen in the uneven trace spacing. For display purposes, both field and synthetic data have been limited to 600-8500 ft offset and only 1 second of data is shown. The correspondence of events looks reasonable for P-wave reflections, but there is much more shear wave energy in the reflectivity synthetic than observed on field data.

In addition to reflectivity synthetic shot records, we computed finite difference (FD) synthetic data (Kelly et al., 1976) based on the acoustic wave equation. Comparison with field data (Figure 39) is very good indicating our field data is dominated by compressional wave energy. Correspondence of reflection events is more easily observed by reversing the offset order of the synthetic data as shown in Figure 40, or by simulating a broad range of offsets and overlaying the field data as in Figure 41. The overlay allows identification of a reflection event in field data not seen in the acoustic FD synthetic, likely a strong PS mode-converted reflection. In summary, we are confident the synthetic seismic data (reflectivity or finite difference) has a good correspondence to observed reflections in our field data.

\section{Populating the 3D survey design}

To illustrate the procedure of populating a 3D survey design with synthetic traces, we consider a single shot location in the Dickman 3D design (Figure 42). A synthetic shot record (including all events) was computed with offset increment of 2 meters using the Humphrey 4-18 well as described above.

For any given receiver location in the 3D design, the offset and azimuth are calculated. The trace with the nearest matching offset is selected from the synthetic shot record and its horizontal components $(\mathrm{R}, \mathrm{T})$ are rotated into field coordinates $(\mathrm{H} 1, \mathrm{H} 2)$ as described in Figures 33 and 34. After this procedure we have 3547 three-component seismic traces organized into 28 east-west receiver lines. These 20 receiver lines, after rotation, constitute a 3D shot record as shown in Figure 43 where the H2 component is displayed. The receiver line labeled A is shown in detail in Figure 44. This gives an important check on our result since horizontal receiver components should (and do) have opposite polarity for positive and negative offsets. The vertical component of the same 3D synthetic shot record is shown in Figure 45.

We have demonstrated how to estimate a shear wave velocity profile from conventional information, simulate realistic acoustic/elastic data traces and components, and use these 
to populate a hypothetical 3D 3C survey design. This workflow will aid survey design, processing and interpretation of $3 \mathrm{D}$ surveys for $\mathrm{CO} 2$ sequestration sites in the U.S.

midcontinent region. 


\section{References}

Carr, T. R., D. F. Merriam, and J. D. Bartley, 2005, Use of relational databases to evaluate regional petroleum accumulation, groundwater flow, and $\mathrm{CO} 2$ sequestration in Kansas: AAPG Bulletin, 89, no. 12, 1607-1627.

Carr, T. R., S. Bhattacharya, and R. Pancake, 2000, Horizontal drilling in Kansas: A case history, accessed August 20, 2012;

http://www.kgs.ku.edu/Workshops/Horz2000/R640/ .

Chakraborty, A. and Okaya, D., 1995, Frequency-time decomposition of seismic data using wavelet-based methods: Geophysics, Soc. of Expl. Geophys., 60, 1906-1916.

Cohen, J. K. and Stockwell, Jr. J. W., (2010), CWP/SU: Seismic Un*x Release No. 42: an open source software package for seismic research and processing, Center for Wave Phenomena, Colorado School of Mines.

Greenberg, M. L., and Castagna J. P., 1992. Shear-wave velocity estimation in porous rocks: Theoritical formulation, preliminary verification and application.

Jorgensen, D.G., J. O. Helgesen, and J. L. Imes, 1993, Regional aquifers in Kansas, Nebraska, and parts of Arkansas, Colorado, Missouri, New Mexico, Oklahoma, South Dakota, Texas, and Wyoming - geohydrologic framework: U.S. Geological Survey Professional Paper 1414-B, B72 p.

Kruger, J. M., 1997, On-line gravity and magnetic maps of Kansas: Kansas Geological Survey Open-File Reports 96-51 and 97-72:

http://www.kgs.ku.edu/PRS/PotenFld/potential.html (Accessed August- September, 2011).

Kuster, G.T., and Toksöz, M.N., 1974, Velocity and attenuation of seismic waves in twophase media: Part I. theoretical formulations: Geophysics, 39, 587-606.

Liner, C. L., 2004, Elements of 3-D Seismology: 2nd edition, 2004, Pennwell, 607 p.

Liu, J. J., and Han D. H., 2009. Shear velocity estimation using Gassmann equation. University of Houston Fluids/DHI consortium report.

Mallick, S. and Frazer, L. N., 1987. Practical aspects of reflectivity modeling, GEOPHYSICS, 52, 1355-1364.

Merriam, D. F.,1963 , The Geologic History of Kansas: Kansas Geological Survey Bulletin, 162, accessed April 14, 2009; http://www.kgs.ku.edu/Publications/Bulletins/162/index.html 
Moore, R.C., 1949, Divisions of the Pennsylvanian System in Kansas: Kansas Geological Survey Bulletin, 83, accessed April 14, 2009; http://www.kgs.ku.edu/Publications/Bulletins/83/index.html

Nelson, R. A., 2001, Geological Analysis of Naturally Fractured Reservoirs: Gulf Publishing Company, Houston, TX.

Nissen, S.E., T. R. Carr, and K. J. Marfurt., and Sulivan, E.C., 2009, Using 3-D seismic volumetric curvature attribute to identify fracture trends in a depleted Mississippian carbonate reservoir: implictions for assessing candidates for $\mathrm{CO}_{2}$ sequestration: AAPG Studies in Geology 59, 297-319.

Sawin, R., Franseen, E., Watney, W. West, R. and Ludvigson, G., 2009, New Stratigraphic Rank for the Carboniferous, Mississippian, and Pennsylvanian in Kansas, Current Research in Earth Sciences, Bulletin 256, part 1.

Seales, J., Brown, T., and Liner, C., 2011, Channel and fracture indicators from narrowband decomposition at Dickman field, Kansas: SEG Expanded Abstracts 30, 1830.

Tsvankin, I., Gaiser, J., Grechka, V., van der Baan, M. and Thomsen L., 2010, Seismic anisotropy in exploration and reservoir characterization: An overview, Geophysics 75, 75A15, DOI:10.1190/1.3481775

Twiss, R. J., and Moores, E. M., 2006, Structural Geology, $2^{\text {nd }}$ edition, W. H. Freeman, $586 \mathrm{pp}$.

Xu, S., and White, R. E., 1996, A physical model for shear-wave velocity prediction: Geophysical Prospecting, 44, 687-717. 


\section{Figures}

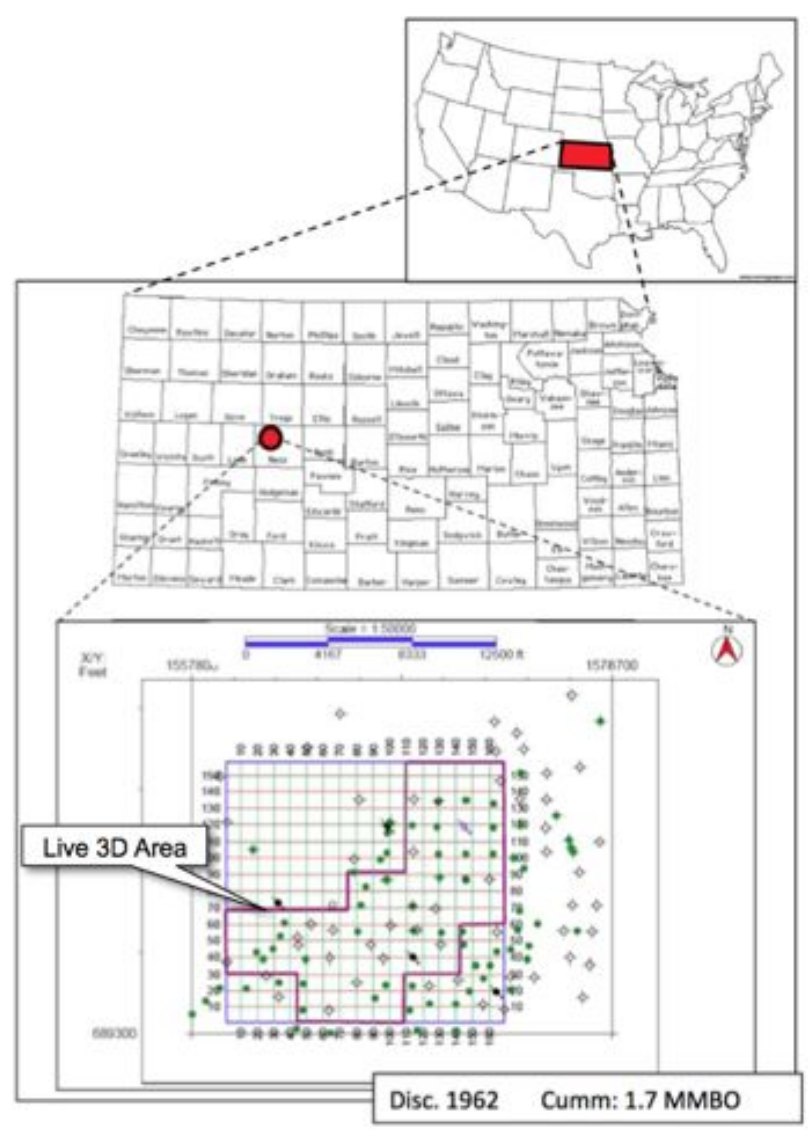

3D Seismic

3.325 sq.mi.

\section{2 wells}

54 in 3D area

45 with digital logs

GR (43), Resistivity (25),

Neutron (27),

P-Sonic (6), Density (3)

7 with core

porosity and permeability

3 full deep saline aquifer penetration

Figure 1. Dickman Field location and description of available data. 


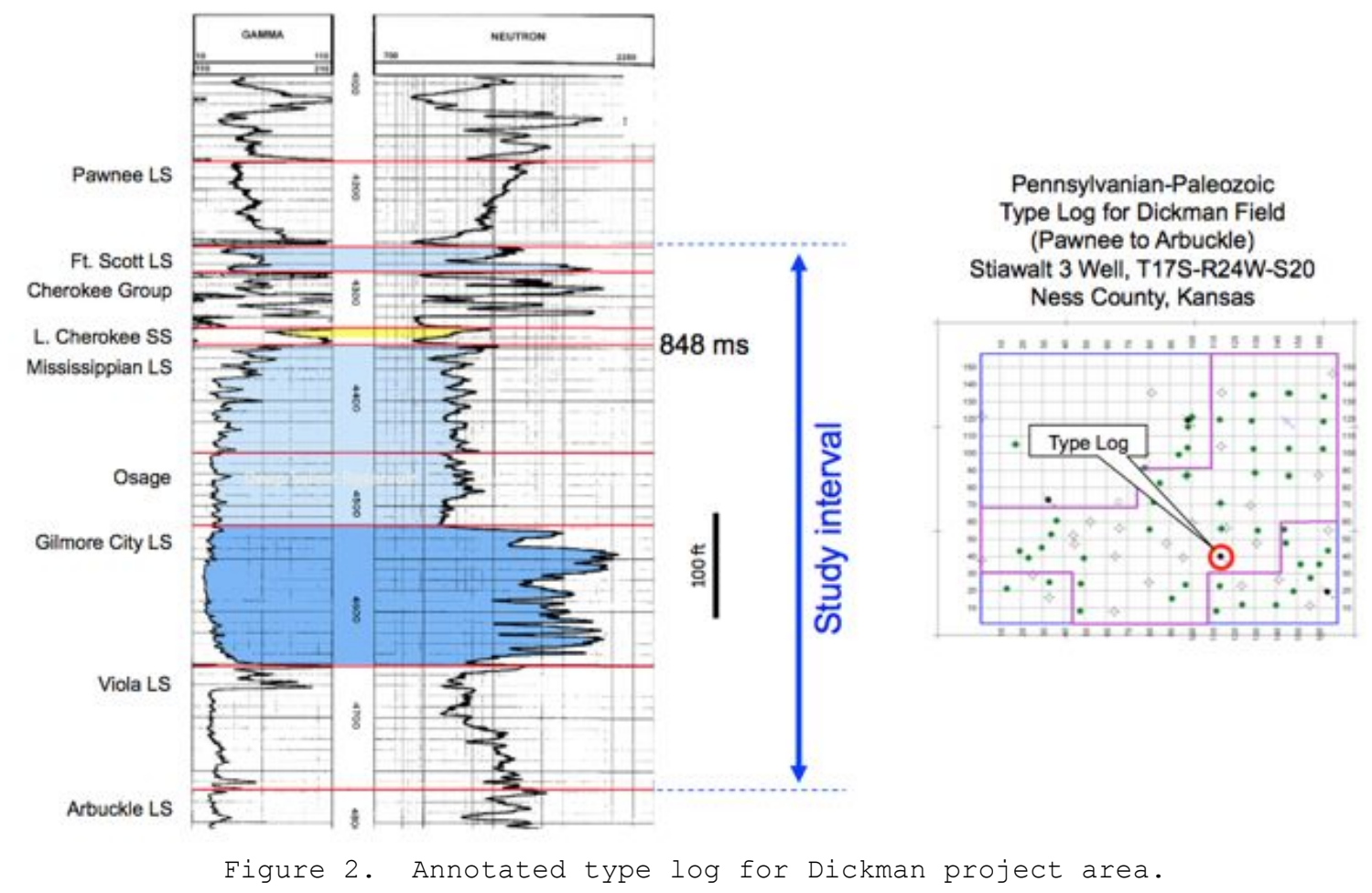






Figure 3. Base map showing 142 wells within Dickman project area. 


\begin{tabular}{|c|c|c|c|c|c|c|c|c|}
\hline \multirow[b]{2}{*}{$\begin{array}{l}\text { prol Jells with } \\
\text { property data }\end{array}$} & \multicolumn{2}{|c|}{ Pay zones } & \multicolumn{3}{|c|}{ Core } & \multicolumn{2}{|c|}{ Porosity Log } & \multirow{2}{*}{$\begin{array}{c}\text { Velocity } \\
\text { Sonic }\end{array}$} \\
\hline & $\begin{array}{l}\text { Sandstone } \\
\text { Reservoir }\end{array}$ & $\begin{array}{l}\text { Carbonate } \\
\text { Reservoir }\end{array}$ & Porosity & Permeability & $\begin{array}{c}\text { Water } \\
\text { Saturation }\end{array}$ & Neutron & Density & \\
\hline Dickman 1 & $x$ & $x$ & & & & $\mathrm{X}$ & & $\mathrm{X}$ \\
\hline Dickman A1 & $x$ & $x$ & & & & $x$ & & \\
\hline Dickman A2 & $x$ & $\mathrm{x}$ & & & & $\mathrm{x}$ & & \\
\hline Dickman 2 & $x$ & $\mathrm{X}$ & $\mathrm{x}$ & $x$ & $\mathrm{x}$ & & & \\
\hline Dickman 3 & & & $x$ & $x$ & $\mathrm{x}$ & $x$ & & \\
\hline Dickman 4 & & & $x$ & $x$ & $\mathrm{x}$ & $x$ & & \\
\hline Dickman 5 & & & $x$ & $\mathrm{x}$ & $\mathrm{x}$ & & & \\
\hline Dickman 6 & $\mathrm{X}$ & & & & & $\mathrm{x}$ & & $\mathrm{x}$ \\
\hline Elmore 1 & show & show & $x$ & $\mathrm{X}$ & $\mathrm{x}$ & $x$ & & \\
\hline Elmore 2 & $?$ & $?$ & & & & $x$ & & \\
\hline Elmore 3 & $?$ & $?$ & & & & $\mathrm{x}$ & & $\mathrm{X}$ \\
\hline Humphrey 1 & $\mathrm{X}$ & $x$ & & & & $\mathrm{x}$ & & \\
\hline Humphrey 3-18 & $x$ & $x$ & & & & $x$ & & \\
\hline Humphrey 4-18 & & $x$ & & & & $\mathrm{x}$ & $\mathrm{x}$ & $\mathrm{x}$ \\
\hline Noll 1 & $?$ & $?$ & $?$ & & & $x$ & $x$ & \\
\hline Noll 'C' 3 & & & & & & & & $\mathrm{X}$ \\
\hline Schaben 1 & & & & & & $\mathrm{x}$ & & \\
\hline Schaben 2 & & & & & & $\mathrm{x}$ & & \\
\hline Schaben 3 & & & & & & $x$ & & \\
\hline Schaben 4 & & & & & & $x$ & $\mathrm{x}$ & \\
\hline Sidebottom 6 & & & & & & $x$ & $x$ & $X$ \\
\hline Tilley 1 & $?$ & $?$ & $\mathrm{x}$ & $\mathrm{X}$ & $\mathrm{x}$ & & & \\
\hline Telley 2 & & $x$ & $x$ & $x$ & $x$ & & & \\
\hline Telley 5 & & & & & & $x$ & & \\
\hline
\end{tabular}

Figure 4. Key property data available in the project area. 

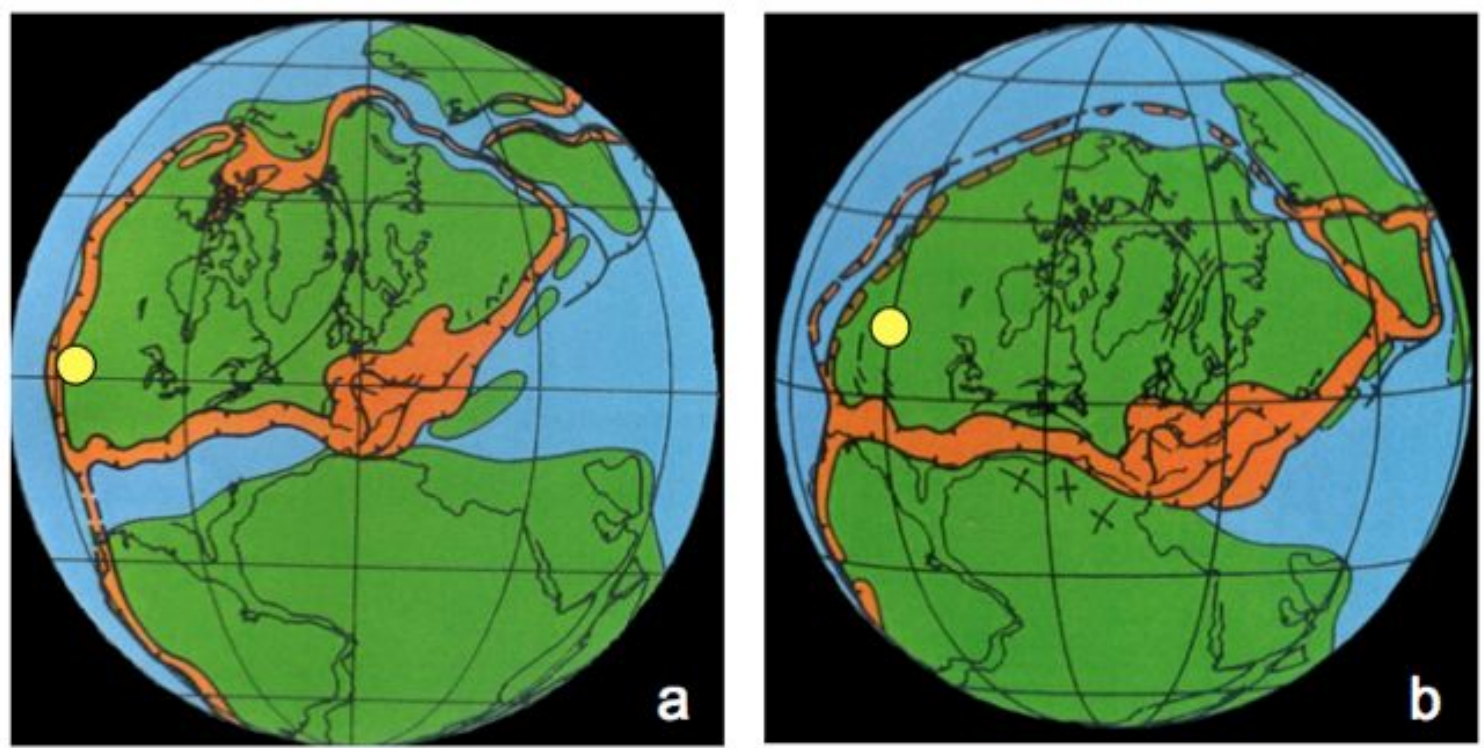

Figure 5. Plate tectonic configuration at a) $335 \mathrm{Ma}$ and b) $310 \mathrm{Ma}$. Study area indicated by yellow dot (after Ziegler, 1989). 
Dickman Field Stratigraphy

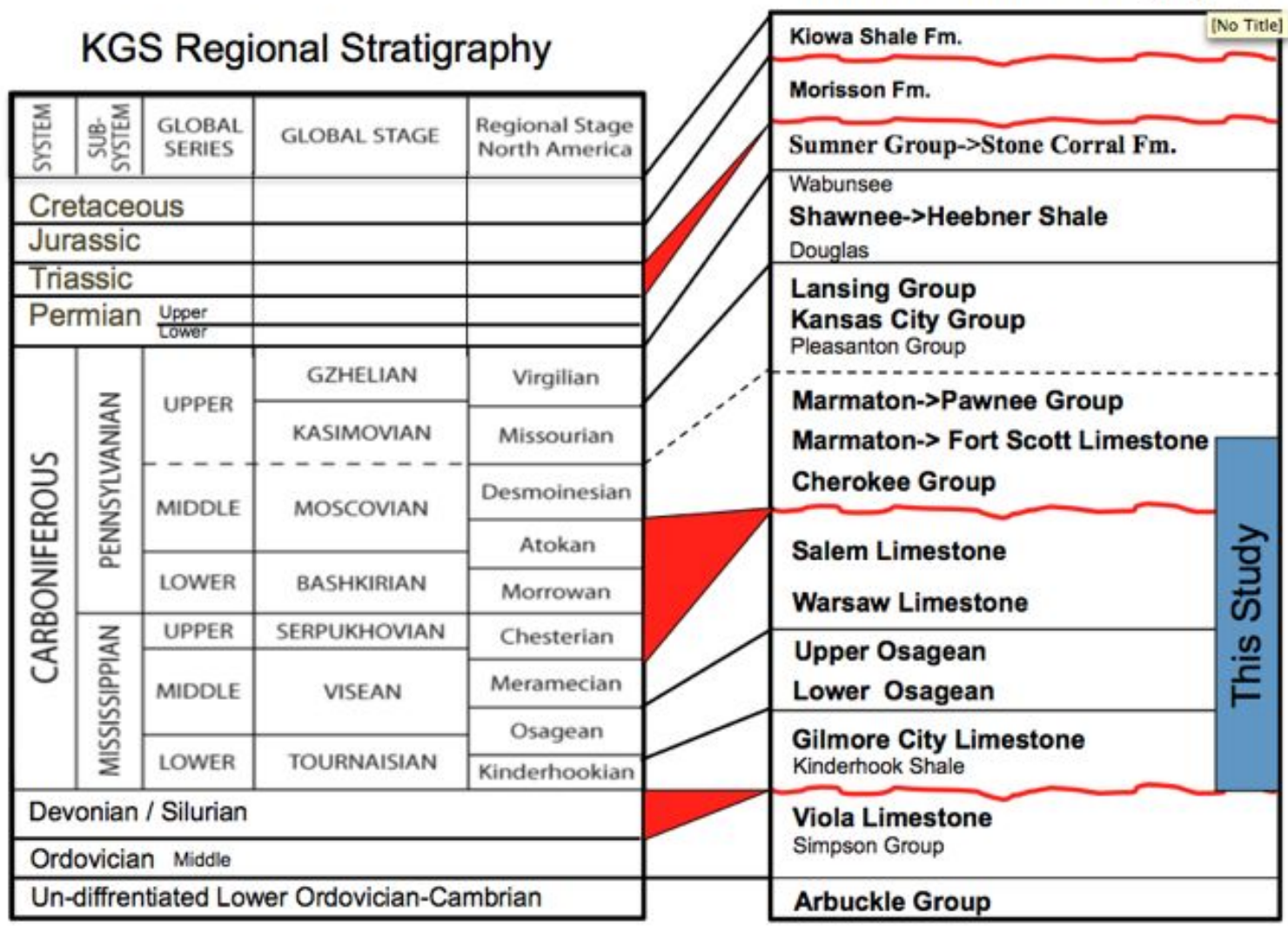

Figure 6. Chart to the left is the stratigraphic rank accepted by the Kansas Geological Survey (Sawin et al., 2008). The chart to the right shows correlation to Dickman local stratigraphic units, with higher confidence correlations in bold. The blue vertical bar indicates the target strata for Dickman research. 

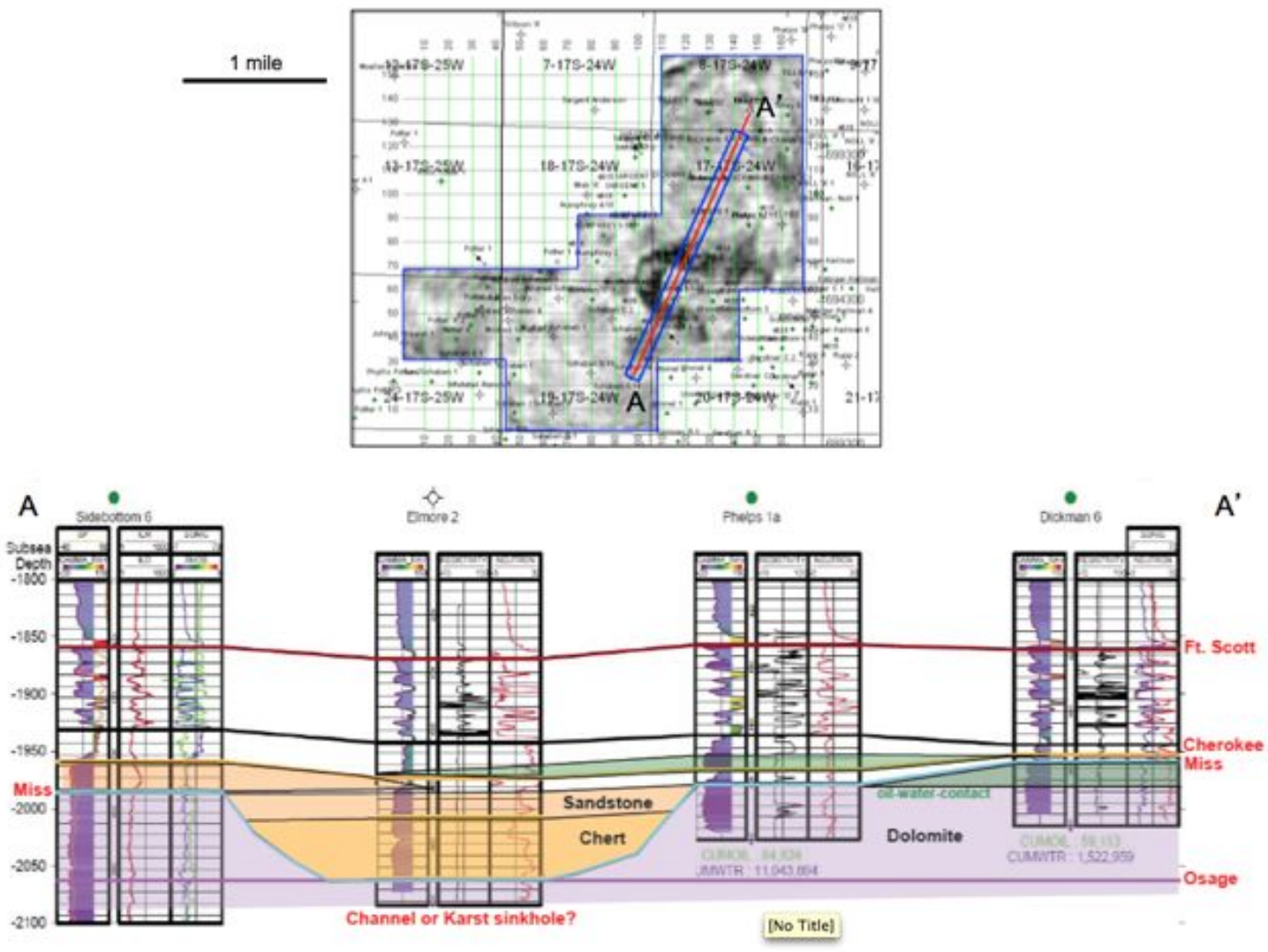

Figure 7. Time slice through 3D amplitude volume at $848 \mathrm{~ms}$ (approximate top Miss level) showing clear evidence of incised channel. Geological interpretation along highlighted line shown below. 







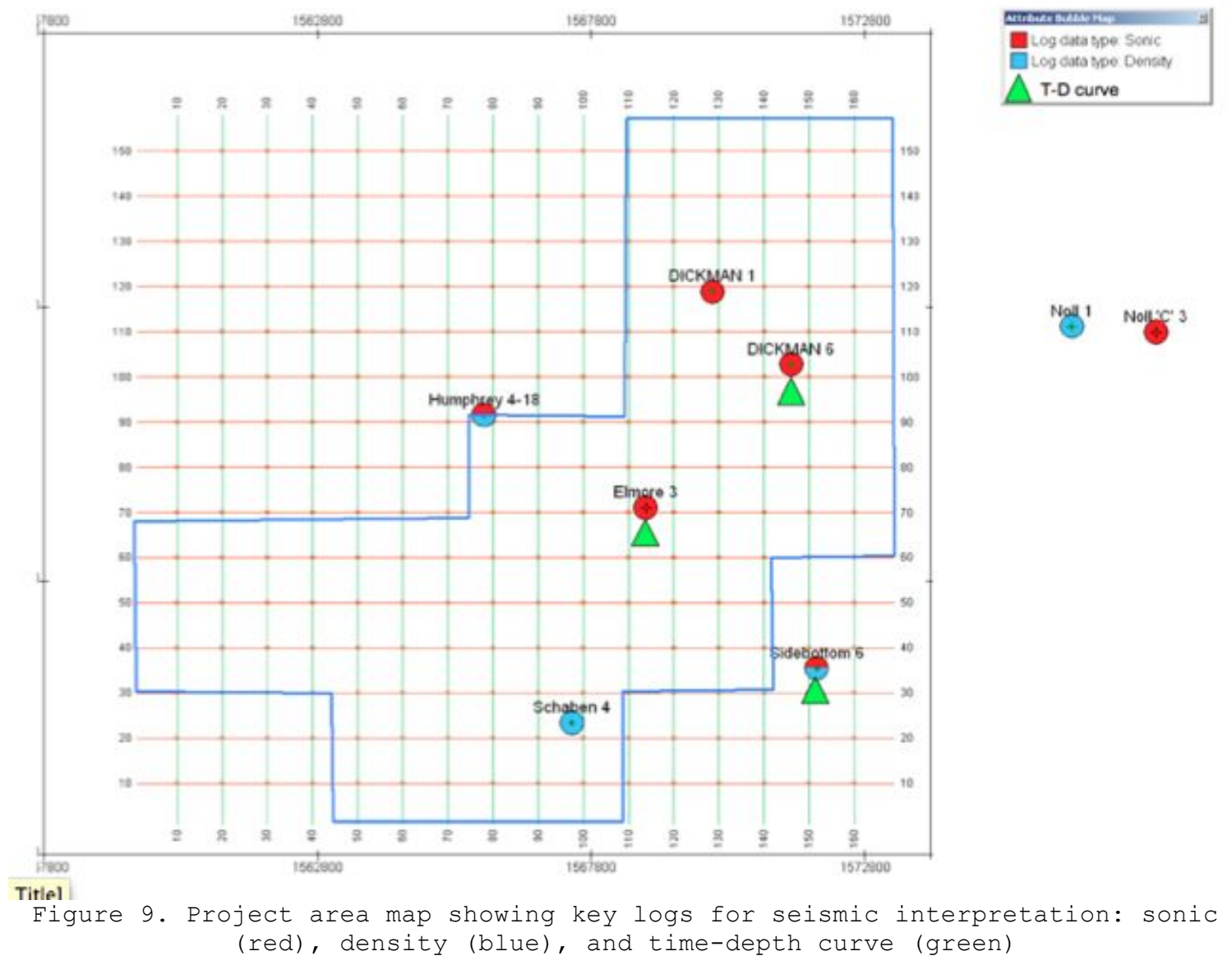




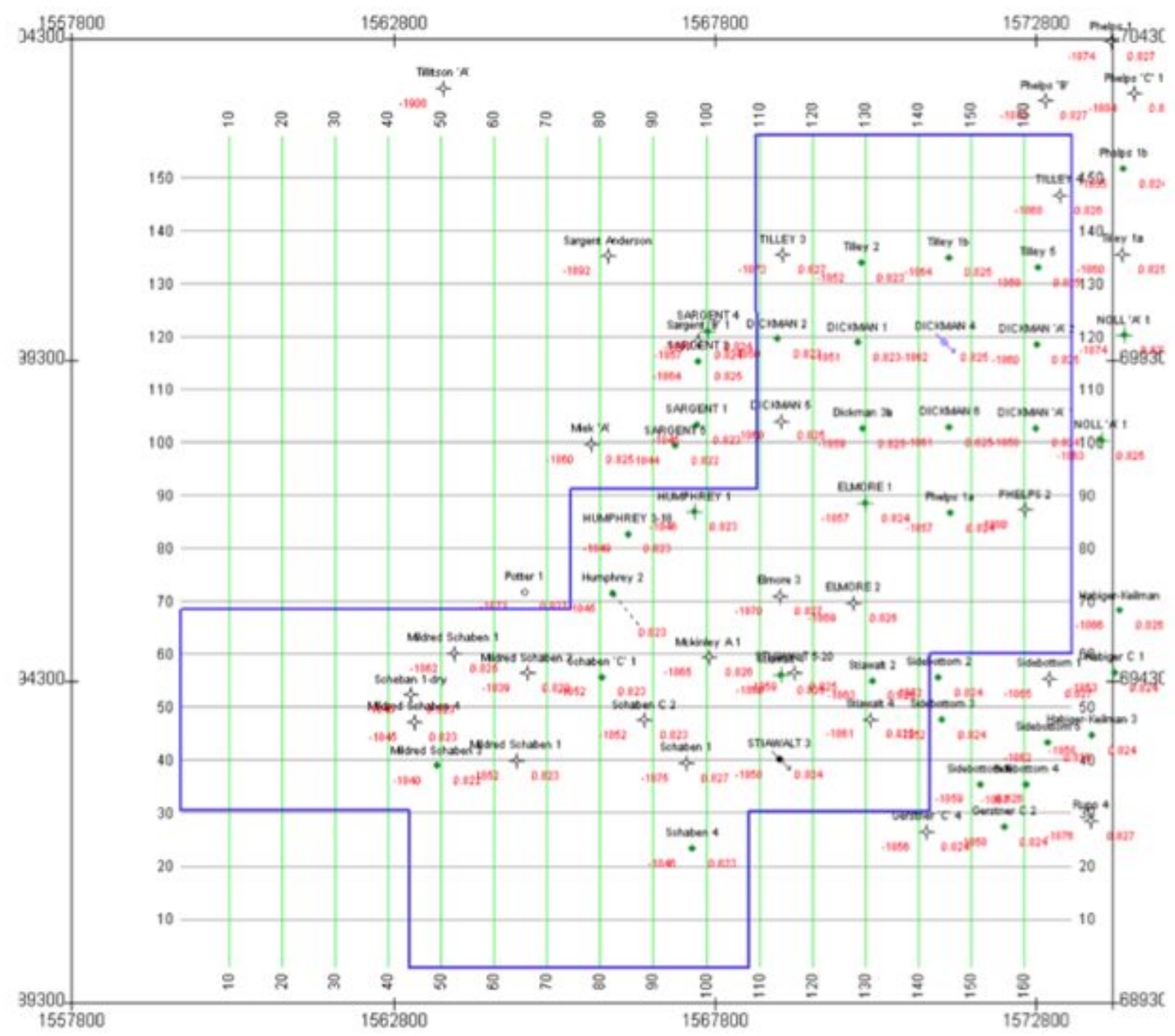

Figure 10a. Map showing wells with a Ft. Scott pick, annotated with subsea depth and seismic time. 


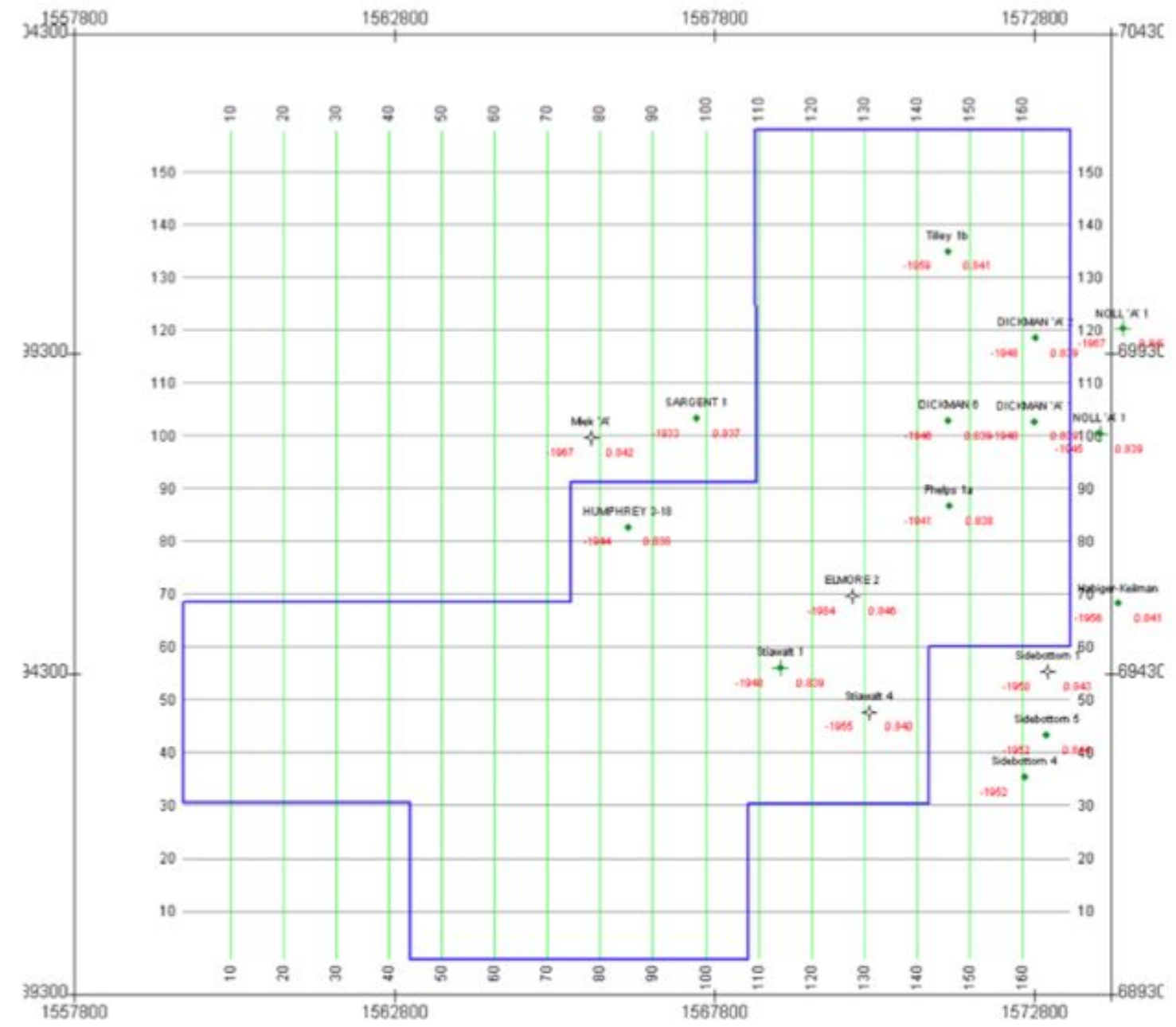

Figure 10b. Map showing wells with a Lower Cherokee pick, annotated with subsea depth and seismic time. 




Figure $10 \mathrm{c}$. Map showing wells with a Mississippian unconformity pick, annotated with subsea depth and seismic time. Seismic line A-A' shown in Fig. 11. 


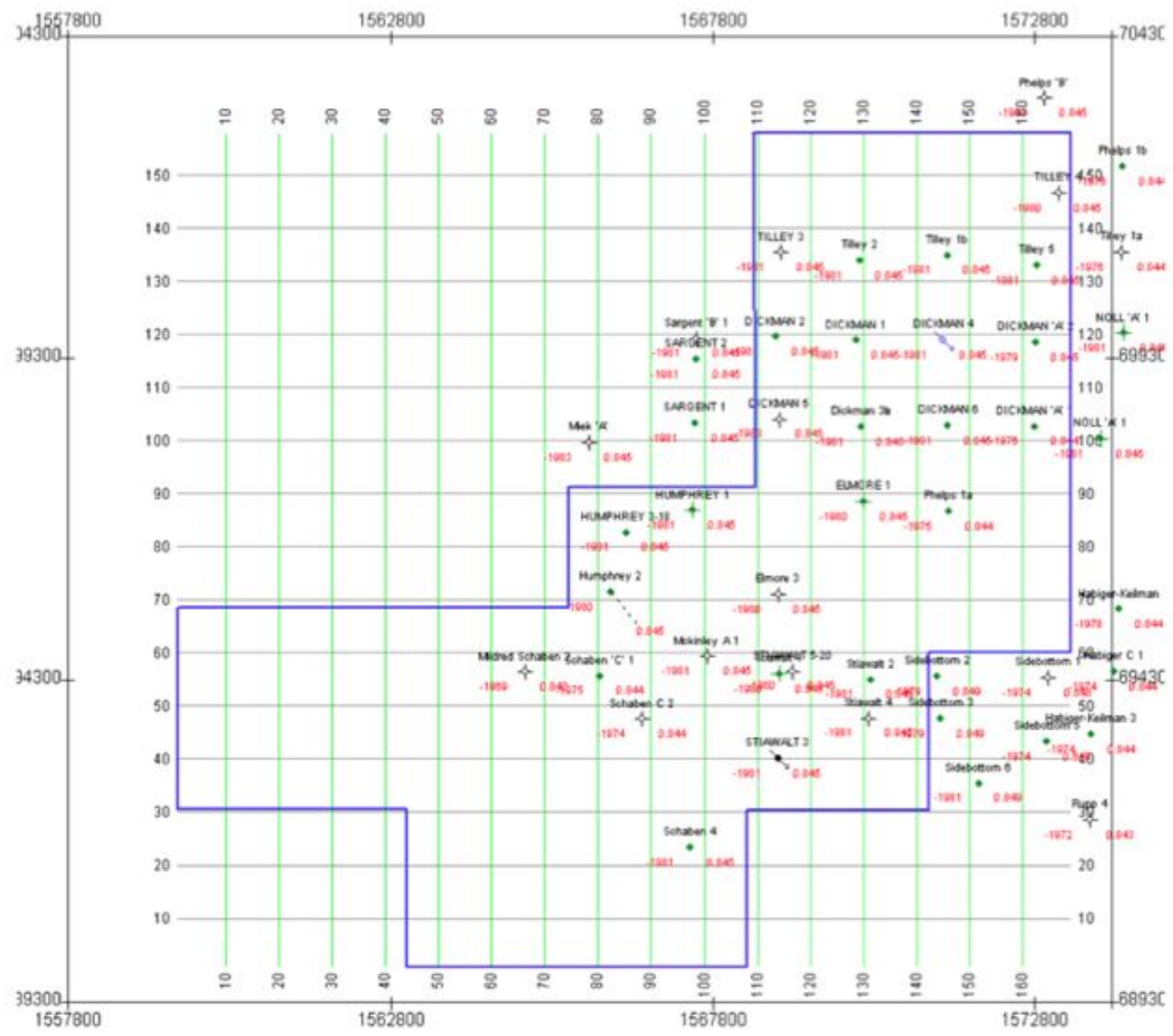

Figure 10d. Map showing wells with an oil-water contact pick, annotated with subsea depth and seismic time. 


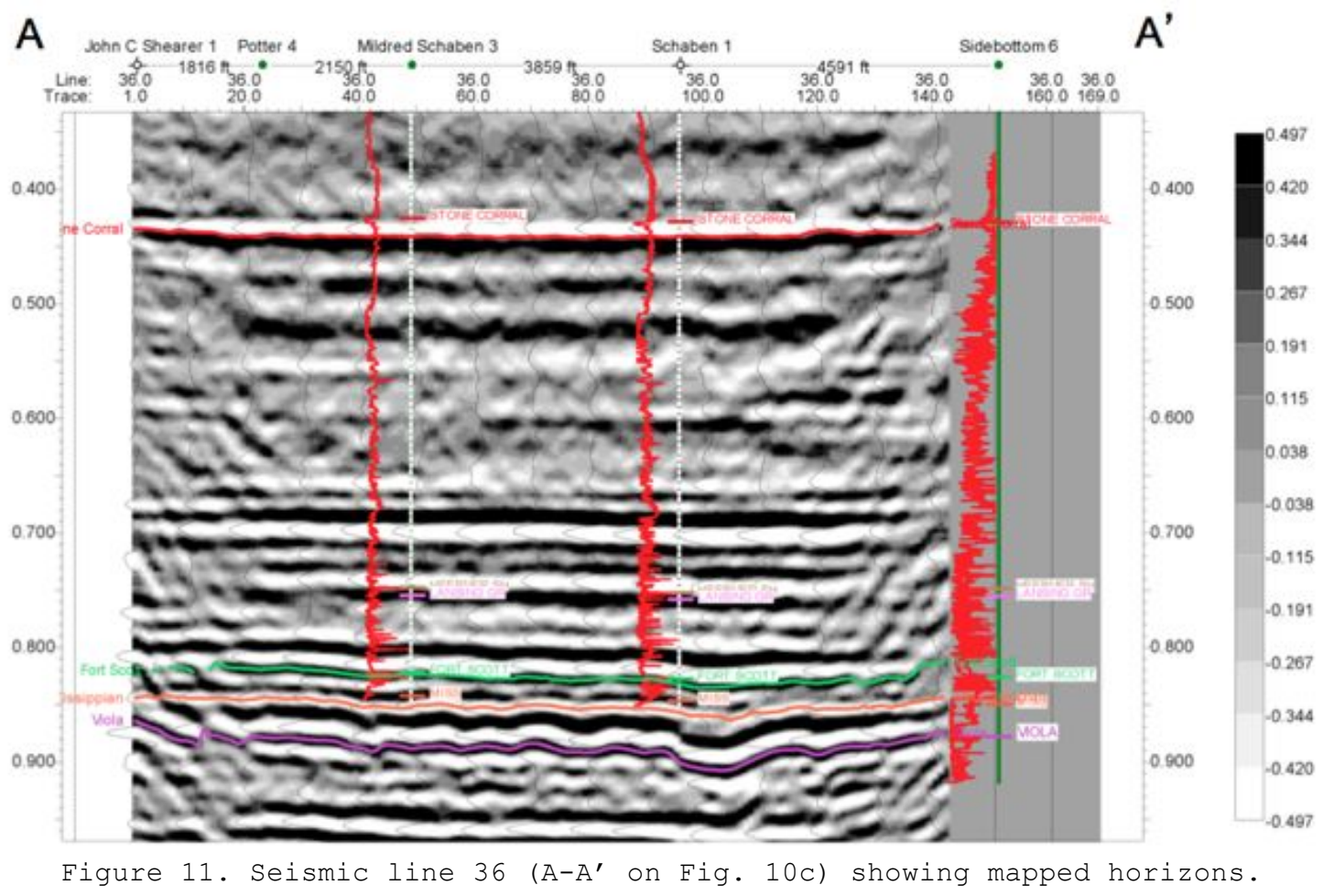




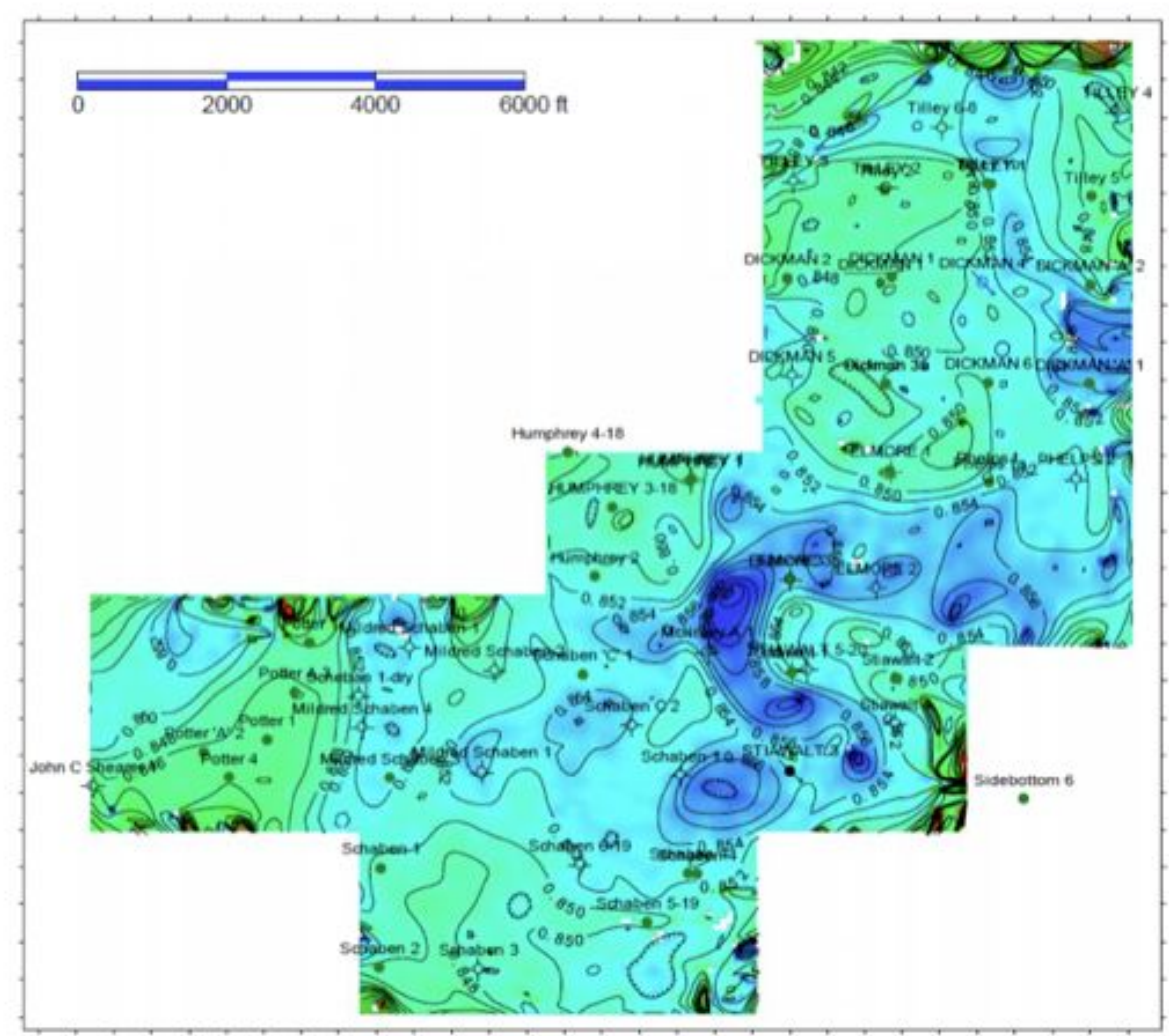

$\stackrel{\mathrm{N}}{\mathrm{a}}$

Figure 12. Top Mississippian time structure. 


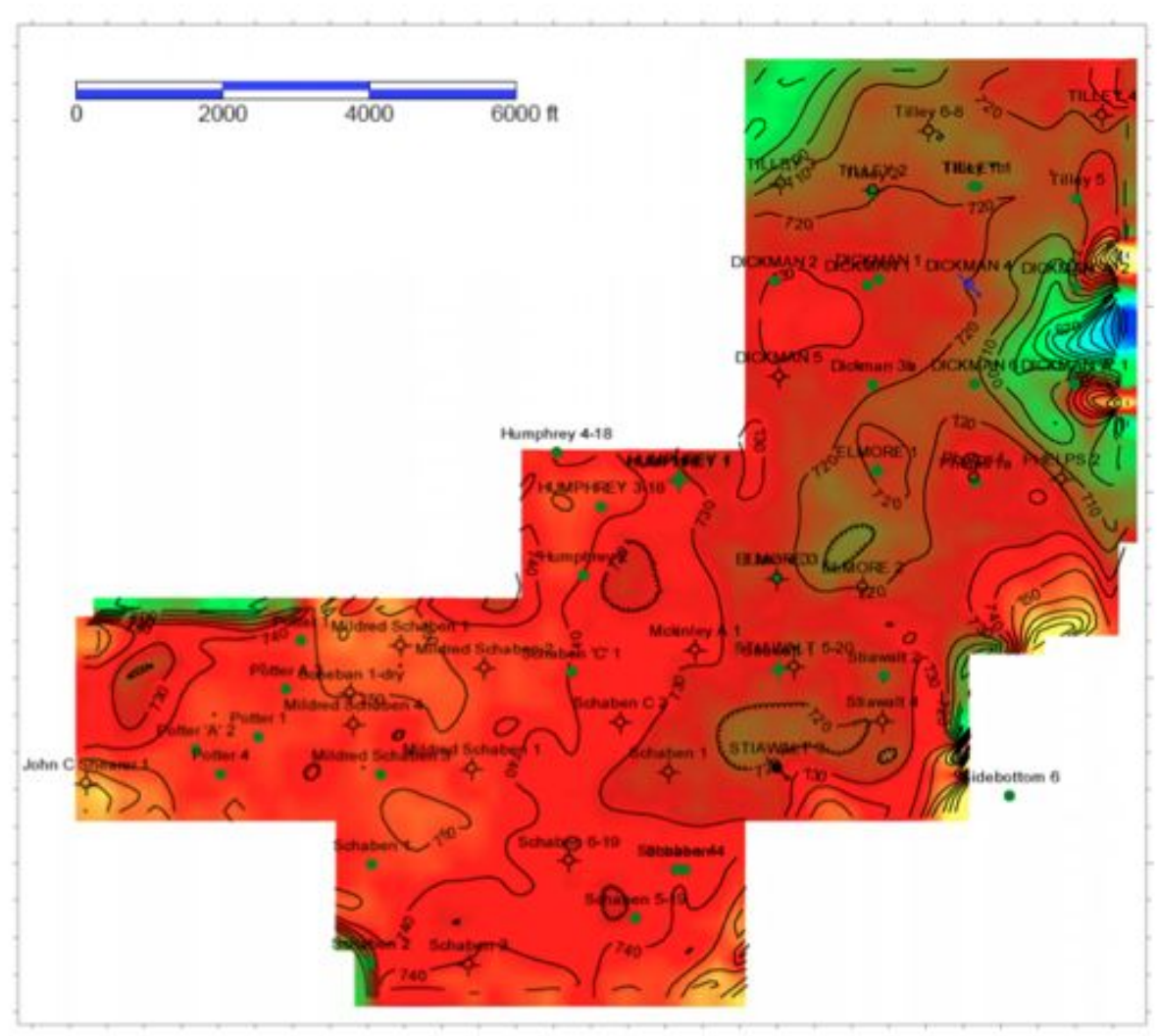

$\stackrel{n}{n}$

571.370

578.161

584.952

591.743

598.534

605.325

612.116

618.907

625.698

639.280

646.071

652862

659.653

666.444

673.234

(6).234

686.816

(68.816

700.398

700.398
707.189

13.980

720.771

727.562

734.353

741.144

747.935

754.726

761.51

768.308

775.099

781.890

788.681

795.472

80226

809.054

15.844

822.635

829.426

836.217

836.217
843.008

Figure 13a. Final Stone Corral depth structure. 


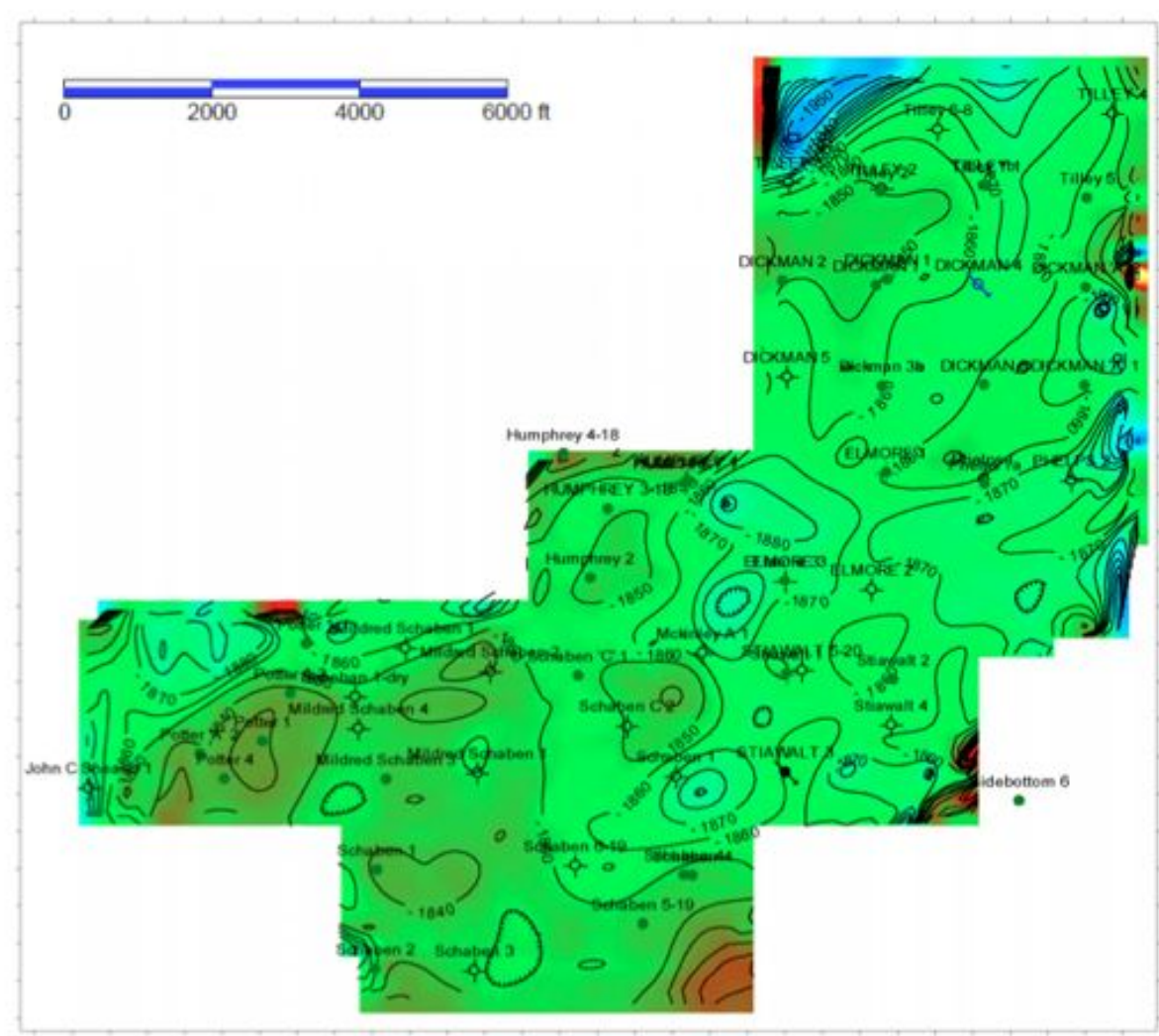

$\stackrel{N}{N}$

Figure 13b. Final Ft. Scott depth structure. 



Figure 13c. Final top Mississippian depth structure. 




$\stackrel{N}{N}$

Figure 13d. Final Viola depth structure based on seismic and two wells (circled). 




Figure 14. Narrowband (NB) spectral decomposition. (a) Broadband time slice. (b) $\mathrm{NB} 5 \mathrm{~Hz}$. (c) $\mathrm{NB} 6 \mathrm{~Hz}$. (d) $\mathrm{NB} 7 \mathrm{~Hz}$. Note persistent diagonal amplitude features in (b) - (d). 


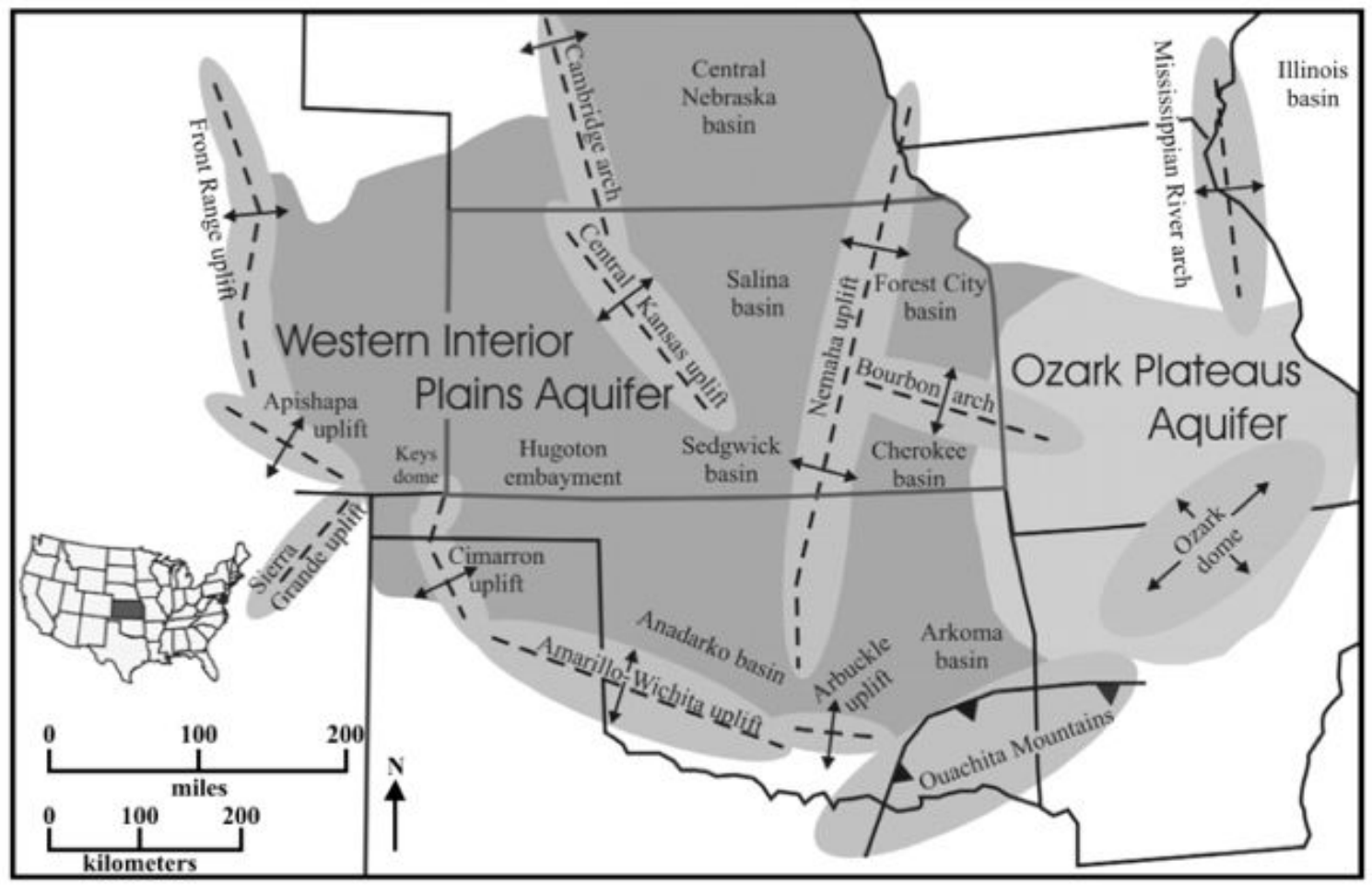

Figure 15. Map of Kansas showing the WIP aquifer system and regional structures of the Central United States (After Jorgensen et al. (1993) and Carr et al., 2005). Note the large-scale NW and NE trending features throughout the region. 


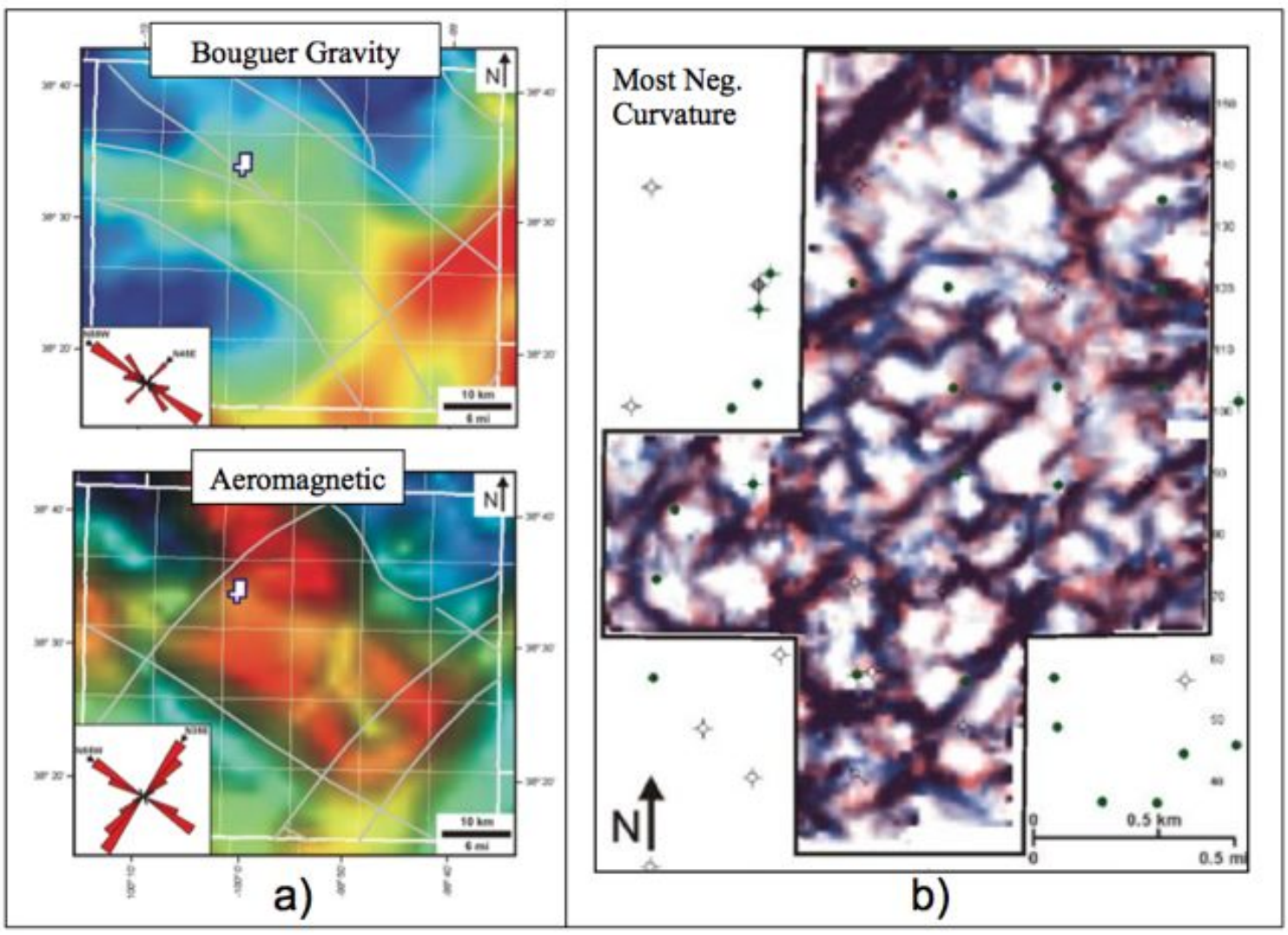

Figure 16: Geophysical evidence of fracturing in Dickman Field area. (a) Bouguer gravity and aeromagnetic maps of Ness County (Kruger, 1997). (b) Mostnegative curvature map of Mississippian horizons extracted from the Dickman 3D seismic data (Nissen et al., 2009). Note the dominant NW-NE oriented features common in all three data types. 


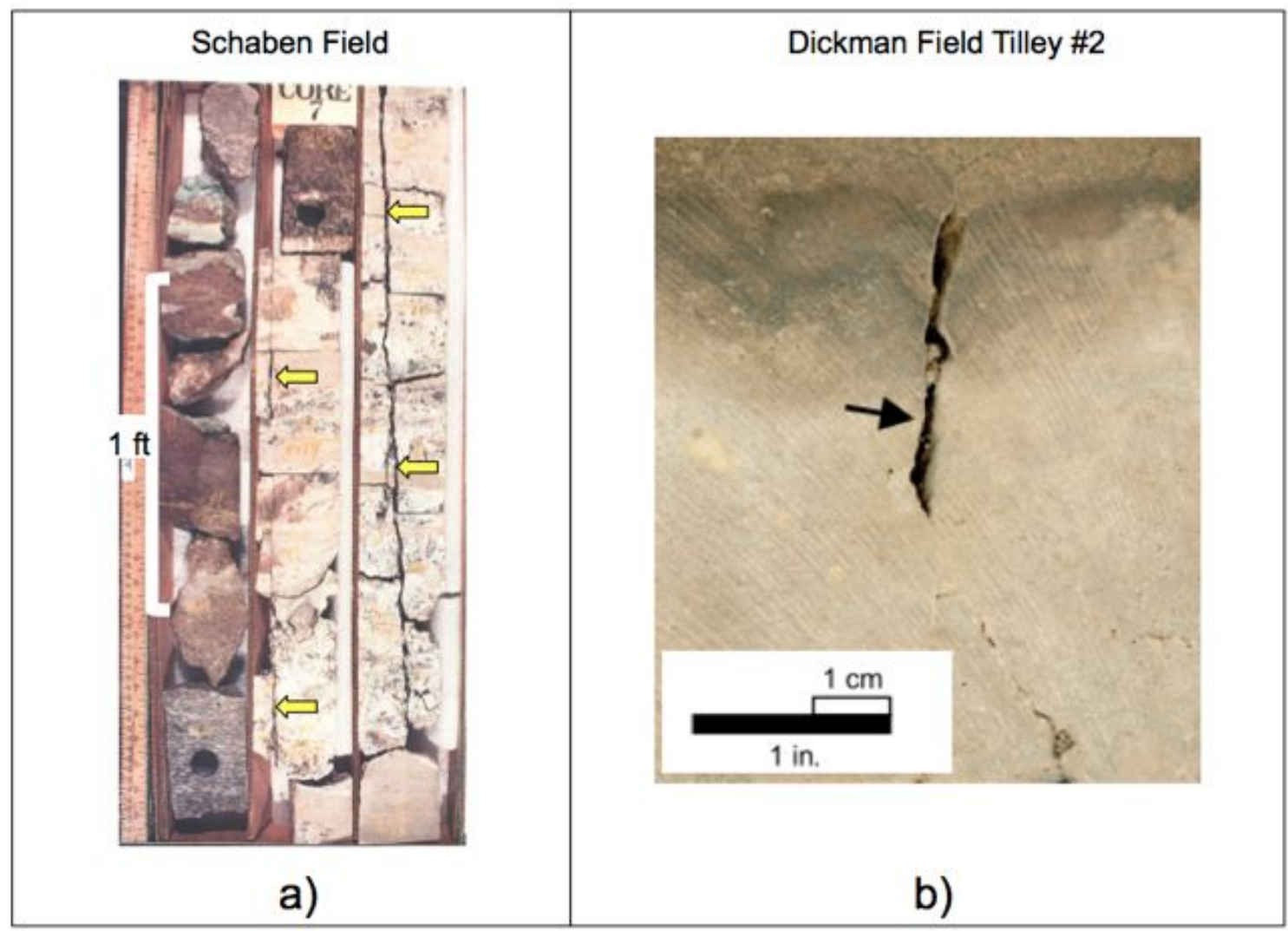

Figure 17: Core photos in the Mississippian section. (a) Schaben Field well covering an $8 \mathrm{ft}$ section in the Osage. (b) Dickman Field Tilley 2 well near the top of the Mississippian. Note the sub-vertical fracture in the right-most column of (a) marked by arrows and continuous up section. Tilley \#2 shows a solution-enhanced vertical fractured (modified from Nissen et al., 2009). 


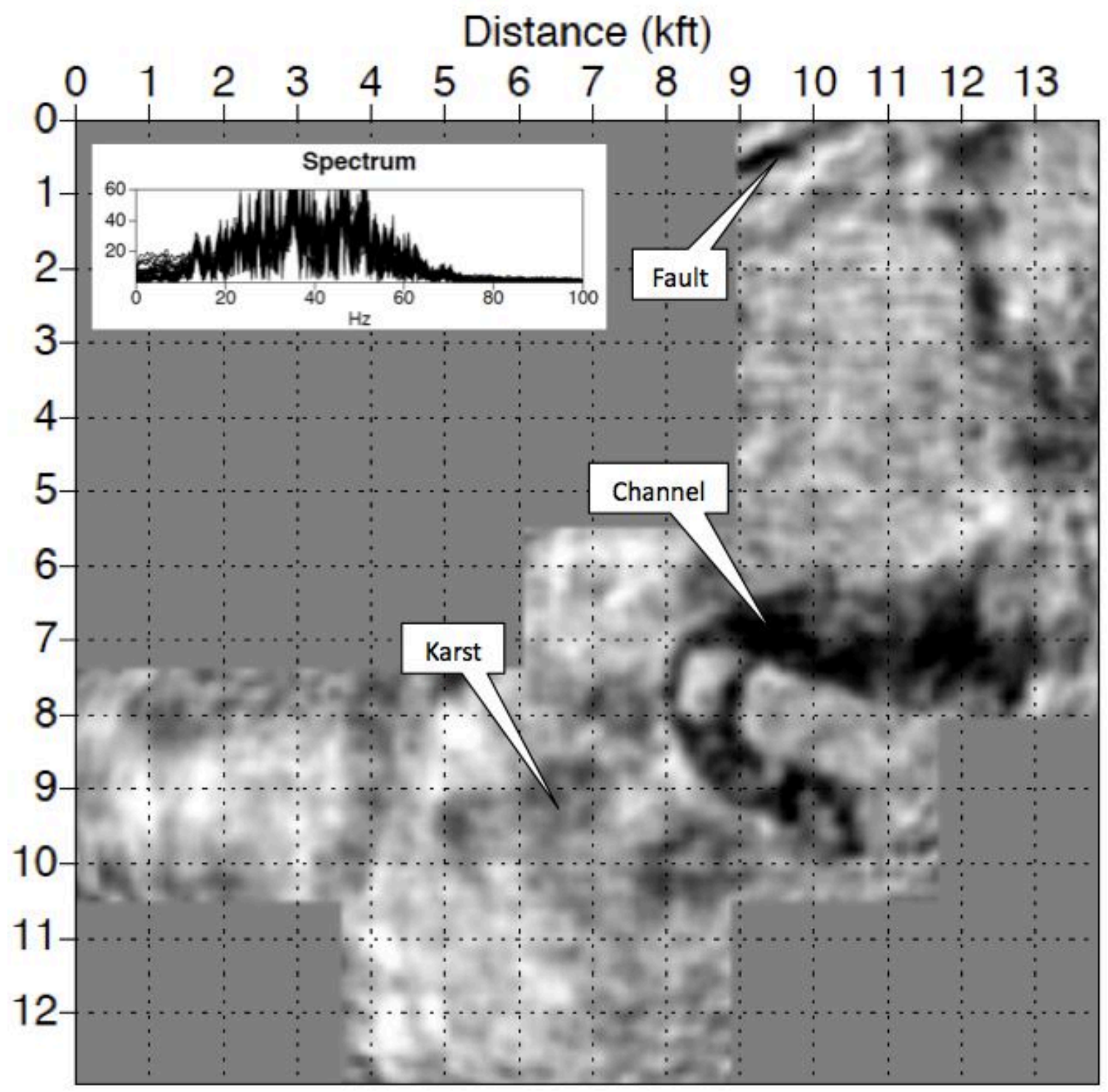

Figure 18: Broadband time slice from the Dickman 3D approximating the Mississippian-Pennsylvanian unconformity. The most notable feature is an incised channel, which represents Lower-Cherokee deposits; other features include a northeast trending fault at the northern edge of the survey as well as evidence of karst southwest of the channel. 


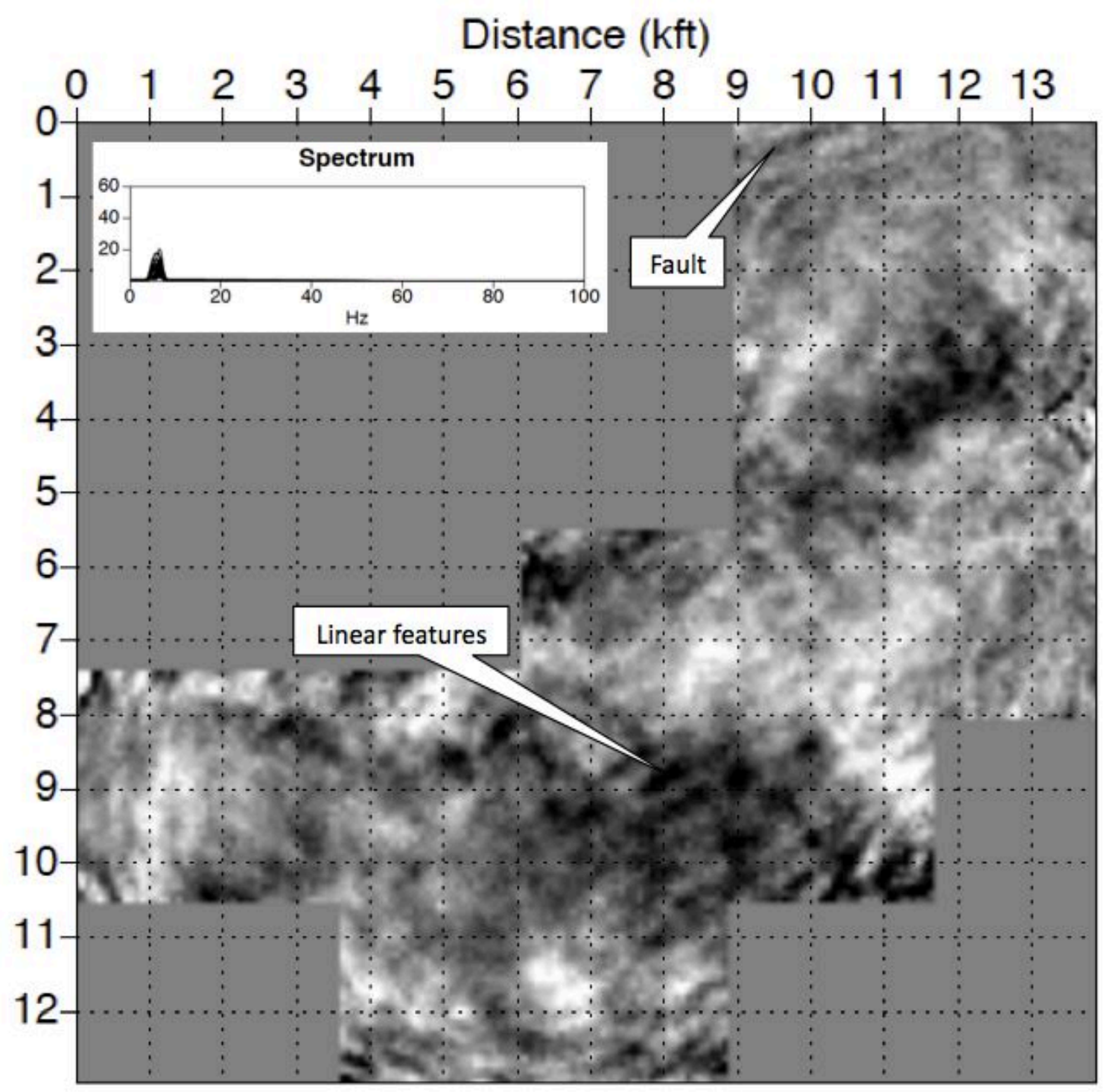

Figure 19: Narrow band $6 \mathrm{~Hz}$ time slice representing the MississippianPennsylvanian unconformity surface. Notice the prominent NE-NW trending features in the center of the survey. The working hypothesis is that these features emanate from natural fracturing in this subsurface interval. Modified from seales et al. (2011). 


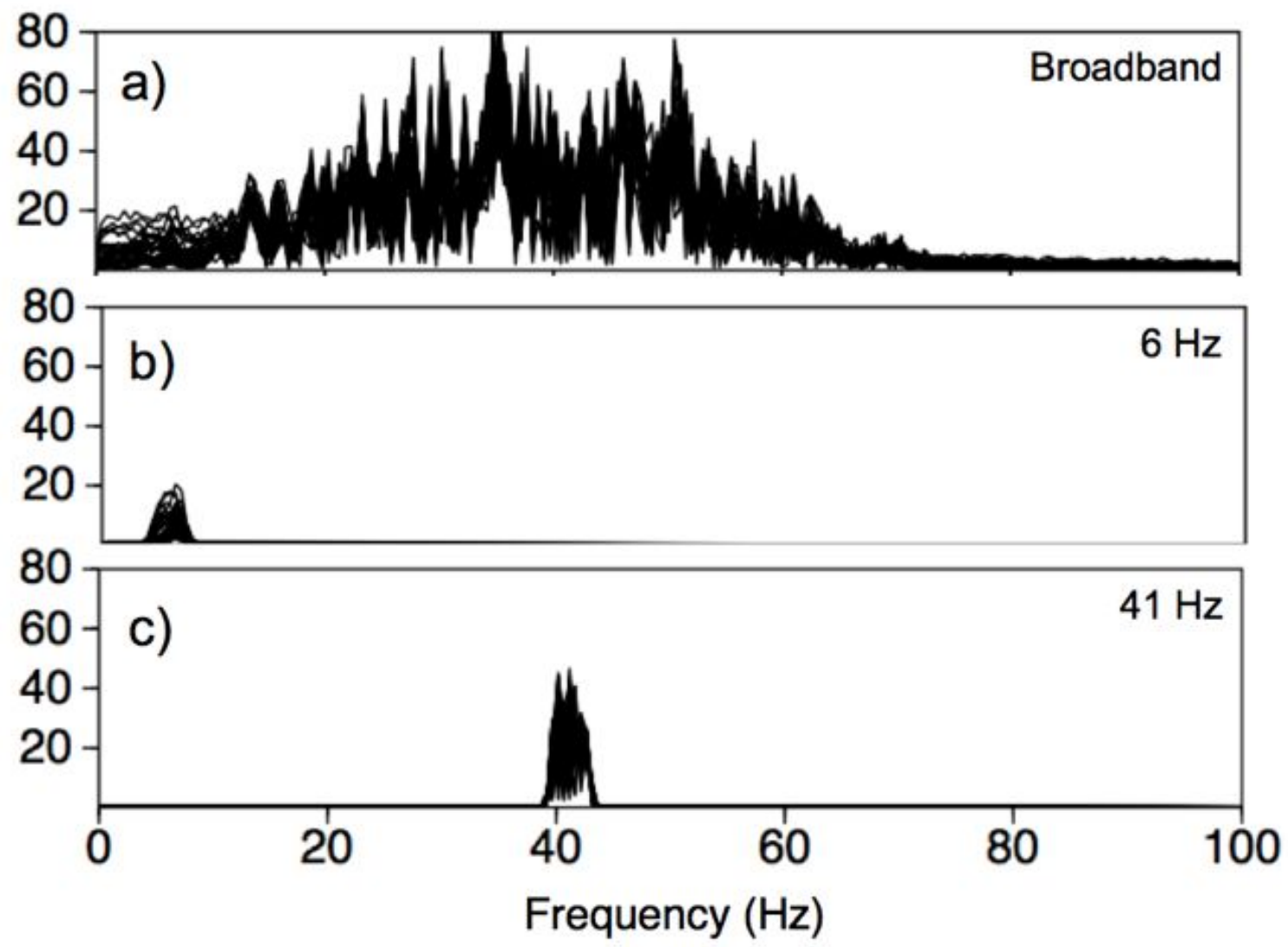

Figure 20: Survey spectra generated by SU program sufilter (filter width $2 \mathrm{~Hz}$ ). (a) Broadband data, (b) Narrowband $6 \mathrm{~Hz}$ data where fracture indicators are present. (c) Narrowband $41 \mathrm{~Hz}$ data where channel indicators are present. 







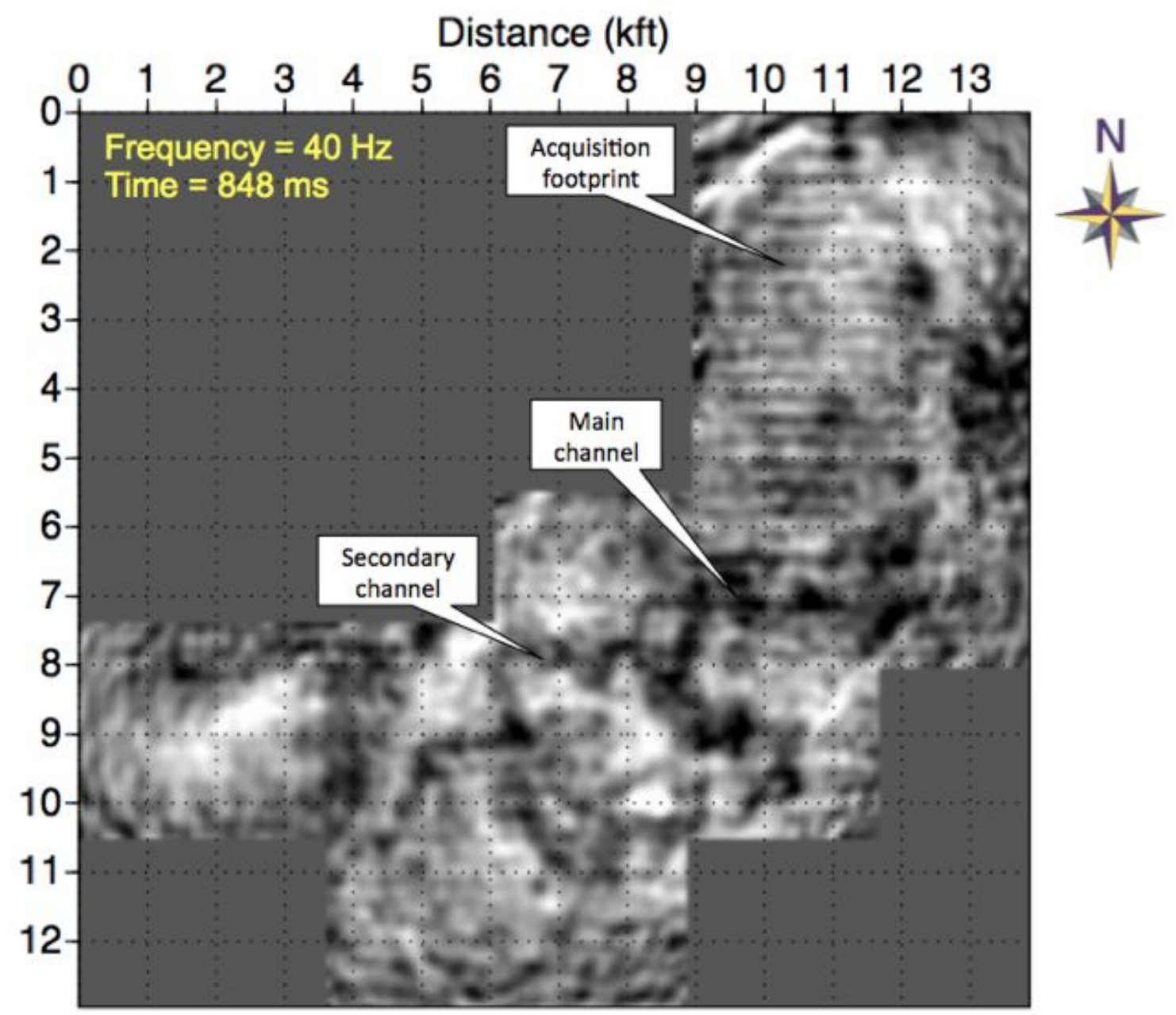

Figure 22a: Time slice at $848 \mathrm{~ms}$ of the $40 \mathrm{~Hz}$ data showing a possible secondary channel feature not seen in the broadband data to the west of the main channel. 


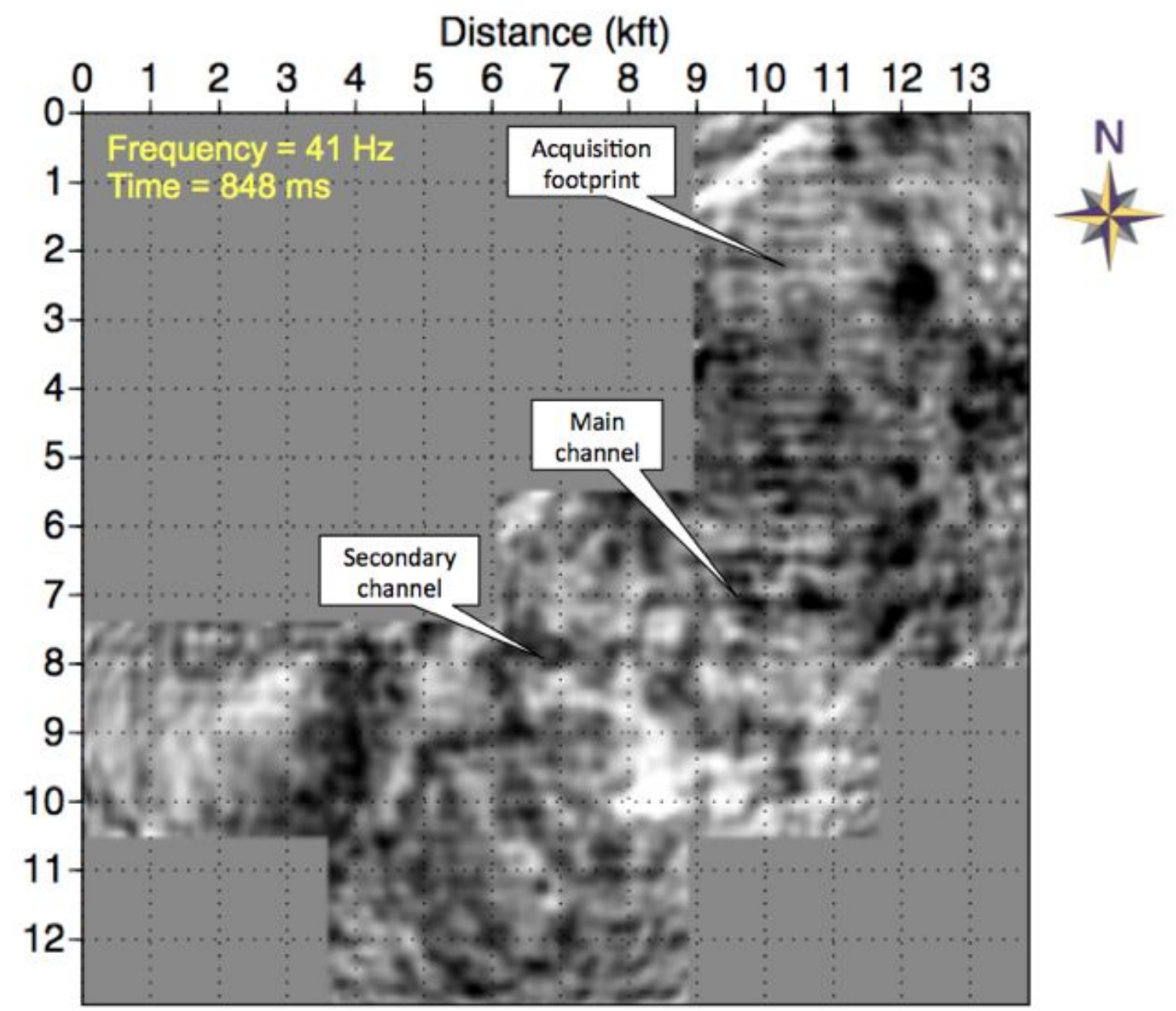

Figure 22b: Time slice at $848 \mathrm{~ms}$ of the $41 \mathrm{~Hz}$ data showing a possible secondary channel feature not seen in the broadband data to the west of the main channel. 


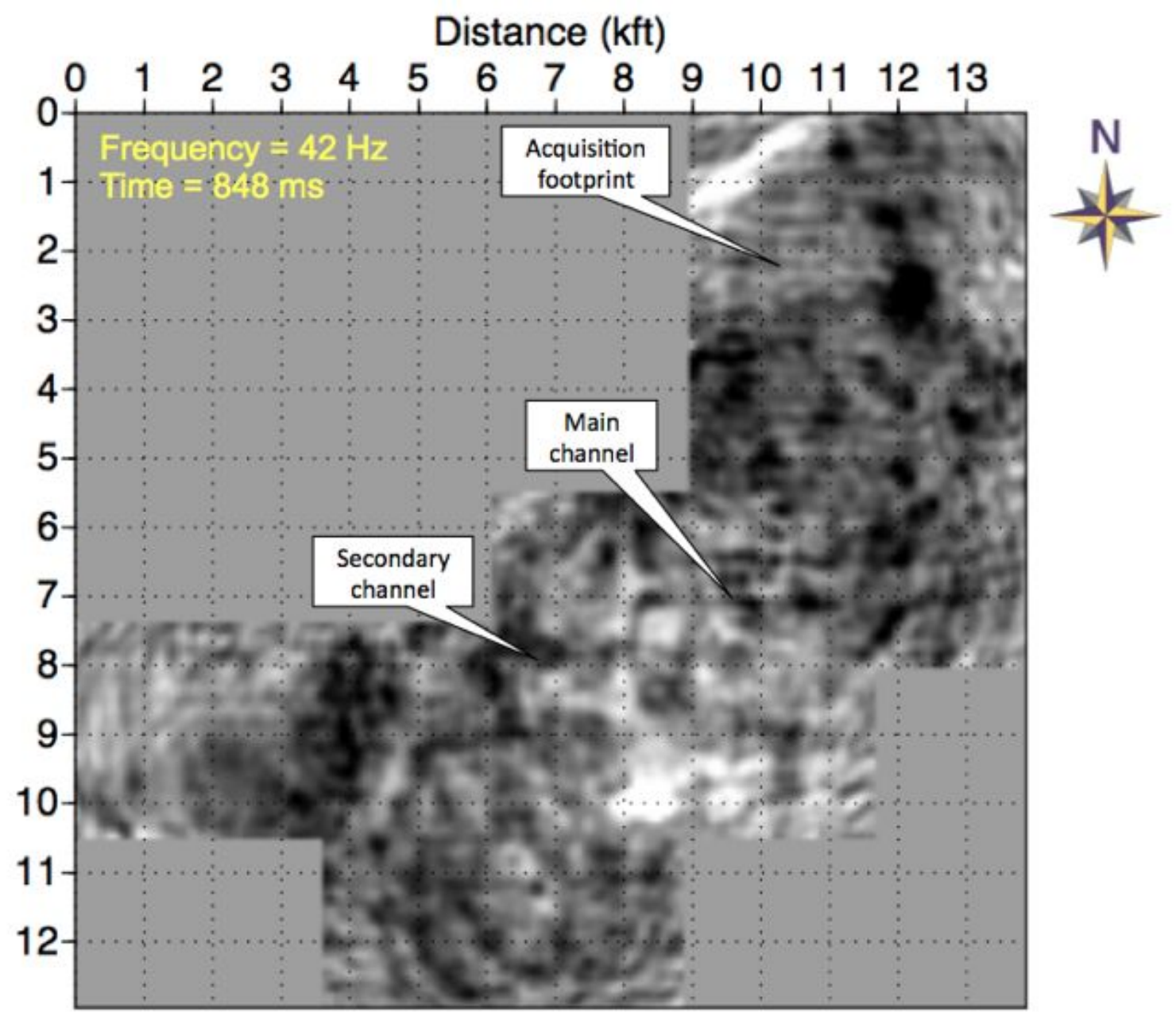

Figure 22c: Time slice at $848 \mathrm{~ms}$ of the $42 \mathrm{~Hz}$ data showing a possible secondary channel feature not seen in the broadband data to the west of the main channel. 


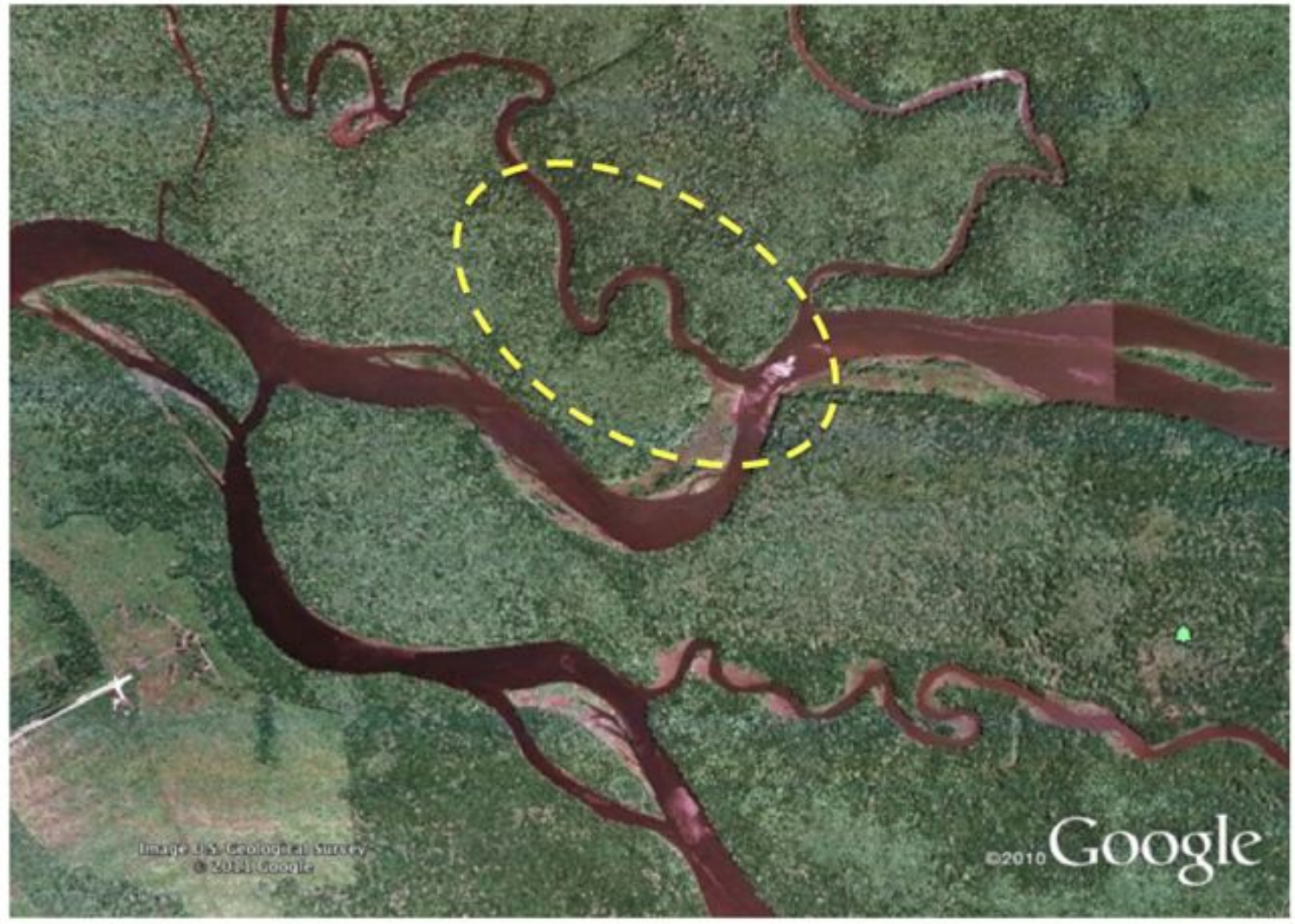

Figure 23: The yellow ellipse shows a modern analog of a tributary-type channel feeding into a main channel in coastal Georgia, USA. 


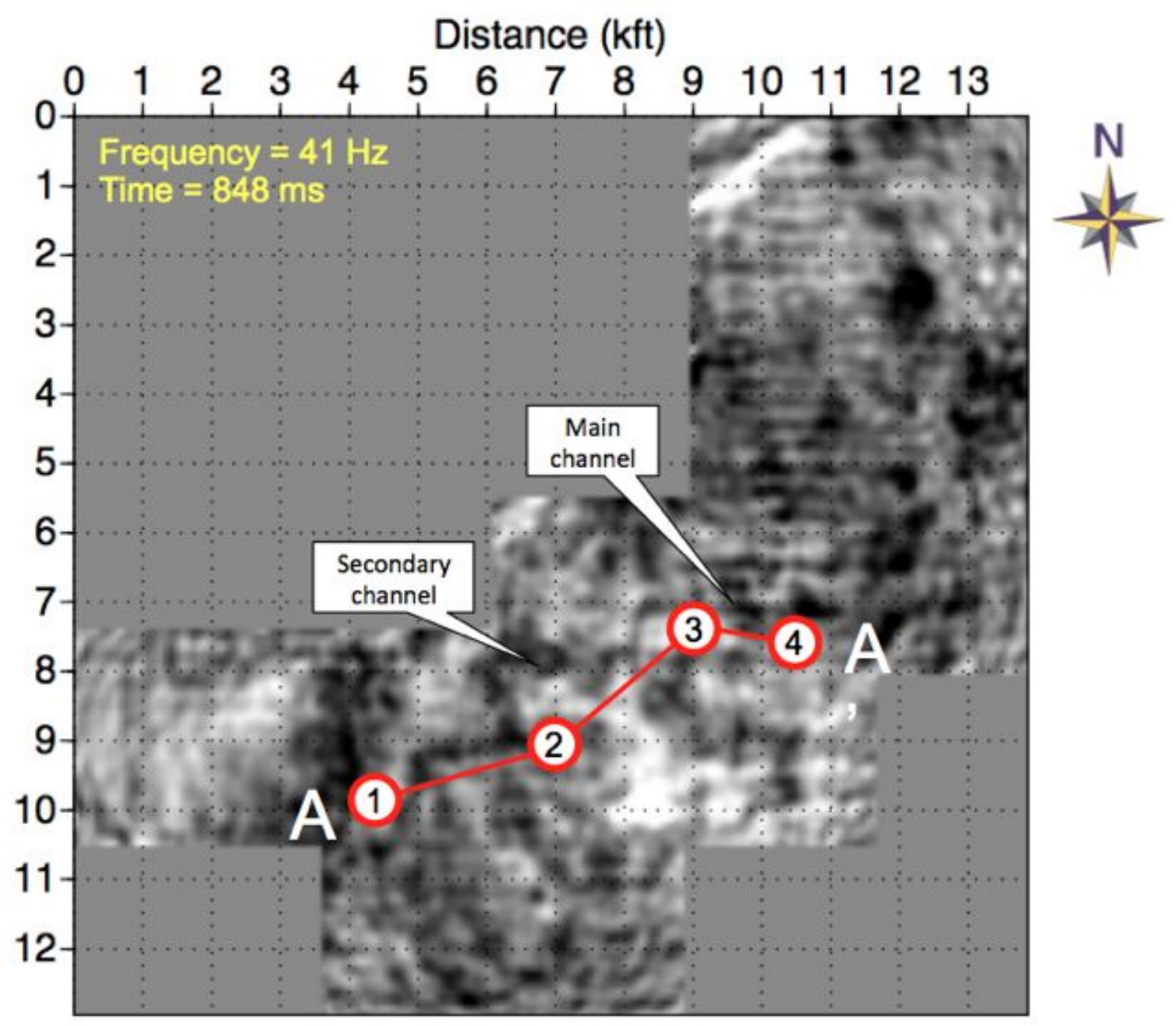

Figure 24: Time slice at $848 \mathrm{~ms}$ of the $41 \mathrm{~Hz}$ data showing a possible secondary channel feature not seen in the broadband data to the west of the main channel. 


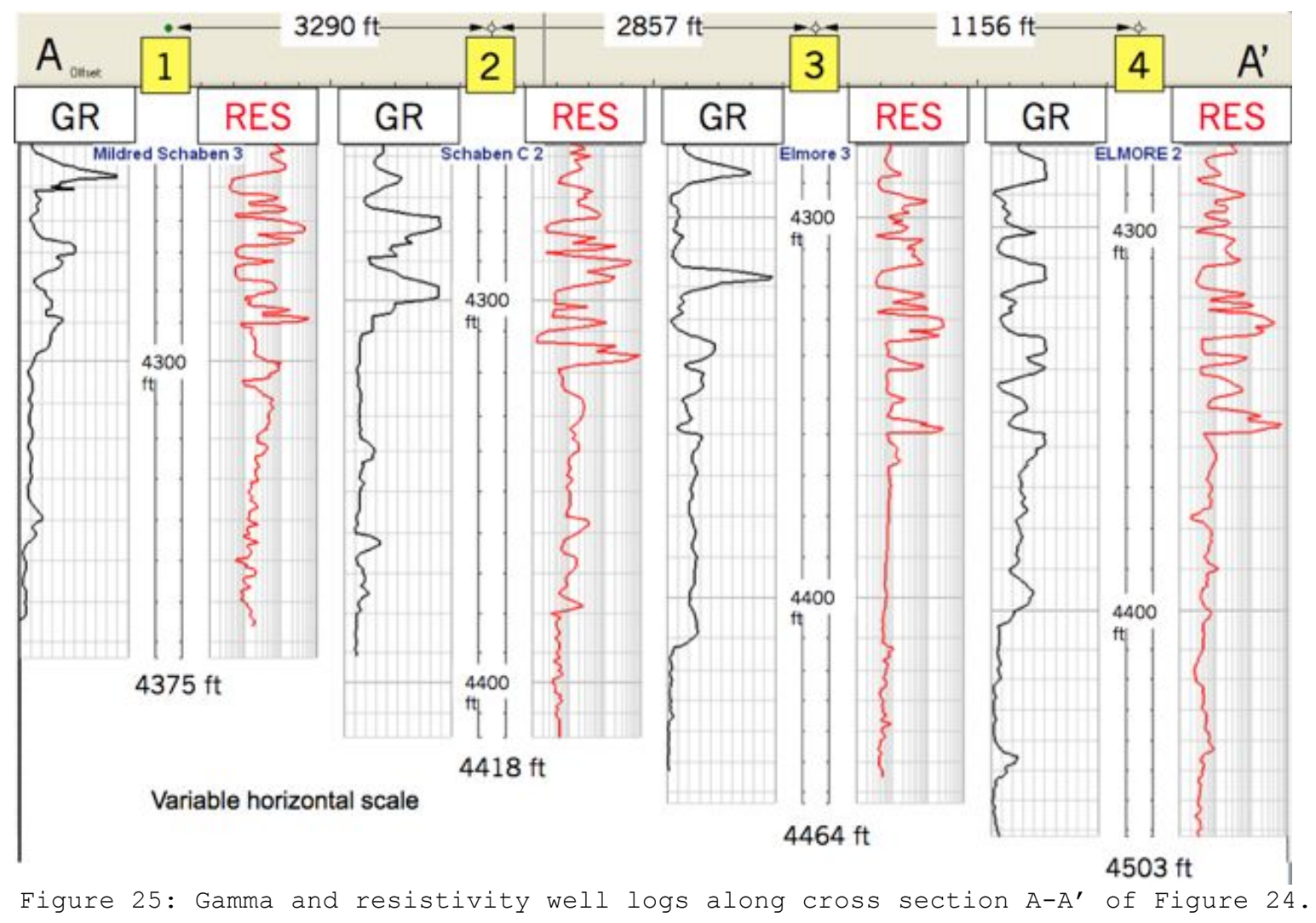




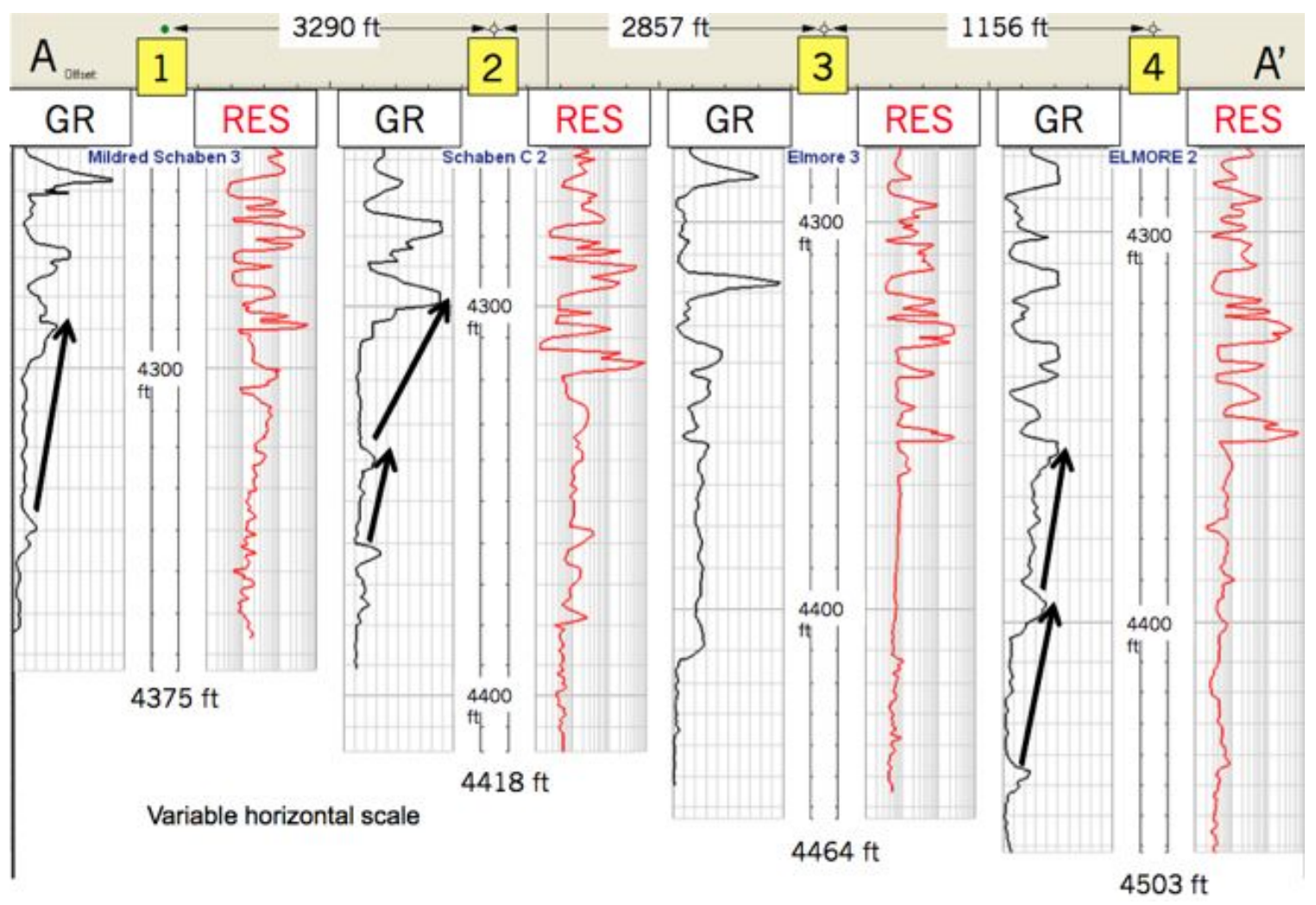

Figure 26: Black arrows show fining upwards sequences from sandstone to shale indicating a channel-like depositional environment. 


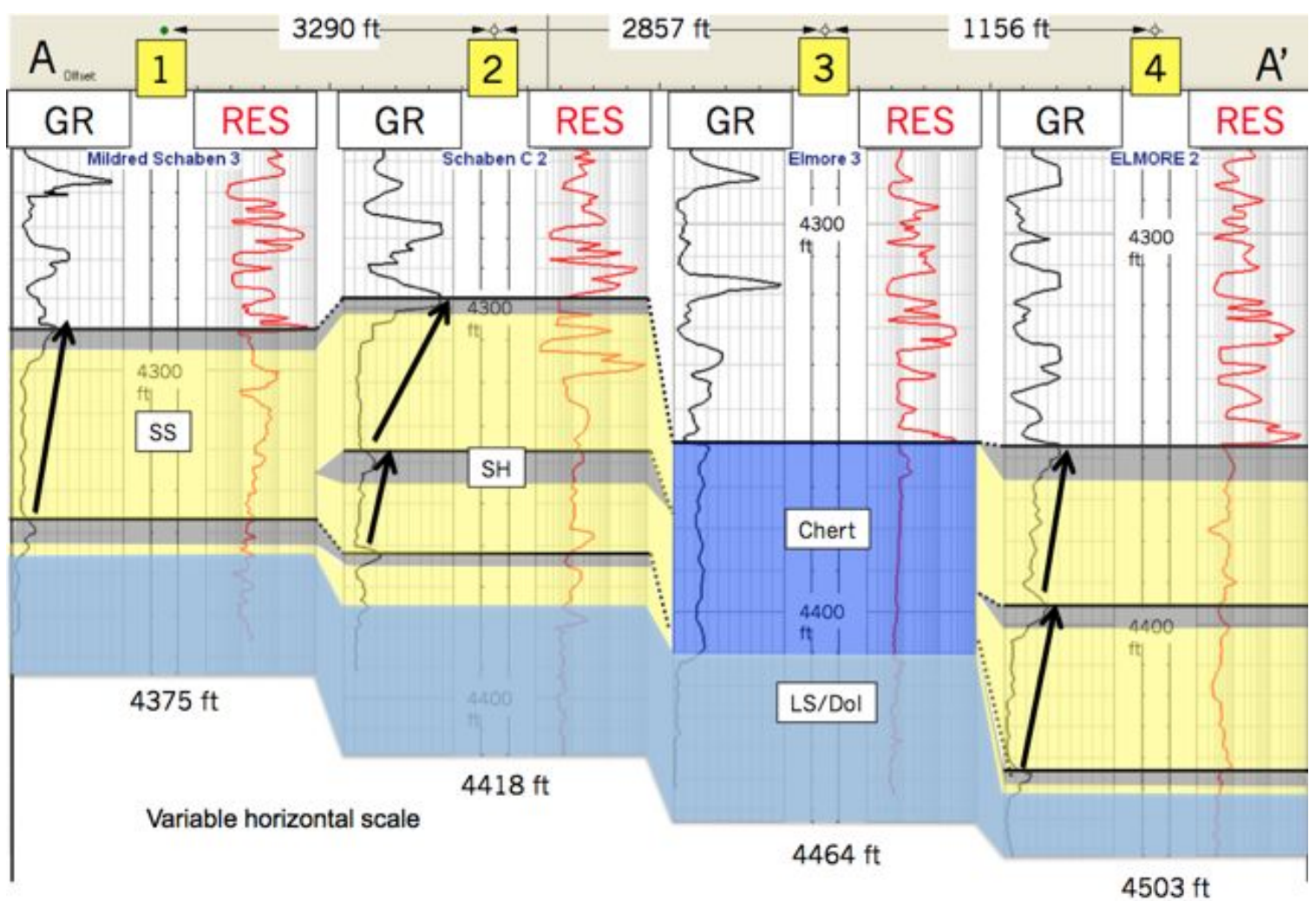

Figure 27: Interpretation confirming the existence of a tributary channel based on fining upwards sequences indicated by shale overlying sandstone. 


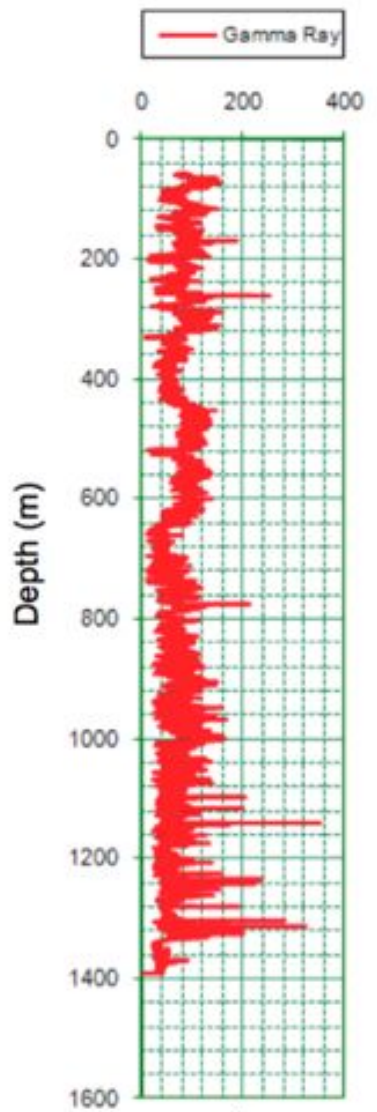

a)

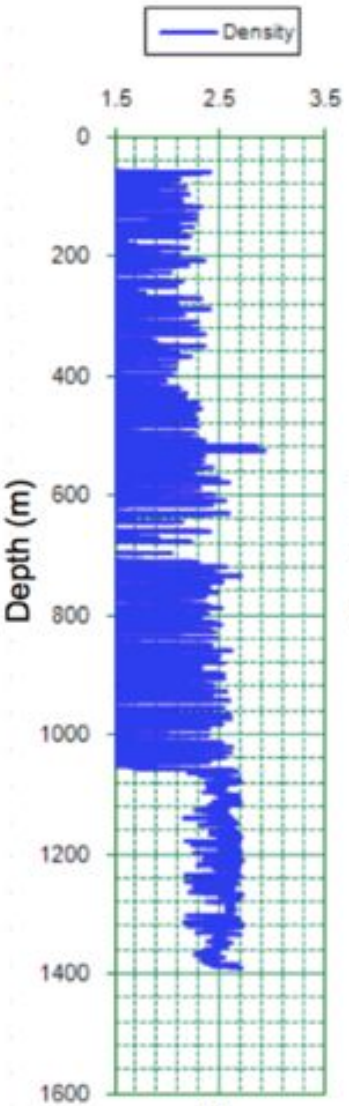

b)

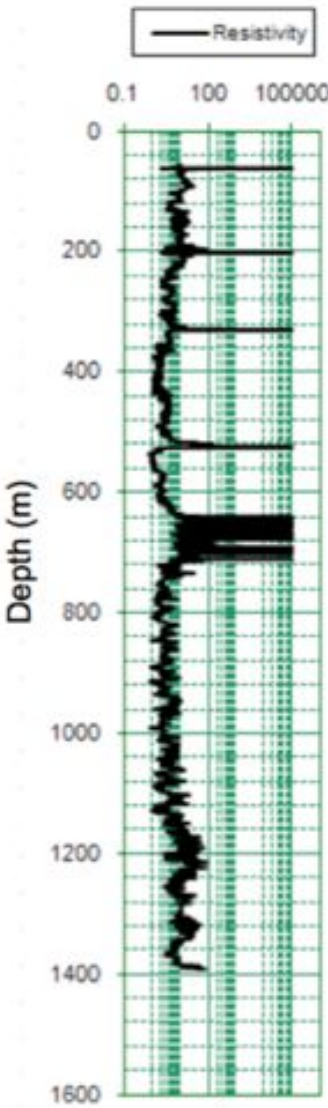

c)

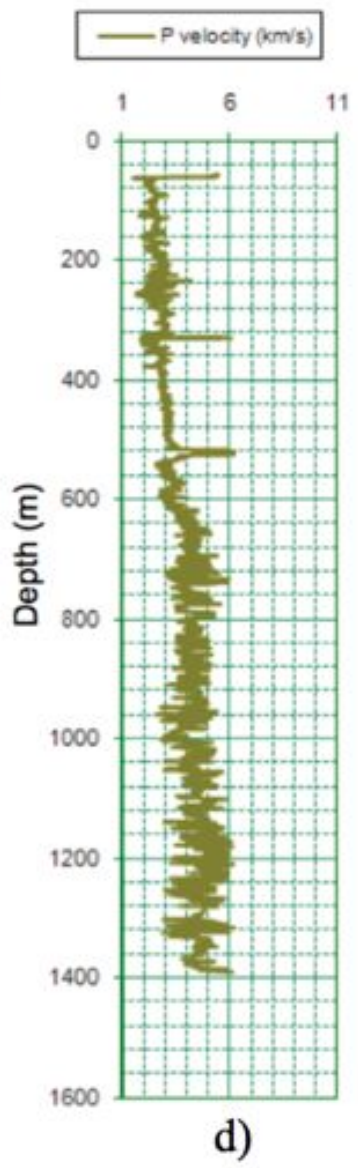

d)

Figure 28. Humphrey 4-18 well logs. (a) Gamma ray. (b) Density with data quality problems above $1050 \mathrm{~m}$. (c) Resistivity showing several unrealistic spikes. (d) P-wave sonic. 
b)

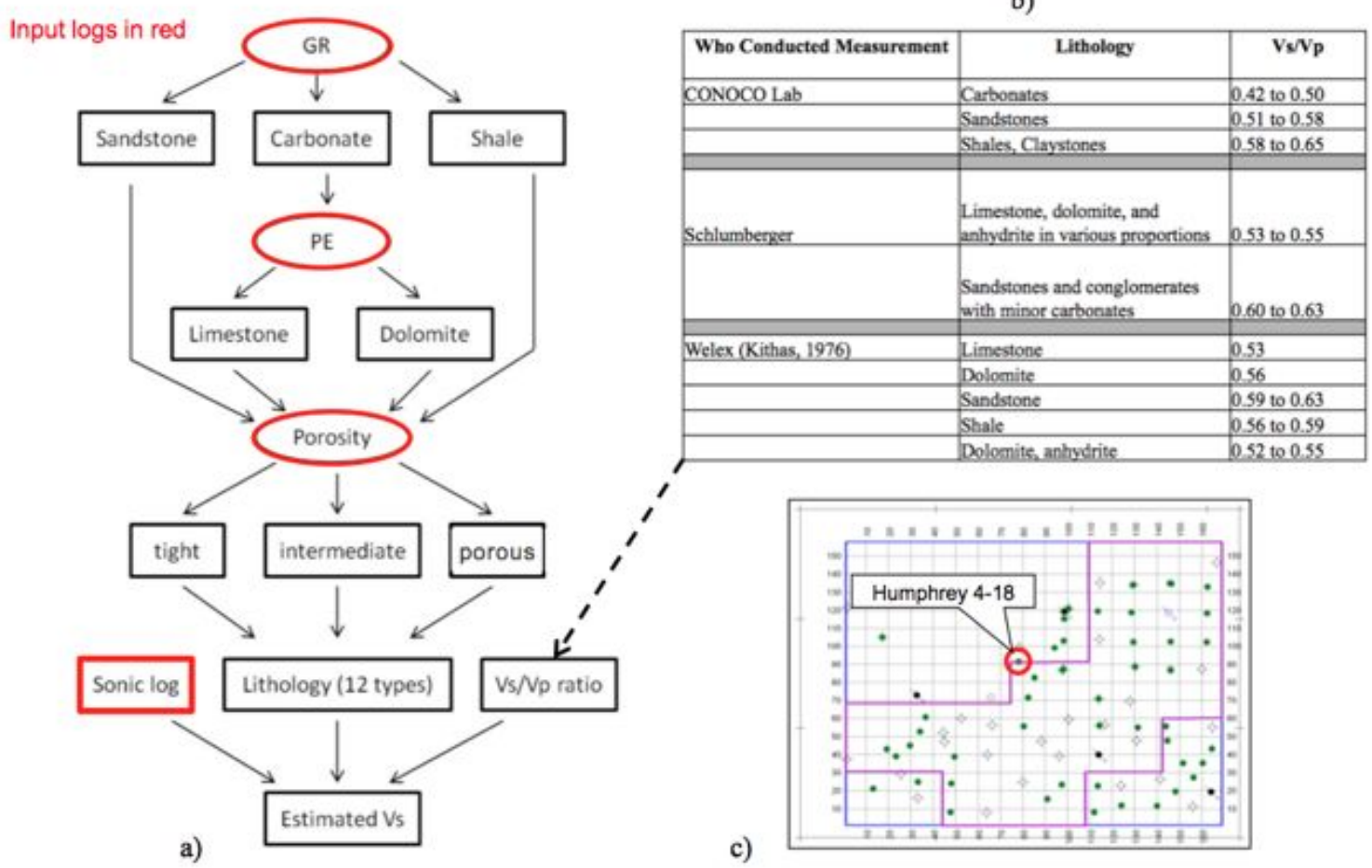

Figure 29. Estimating Vs at Dickman. (a) Workflow for Vs estimation using logs available in Humphrey 4-18 well. (b) Published Vp/Vs ratios for selected lithologies. (c) Location of Humphrey 4-18 well. 


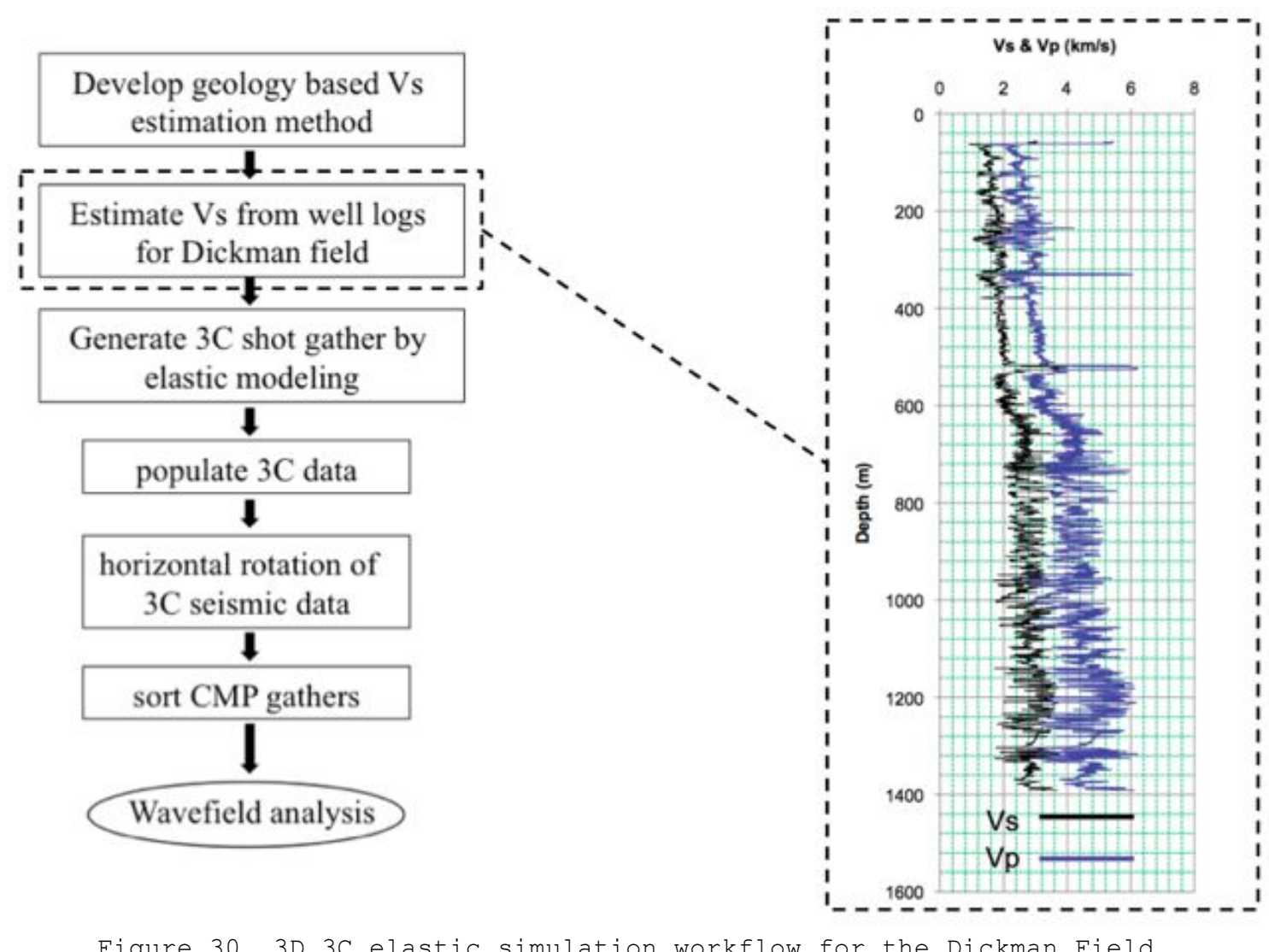




\section{Dickman 3D \\ Design Map}
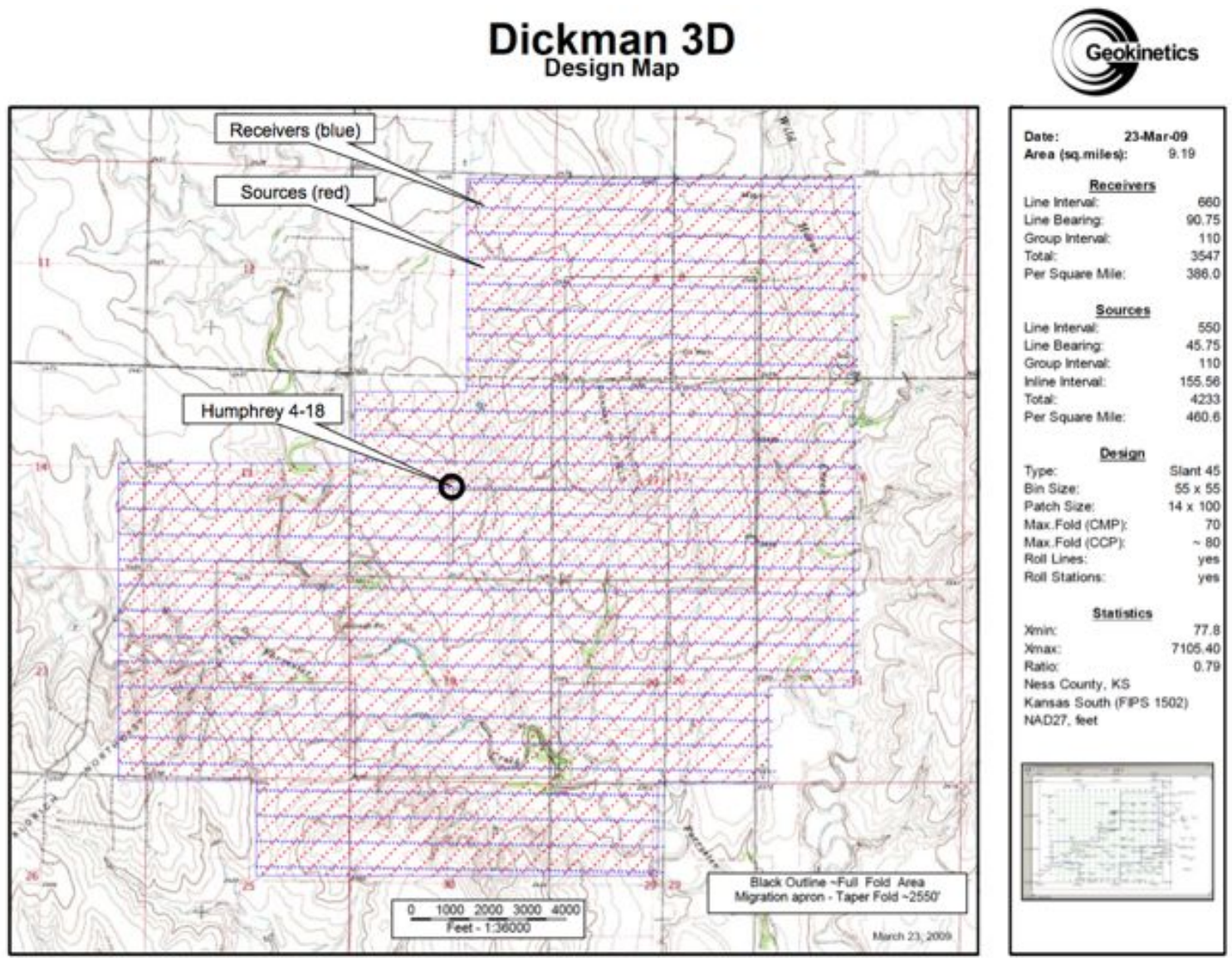

Figure 31. Survey design at the Dickman Field courtesy of Geokinetics. Shot locations are red and receiver locations are blue. The H418 well is indicated by a black circle. 


\section{$\underset{\text { Dickign Map }}{\text { Dick }}$}

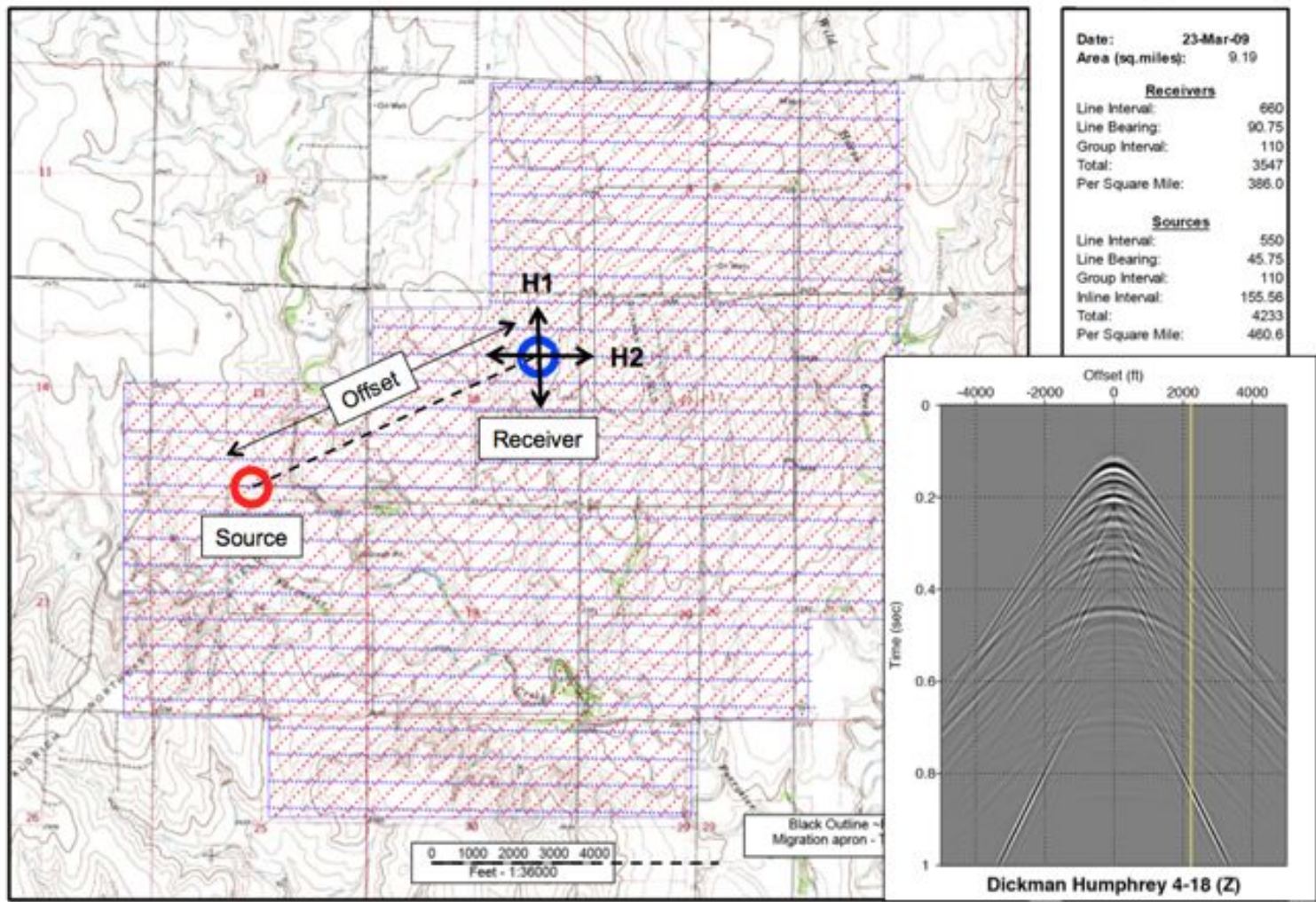

Figure 32. A 3D seismic trace has a source location (red circle) and receiver location (blue circle) that determines offset and azimuth (angle from north). Field data components are (H1,H2). The inset shot record shows the $\mathrm{Z}$ component of synthetic data generated from H418 well logs. The yellow trace represents the offset associated with the shot-receiver pair shown on the map. 


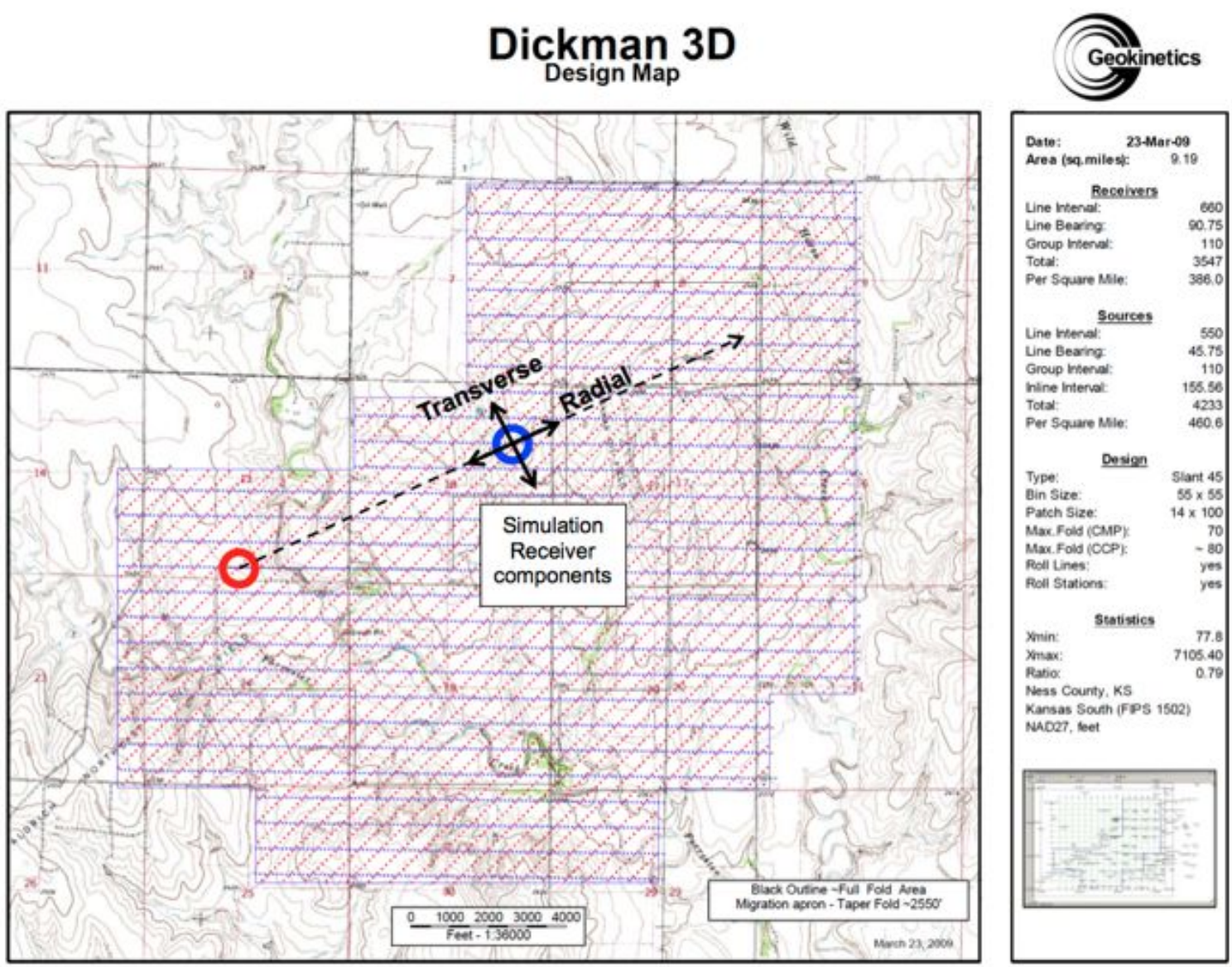

Figure 33. Horizontal synthetic seismic data components are radial and transverse $(R, T)$ relative to the shot-receiver line. The $(R, T)$ components require rotation into field components (H1,H2) as shown in Figure 34 . 


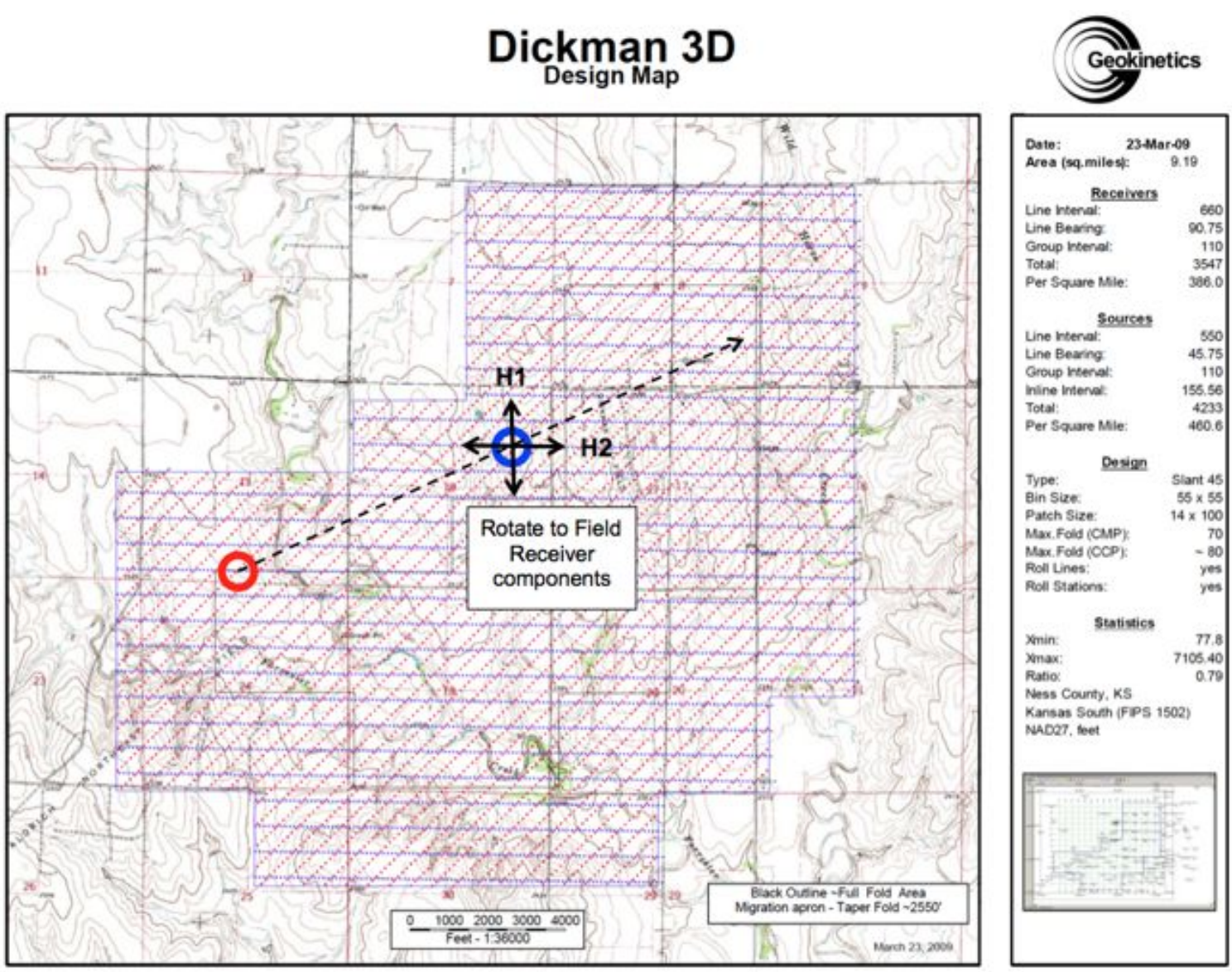

Figure 34. After coordinate rotation based on shot-receiver azimuth, the data components are in field coordinate orientation of $\mathrm{H} 1$ (N-S) and $\mathrm{H} 2$ (E-W) 


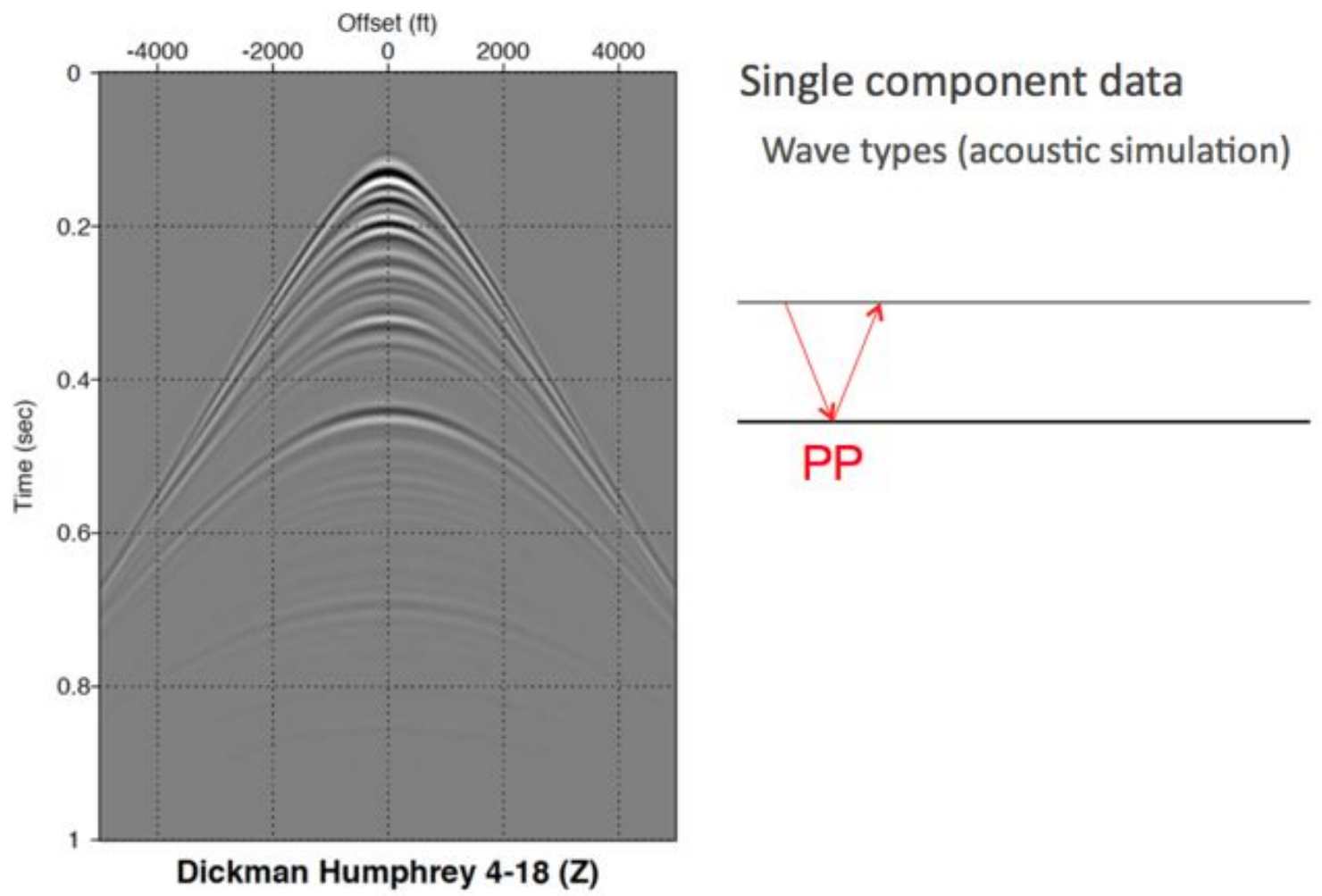

Figure 35. Acoustic simulation only includes P-wave reflection events (PP) that have a very loose association with geological fractures. 


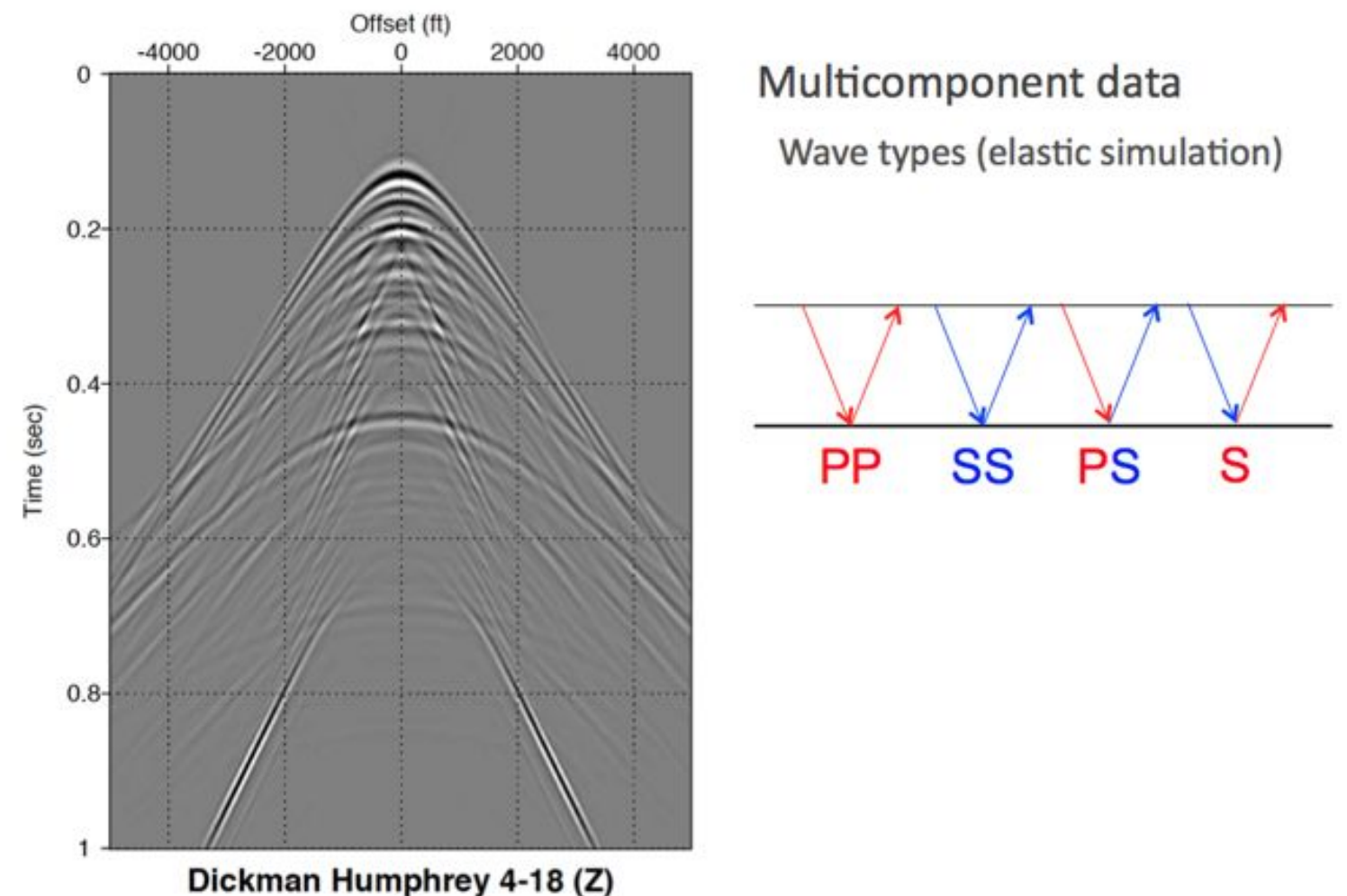

Figure 36. Elastic simulation includes shear (SS) and mode converted (SS<PS) events that may give direct evidence of anisotropy (shear wave splitting) related to fractures 


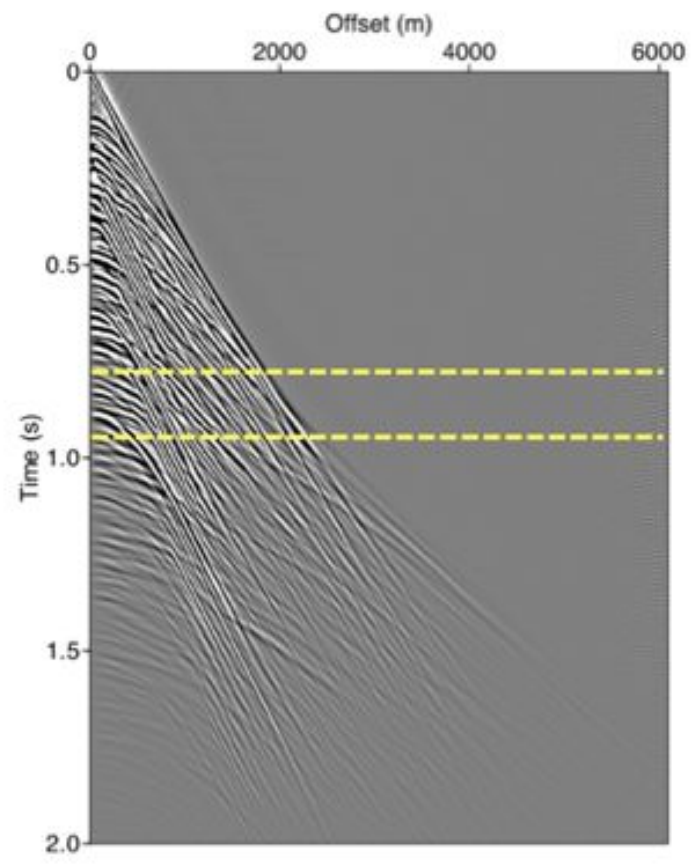

a)

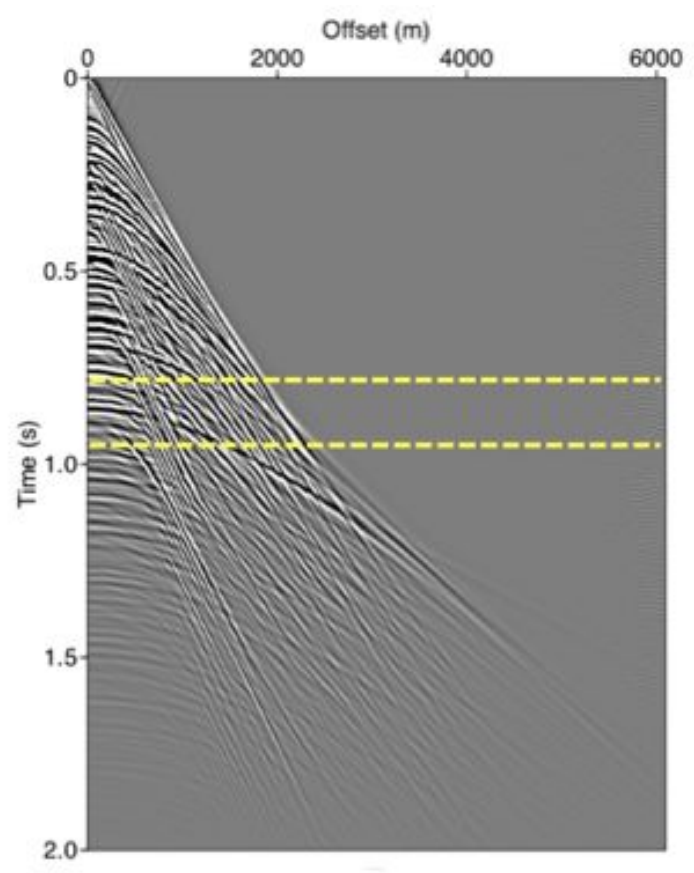

b)

Figure 37. 2D elastic shot gather for Humphrey 4-18. (a) Radial component of motion. (b) Vertical component of motion representing standard single-component seismic recording. Not shown is the transverse component of motion since it is zero (the source is a vertical force with no transverse component). Approximate Mississippian interval shown with dash yellow lines. 


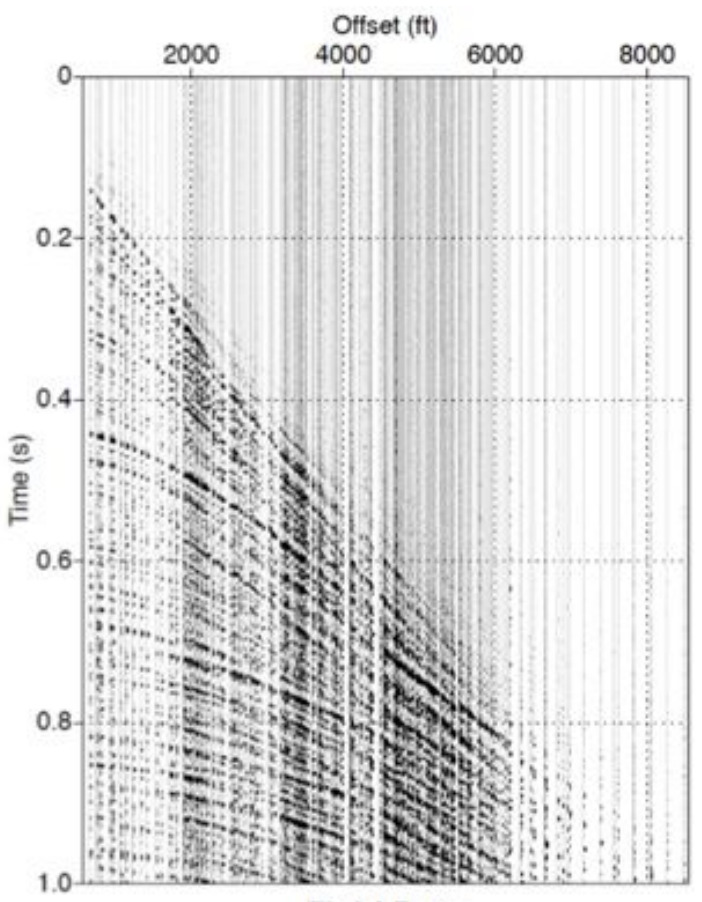

Field Data

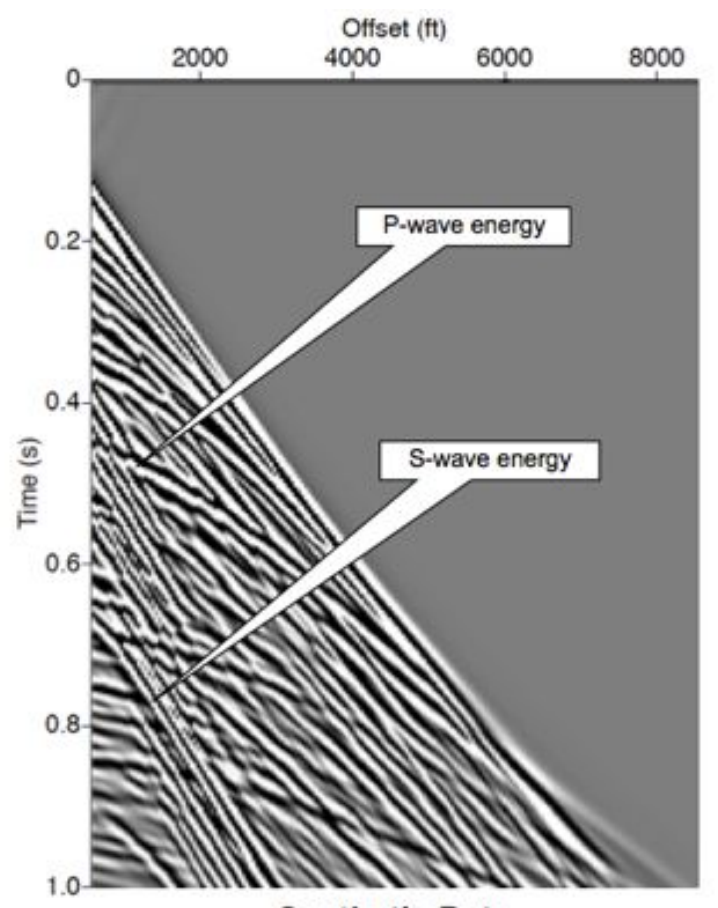

Synthetic Data

Figure 38. Comparison of field data and vertical component of a reflectivity synthetic seismogram based on Humphrey 4-18 well logs. The field data is a super gather composed of five CMP gathers (4500-4505). Uneven trace spacing in field data results from irregular offset distribution. Correspondence of events is good, but the synthetic has much stronger shear wave energy than observed in field data. 


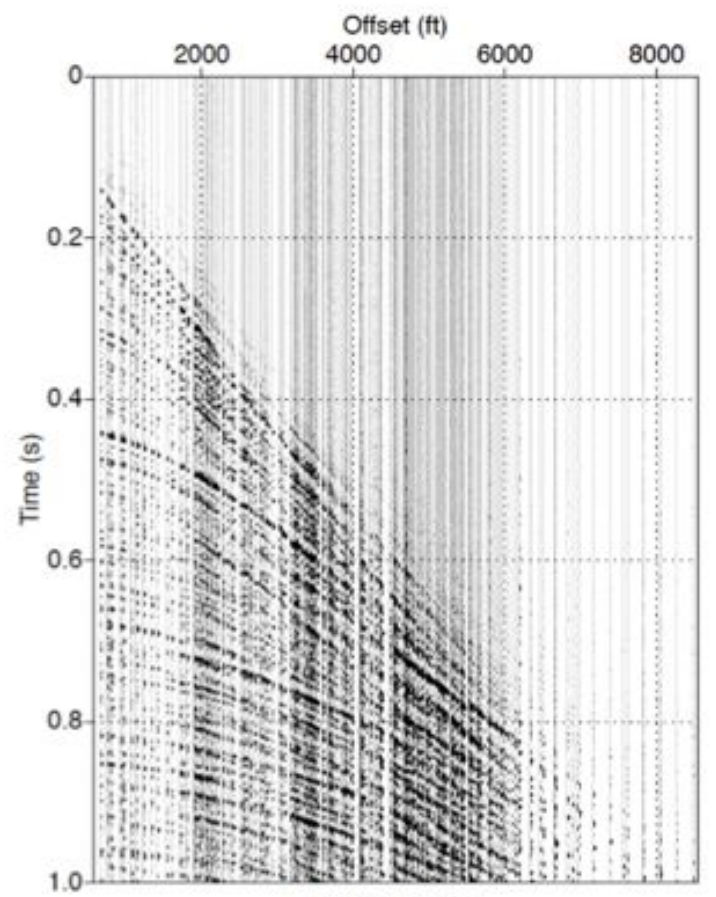

Field Data

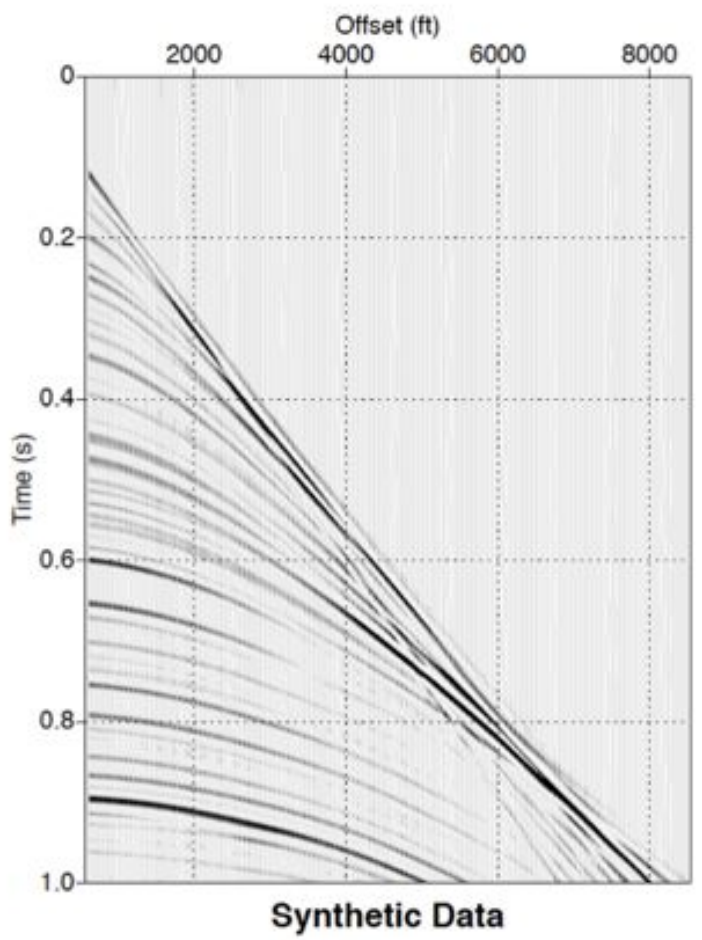

Figure 39. Comparison of field data and acoustic finite difference synthetic seismogram based on Humphrey 4-18 well logs. The field data is a super gather composed of five CMP gathers (4500-4505). Uneven trace spacing in field data results from irregular offset distribution. Correspondence of events is quite good. 


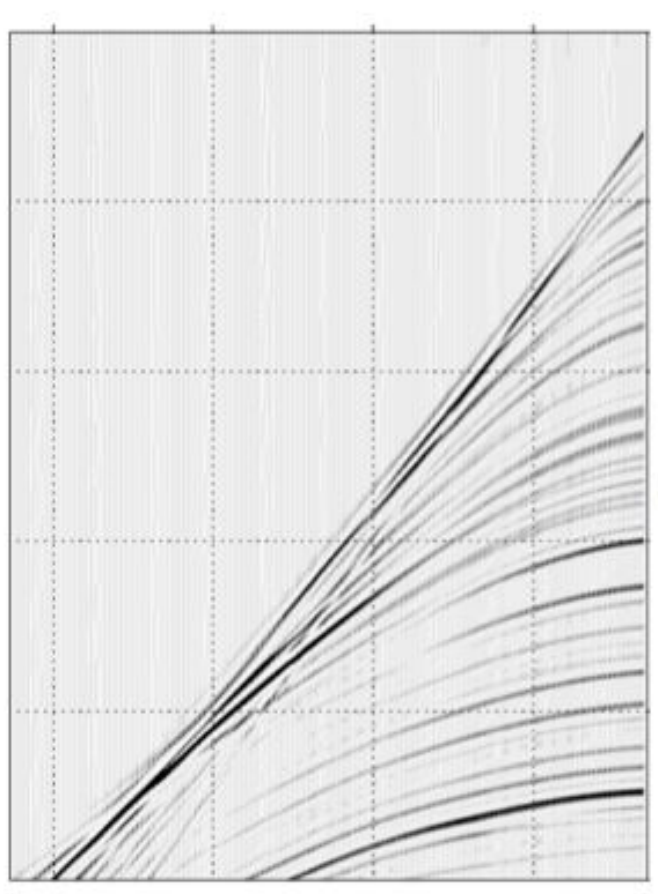

Synthetic Data

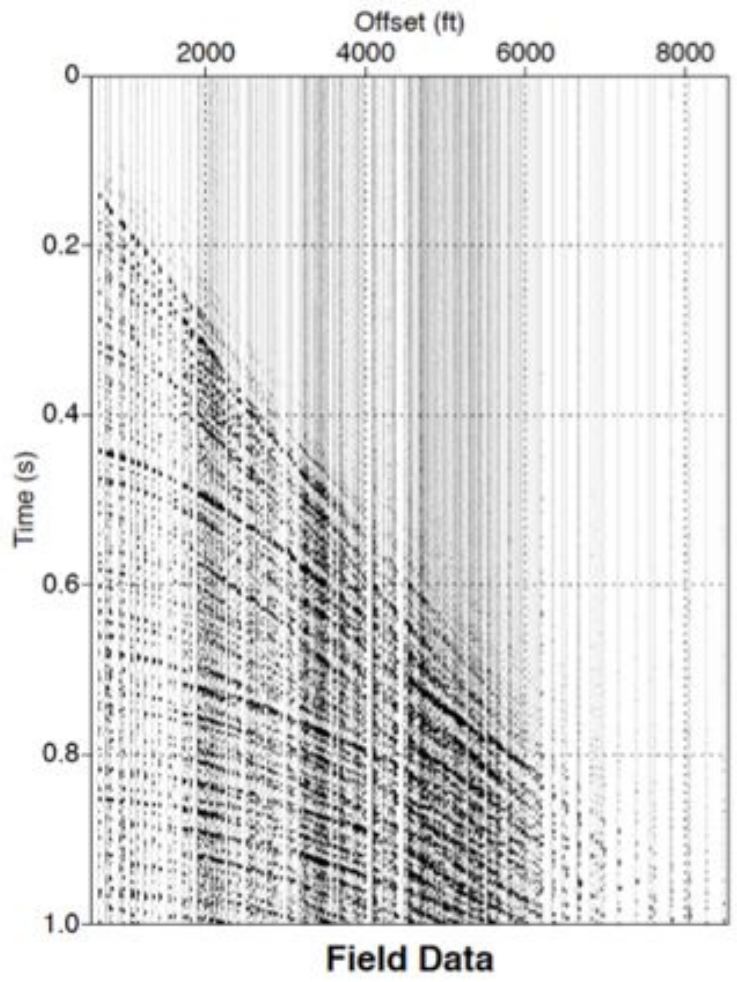

Figure 40. Another way of displaying the data in Figure 40 that more easily shows the correspondence of events. 


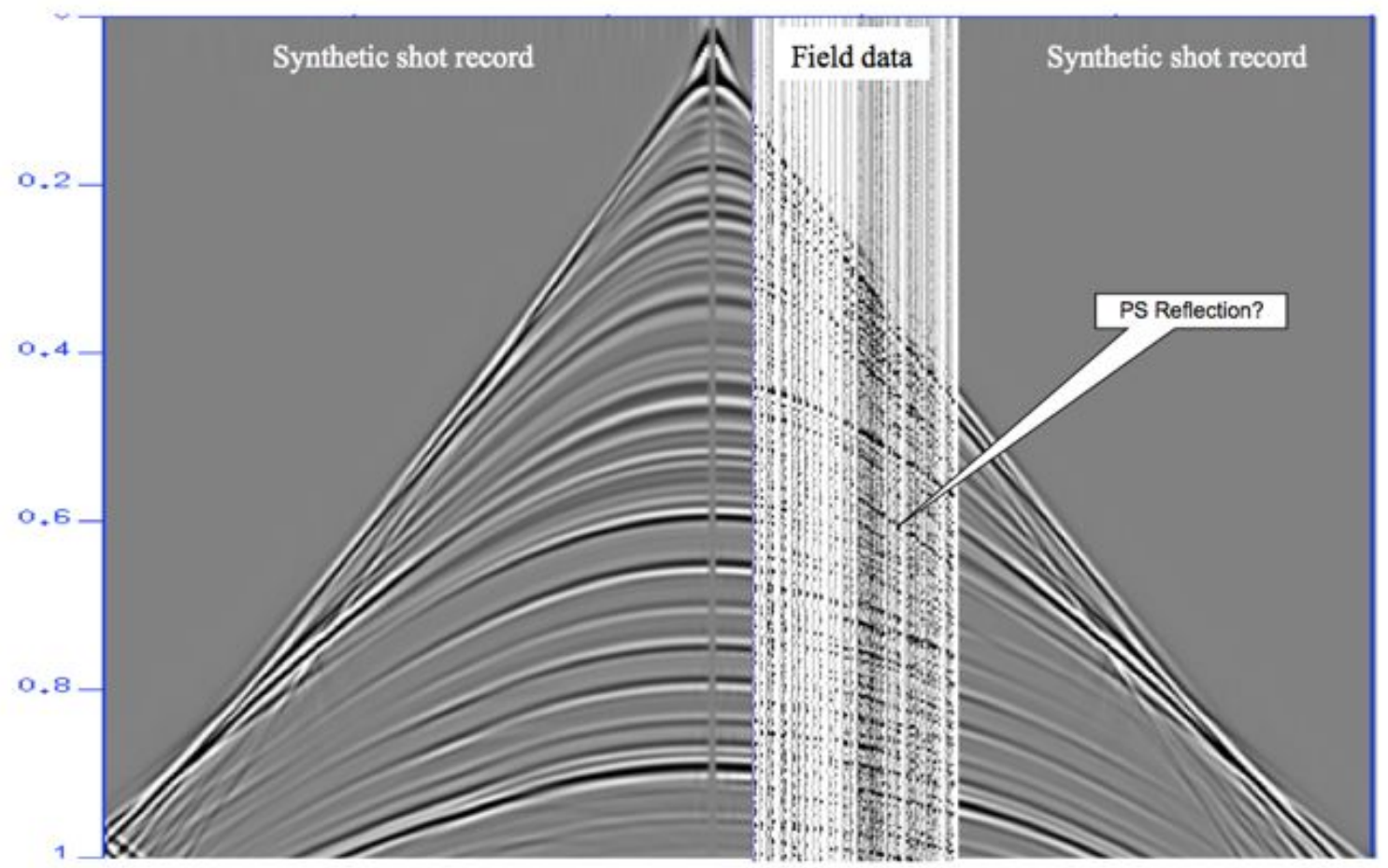

Figure 41. Overlay of field data and acoustic finite difference synthetic seismogram based on Humphrey 4-18 well logs. 




Figure 42. Survey design map with synthetic shot location. 




Figure 43. Dickman area 3D shot gather after population with synthetic seismic traces and rotation into field components (see Figure 34). The H2 component is shown. Source location is shown in Figure 37 and there are 28 receiver lines. Highlighted receiver line $\mathrm{A}$ is displayed in Figure 40. 


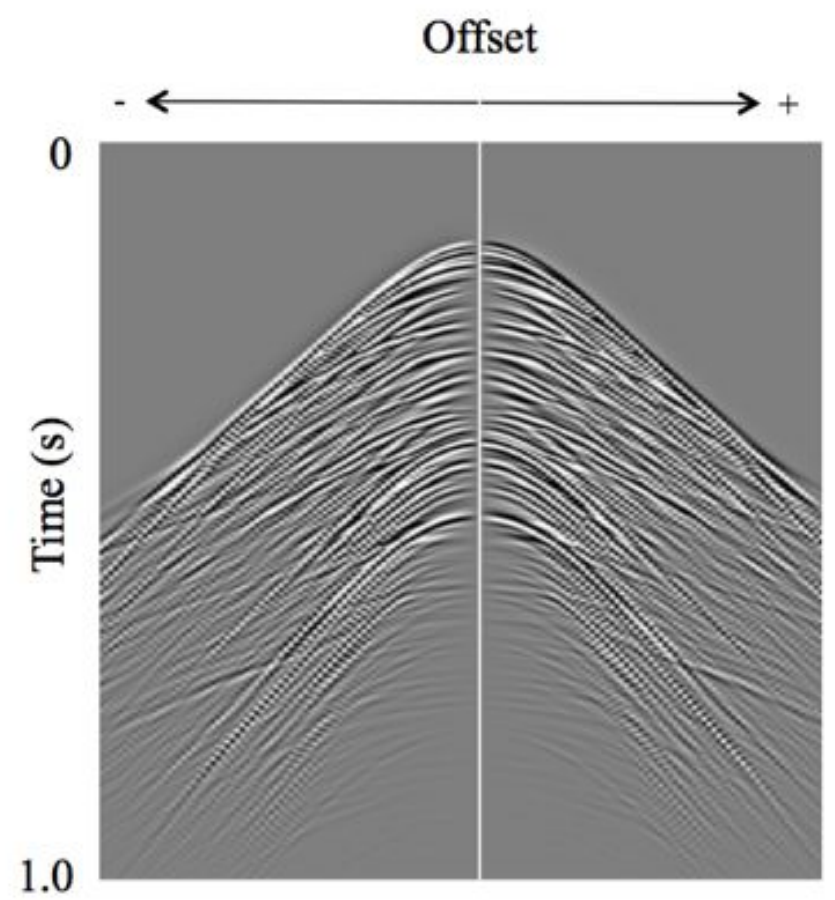

Figure 44. Validation check on rotated seismic components. Zoom view of H2 component of receiver line A in Figure 39 shows polarity reversal. 







\section{Appendix A: 3D Seismic acquisition and processing parameters}

\section{Acquisition details}

Date Recorded...........................11/2001

Crew. Lockhart Geophysical

Source Type Vibroseis

Sample Rate $2 \mathrm{~ms}$

Record End Time 2 seconds

Receiver Interval. $220 \mathrm{ft}$

Receiver Line Interval. $660 \mathrm{ft}$

Shot Interval $65 \mathrm{ft}$

Shot Line Interval. 880

Sweep. $20-128 \mathrm{~Hz} 12 \mathrm{sec} 3 \mathrm{DB} / \mathrm{OCT}$

Instruments GDAPS

Format SEGY

Number of Data Channels 324 MAX

Processing Details

(Note that all amplitude data shown in this report is the reprocessed PSTM seismic data migrated by Kurt Marfurt at University of Houston in 2007)

Original processing by: Sterling Seismic Services LTD. Date: 12/2001

1. SEGD to internal format conversion Field correlated

2. Geometry and trace edit

3. Gain recovery

4. Surface consistent amplitude analysis and recovery

5. Minimum phase filter application

6. Surface consistent deconvolution

7. Spectral enhancement Spiking, $160 \mathrm{~ms}$ operator, $0.1 \%$ noise

8. Refraction and data correction

9. Green mountain geophysics refraction statics analysis 3D Fathom

Datum: 2600 feet

Velocity: VR $9000 \mathrm{ft} / \mathrm{sec}-$ Vo $3000 \mathrm{ft} / \mathrm{sec}$

10. Iteration 1 velocity/mute analysis and application

11. Surface-consistent automatic statics 200-1000 ms statics gate

12. Iteration 2 velocity/mute analysis and application

13. Surface-consistent automatic statics $150-1050 \mathrm{~ms}$ statics gate

14. Final velocity/mute/scale analysis and application

15. CDP-consistent trim statics

4 ms max stat 
16. Bandpass filter

17. Time variant scaling windows

18. Common depth point stack

19. Spectral enhancement

20. Post stack noise suppression

21. Fourier trace interpolation

22. 3D FD migration

23. Spectral enhancement

24. Bandpass Filter
$20-128 \mathrm{~Hz}$

FXY Decon

$110 \mathrm{ft}$ xline interval to $82.5 \mathrm{ft}$

95\% of RMS velocity field

$20-128 \mathrm{~Hz}$

20/24-120-72 Hz/DB

25. Trace balance time variant scaling windows 


\section{Appendix B: Seismic Unix narrow band decomposition shell script}

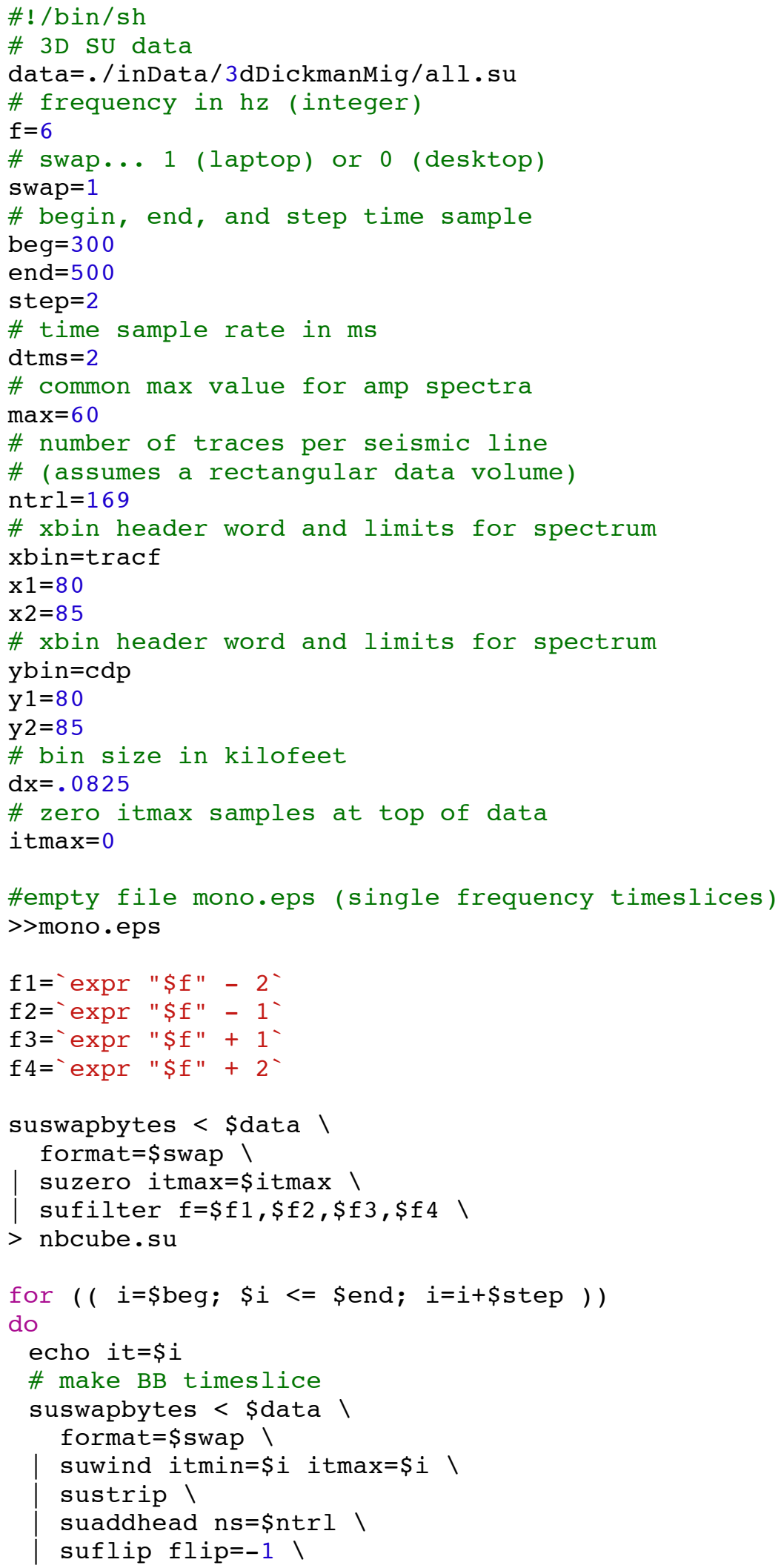




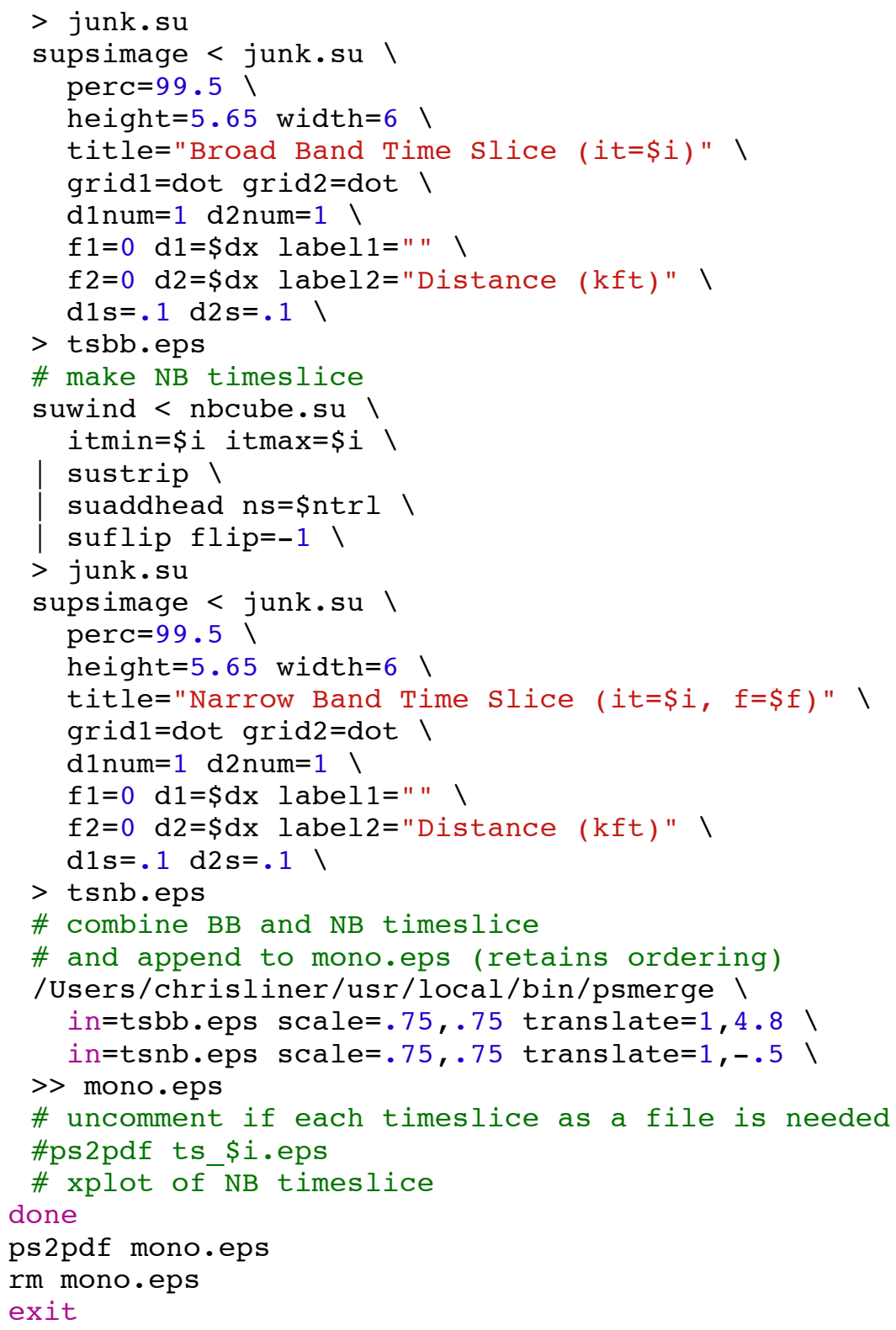




\section{Appendix C: Elastic simulation of various events}

Shown below are shot records computed from the Humphrey 4-18 well using the anivec elastic reflectivity modeling code. In each case certain wave types are included as indicated by the check boxes.

Include free surface

Include direct waves

Include shear waves

Include multiples

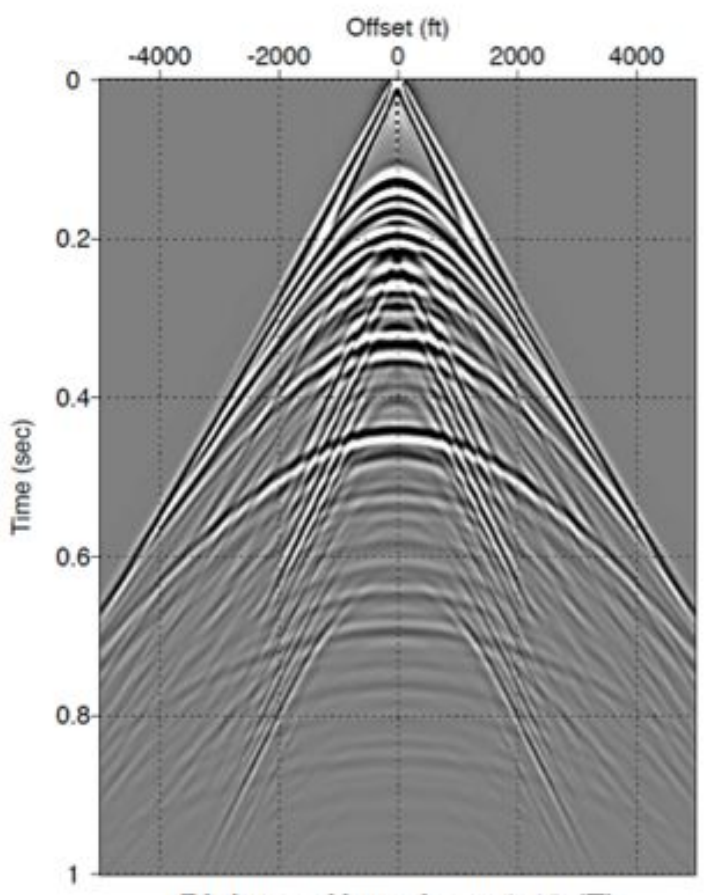

Dickman Humphrey 4-18 (Z)

Include free surface Include direct waves

Include shear waves Include multiples

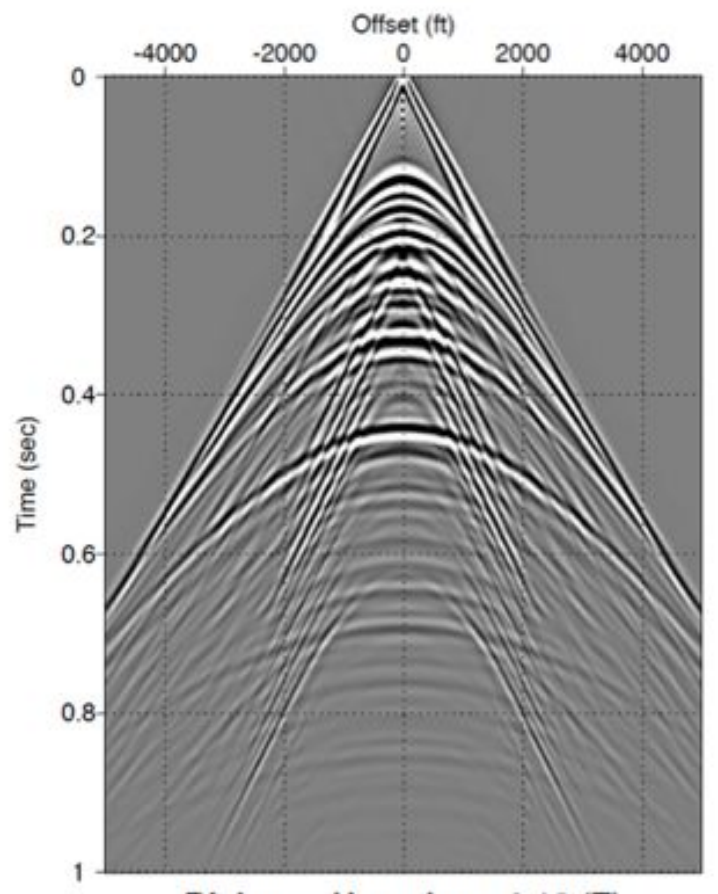

Dickman Humphrey 4-18 (Z) 

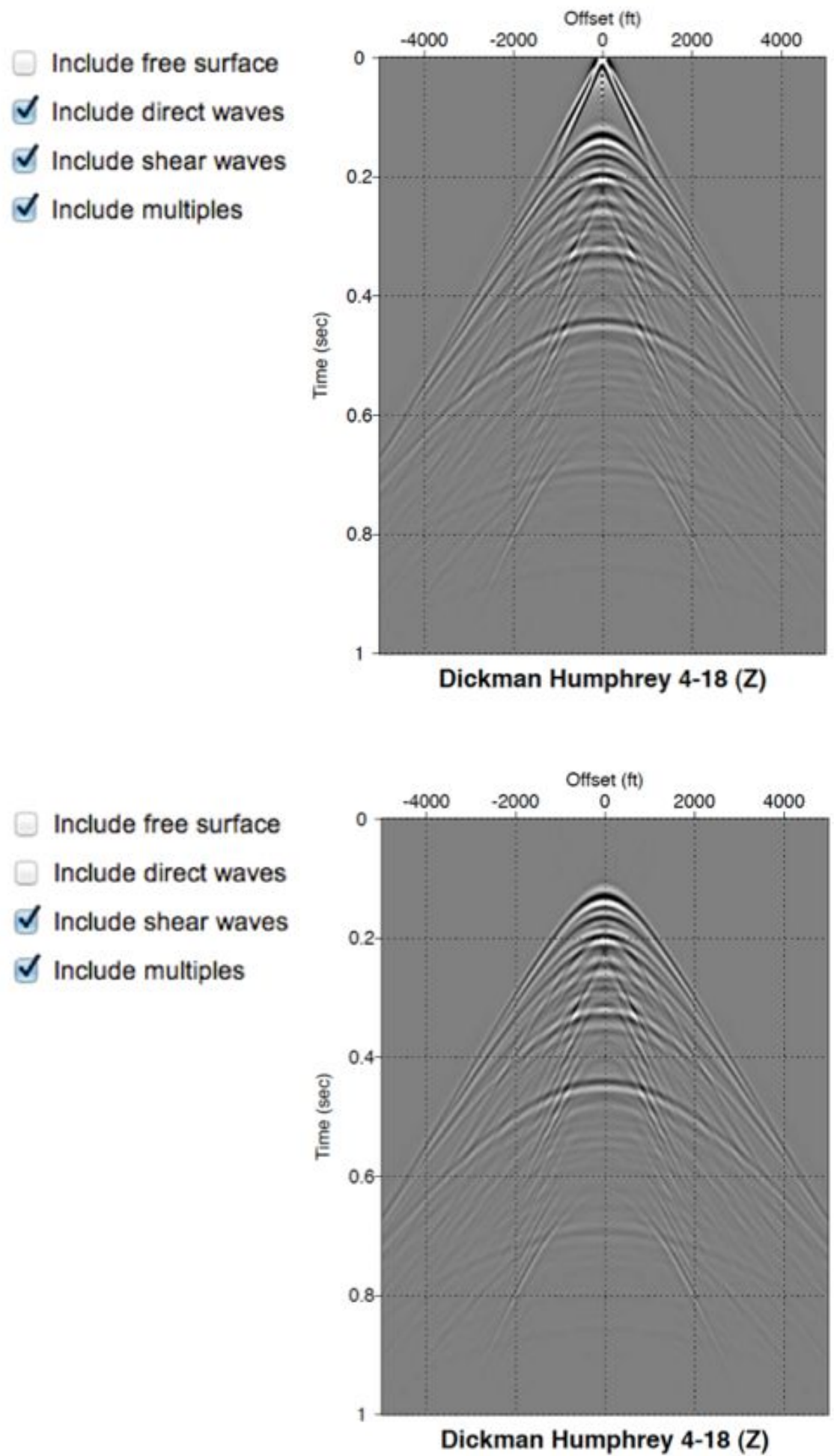

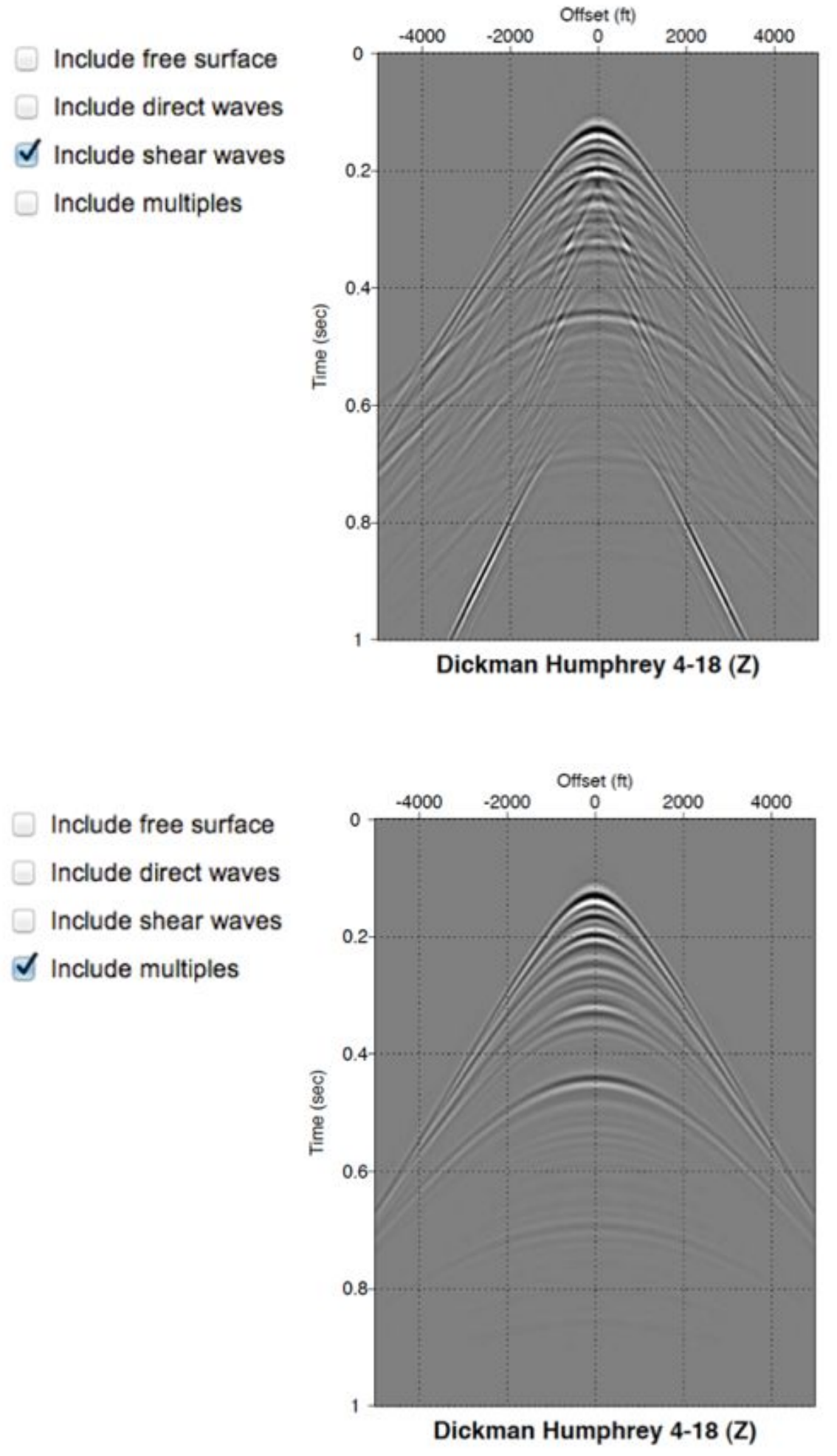


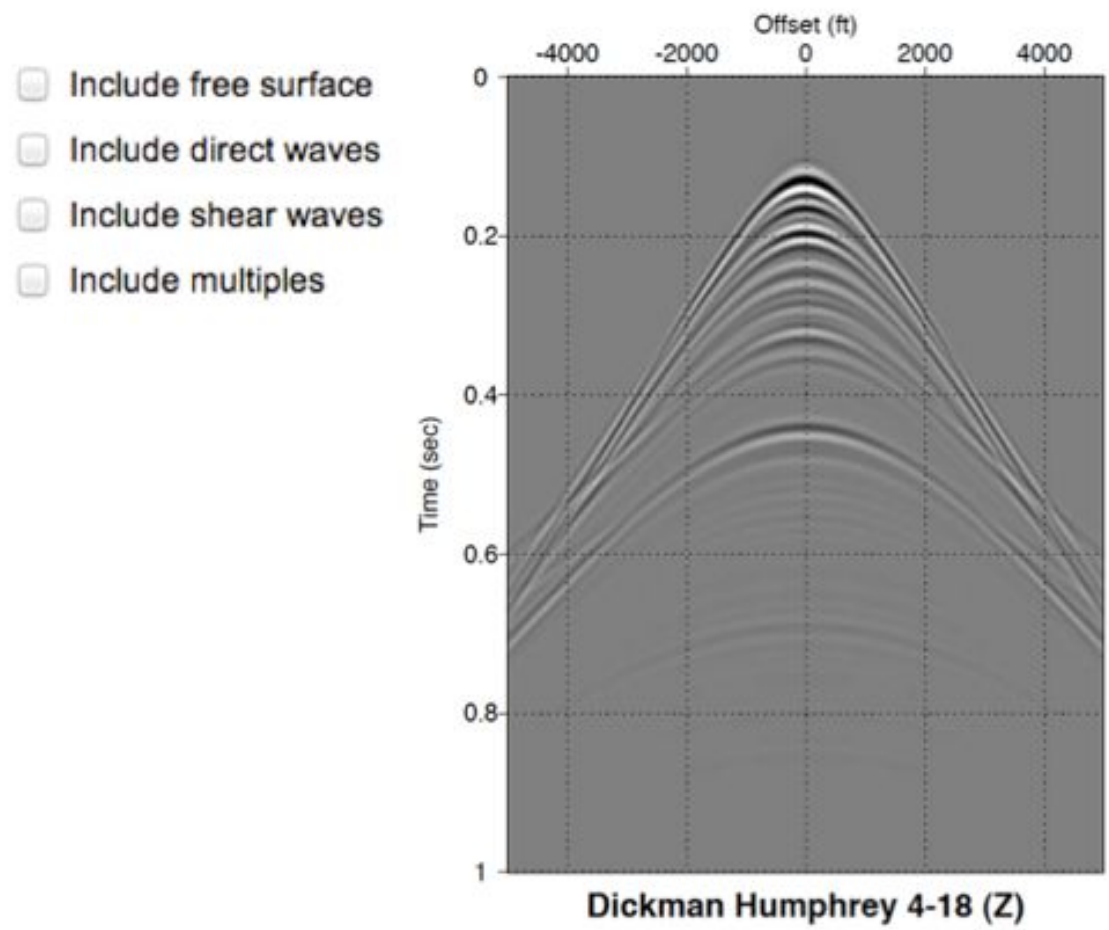

